\title{
INTERACTIONS BETWEEN ADHERENT-INVASIVE ESCHERICHIA COLI AND HOST MACROPHAGES: A VIRULENCE PHENOTYPE
}

\author{
by \\ Michael John Dill Renouf B. Sc., Queen's University, 2011

\begin{abstract}
A thesis
presented to Ryerson University

in partial fulfillment of the

requirements for the degree of

Master of Science

in the program of

Molecular Science

Toronto, Ontario, Canada, 2018

(C) Michael John Dill Renouf, 2018
\end{abstract}




\section{AUTHOR'S DECLARATION}

\section{AUTHOR'S DECLARATION FOR ELECTRONIC SUBMISSION OF A THESIS}

I hereby declare that I am the sole author of this thesis. This is a true copy of the thesis, including any required final revisions, as accepted by my examiners.

I authorize Ryerson University to lend this thesis to other institutions or individuals for the purpose of scholarly research.

I further authorize Ryerson University to reproduce this thesis by photocopying or by other means, in total or in part, at the request of other institutions or individuals for the purpose of scholarly research.

I understand that my thesis may be made electronically available to the public. 
Interactions between adherent-invasive Escherichia coli and host macrophages: a virulence phenotype.

Michael John Dill Renouf, Master of Science, Molecular Science, Ryerson University, 2018.

\begin{abstract}
Inflammatory bowel disease (IBD) is a chronic condition increasing in prevalence throughout the western world and in developing countries. Adherent-invasive Escherichia coli (AIEC) are an opportunistic pathogen associated with IBD. Well-characterized genetic risk factors for IBD include mutations in genes associated with host-cell autophagy. A phenotype of interest in AIEC pathogenesis is survival within host macrophages. Intracellular survival of AIEC strains has been correlated with existing virulence factors but no single factor has been identified to explain this behaviour. In this thesis, infections of RAW264.7 macrophages with AIEC strains from diverse sources demonstrates increased frequency of both bacterial uptake and intracellular survival in disease-associated strains. A secondary infection model reveals the effect of primary AIEC infection on downstream macrophage function and a novel phenotype was identified in the disease-associated strain HM605. Co-localization using fluorescence microscopy shows changes in intracellular trafficking of HM605. This work aims to provide insight into one bacterial phenotype that contributes to the development of disease.
\end{abstract}




\section{ACKNOWLEDGEMENTS}

First and foremost I would like to acknowledge and thank my supervisor Dr. Joseph McPhee whose guidance and mentorship has not only helped in the completion of this body of work, but contributed greatly to my development as a scientist and researcher. I am appreciative for the opportunity to conduct interesting and meaningful research in such a positive and nurturing research environment that is fostered by a caring supervisor. I would also like to thank the members of my supervisory committee Dr. Debora Foster and Dr. Roberto Botelho for their ideas, advice and guidance throughout my time working on this project. The process of reflecting on and refocusing my research was greatly mediated by meetings with my committee and their contributions to this body of work cannot be overstated.

Although my name is on the cover of this document, research does not happen in a vacuum. I have been supported by friends, family and coworkers throughout this process. My thanks to my lab mates Youn Hee Cho, Adam Khan and Mario Vargas as well as Victoria Hipolito and Aaron Fountain from the Botelho lab for help with experiments. It has been a joy to come to work every day and experience this journey with you.

I would like to acknowledge my parents Andrew and Janet for their support of my academic pursuits and creating an environment from an early age where curiosity and inquiry were encouraged. I feel very privileged to have been raised in a household where academic interests are valued. I believe, as they imparted, that pursuing a passion to the best of one's ability will eventually lead to success. I would also like to thank my siblings Claire and David for providing support and at times, much-needed distraction from work.

Lastly, I would like to acknowledge my partner Susie, without whom I would not have been able to even engage in graduate studies. I am unbelievably fortunate to have a partner who provides constant love, support, encouragement and a strong voice of reason. Through the ups and downs that are part and parcel of the research process, she has been a 
steadfast supporter of this endeavor. I simply would not have made it through my studies without Susie by my side. 
TABLE OF CONTENTS

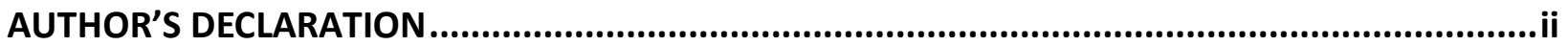

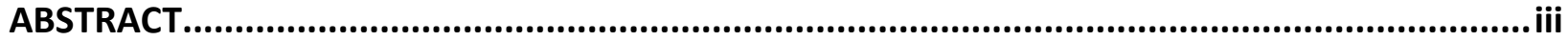

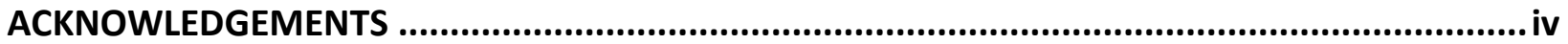

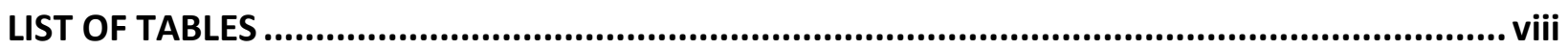

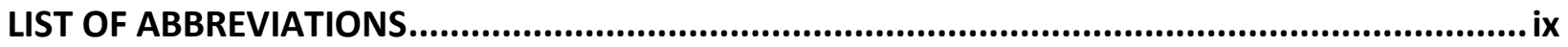

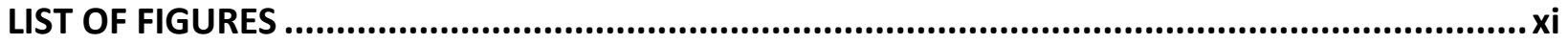

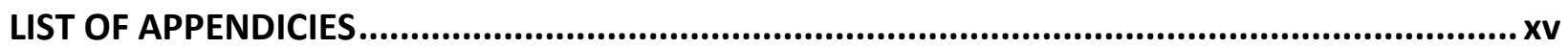

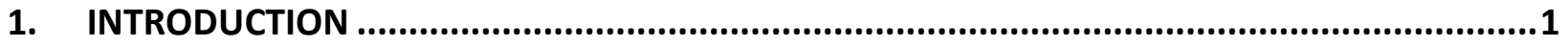

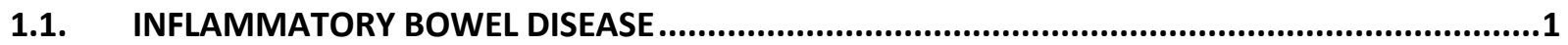

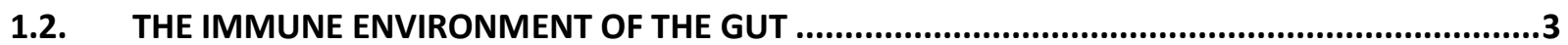

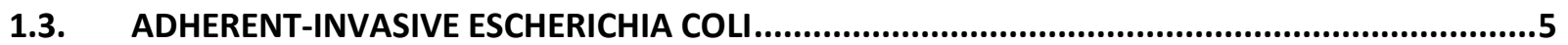

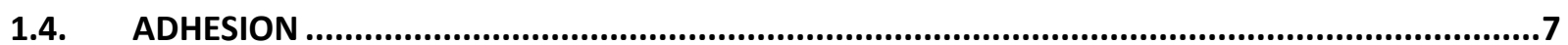

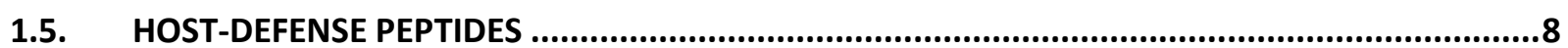

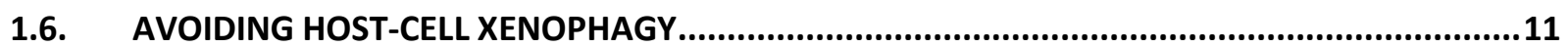

1.7. KNOWN ALTERATIONS TO ENDOSOMAL TRAFFICKING CAUSED BY E. COLI..........................13

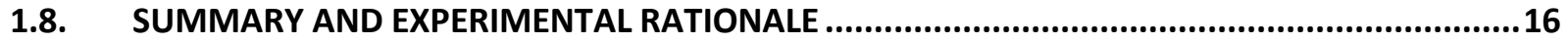

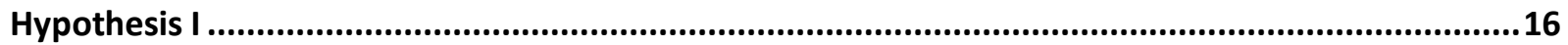

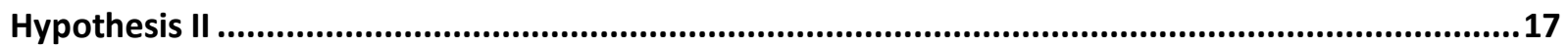

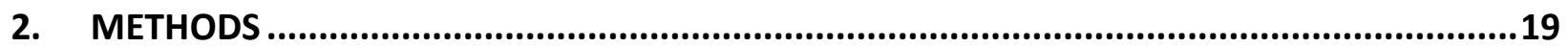

2.1. BACTERIAL CULTURE METHODS \& LIST OF BACTERIAL STRAINS USED ..............................19

2.2. CREATION OF ANTIBIOTIC RESISTANT AND GFP-EXPRESSING BACTERIA...........................20

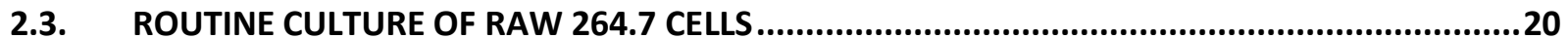

2.4. QUANTIFICATION OF UPTAKE AND SURVIVAL PHENOTYPES OF AIEC ..............................21

2.5. INFLAMMATORY CYTOKINE SAMPLE COLLECTION AND ANALYSIS....................................22

2.6. QUANTIFICATION OF SECONDARY BACTERIAL SURVIVAL PHENOTYPE ...............................22

2.7. INTERROGATION OF SECONDARY BACTERIAL SURVIVAL PHENOTYPES..............................23

2.8. QUANTIFICATION OF LACTATE DEHYDROGENASE FROM 24-HOUR PRIMARY INFECTIONS..23

2.9. VISUAL QUANTIFICATION OF INTRACELLULAR BACTERIA AND LAMP1 FLUORESCENCE .......24

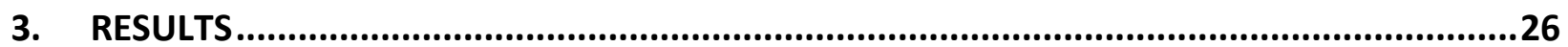

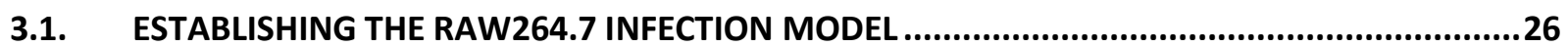

3.2. DISEASE-ASSOCIATED AIEC STRAINS DEMONSTRATE HIGHER UPTAKE AND INTRACELLULAR

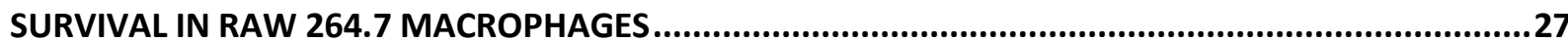

3.3. INFLAMMATORY CYTOKINE EXPRESSION OF 24-HOUR INFECTED MACROPHAGES IS STRAIN-

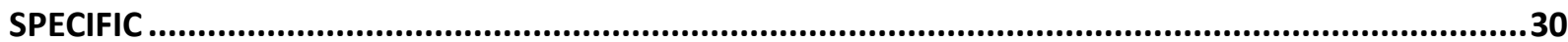

3.4. PRIMARY INFECTION WITH AIEC DOES NOT AFFECT 1-HOUR UPTAKE OF SECONDARY

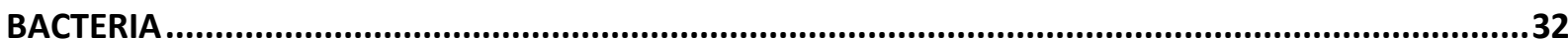

3.5. PRE-TREATMENT WITH SL1344 OR HM605 LEADS TO A DECREASE IN INTRACELLULAR

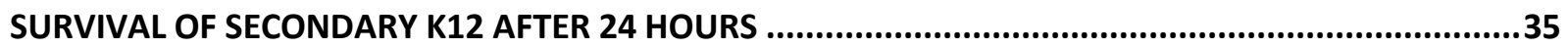

3.6. EEFFECTS ON SECONDARY BACTERIAL SURVIVAL ARE TIME-DEPENDENT .............................37

3.7. EFFECTS ON SECONDARY BACTERIAL SURVIVAL REQUIRE DIRECT CONTACT OF LIVE PRIMARY BACTERIA WITH MACROPHAGES 
3.8. MACROPHAGES CONTAINING HM605 EXPRESS LOWER LEVELS OF LAMP1........................40

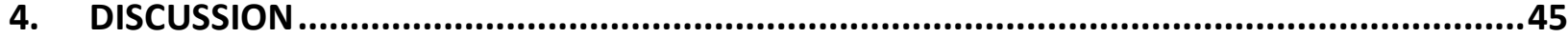

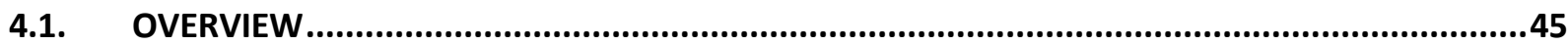

4.2. 1 AND 24-HOUR PRIMARY INFECTION PHENOTYPES OF AIEC ............................................46

4.3. 24-HOUR EXTRACELLULAR CYTOKINE EXPRESSION ............................................................48

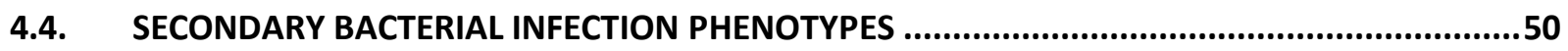

4.5. LAMP1 EXPRESSION AS A PROXY FOR LYSOSOMAL ACTIVITY ........................................53

4.6. SIGNIFICANCE AND FUTURE WORK

Appendix 1 - Cytokines analyzed from 24-hour infections ..................................................60

Appendix 2 - Supplementary 24-hour cytokine data .................................................62

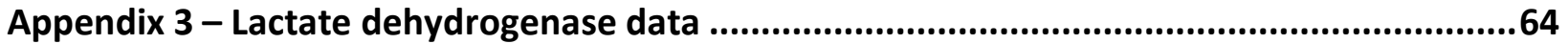

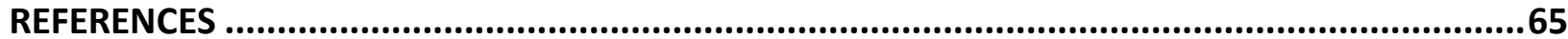




\section{LIST OF TABLES}

Table 1: A subset of host-defense peptides that have been identified in the human intestine. Adapted from Hancock, Haney and Gill.

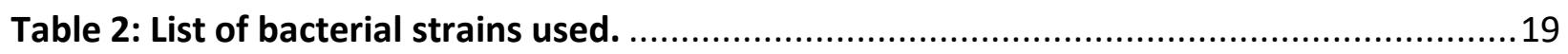

Table 3: The phenotypic diversity of invasion and survival phenotypes of AIEC in macrophage infections. Control strains are in blue, while disease-associated strains appear in red. ..........30

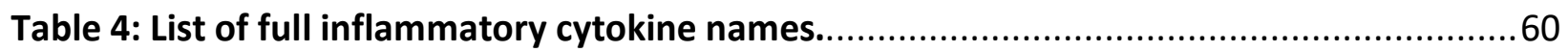

Table 5: Average 24-hour inflammatory cytokine values $(\mathrm{pg} / \mathrm{mL})$ from RAW264.7

macrophages. 60 


\section{LIST OF ABBREVIATIONS}

AIEC - Adherent-invasive Escherichia coli

BSA - Bovine serum albumin

CD - Crohn's disease

CEACAM - Carcinoembryonic antigen-related cell adhesion molecule

CTFC - Corrected total cell fluorescence

DC - Dendritic cell

DMEM - Dulbecco's modified Eagle's medium

DPBS - Dulbecco's phosphate-buffered saline

ExPEC - Extraintestinal pathogenic Escherichia coli

FAK - Focal adhesion kinase

FBS - Fetal bovine serum

Gent - Gentamicin

GFP - Green fluorescent protein

GI - Gastrointestinal

GM-CSF - Granulocyte-macrophage colony-stimulating factor

HBD3 - Human Beta-defensin 3

$\mathrm{Hcp}$ - Haemolysin co-regulated protein

HDP - Host-defence peptide

IBD - Inflammatory bowel disease

IFN - Interferon

$\mathrm{IL}$ - Interleukin

Kan - Kanamycin

KC - Keratinocyte chemoattractant

LAMP - Lysosomal-associated membrane protein

LB - Lysogeny broth

LDH - Lactate dehydrogenase

LIF - Leukemia inhibitory factor

LPF - Long polar fimbrae

LPS - Lipopolysaccharide

MCP-1 - Monocyte chemoattractant protein-1

$\mathrm{MOI}$ - Multiplicity of infection

OD - Optical density

PFA - Paraformaldehyde

RILP - Rab7-interacting lysosomal protein

SCV - Salmonella-containing vacuole

SNARE - Soluble N-ethylmaleimide-sensitive factor attachment protein receptor

SNP - Single-nucleotide polymorphism

$\mathrm{SPI}$ - Salmonella pathogenicity island

T3SS - Type three secretion system 
T6SS - Type six secretion system

TGF - Transforming growth factor

TLR - Toll-like receptor

TNF - Tumor necrosis factor

UC - Ulcerative colitis

UPEC - Uropathogenic Escherichia coli 


\section{LIST OF FIGURES}

Figure 1: Percent survival of AIEC strains exposed to: A) $2 \mu \mathrm{g} / \mathrm{mL}$ of HBD3 or B) $50 \mu \mathrm{g} / \mathrm{mL}$ of LL-37 for 10 minutes compared to an unexposed control. 4 biological replicates were performed. Statistical significance was determined using a one-way ANOVA. Bars of central tendency represent the average, error bars represent standard deviation (Cho, 2017 unpublished).

Figure 2: Internalization of Kan-resistant K12 after 1 hour of infection in pre-treated RAW264.7 macrophages. MOI ratios represent ratio of primary bacteria to macrophages, followed by ratio of secondary bacteria to macrophages. Experiment was performed in biological triplicate. Statistical significance was determined via two-way ANOVA $* *=p<0.01$. Bars of central tendency represent averages, error bars represent standard deviation.

Figure 3: Percent uptake of bacteria after a 1-hour exposure to RAW264.7 macrophages normalized to inoculum. Experiments were performed in technical duplicate and biological replicates of at least 3 . Statistical significance was determined using a one-way ANOVA, $* * * *$ $=p<0.0001, * *=p<0.01$. ROUT outlier analysis was performed prior to statistical analysis. Bars of central tendency represent averages, error bars represent standard deviation.

Figure 4: Percent survival of intracellular bacteria after 24 hours in RAW264.7 cells normalized to intracellular levels after 1 hour of uptake. Experiments were performed in technical duplicate with at least 3 biological replicates. Statistical significance was determined using a non-parametric ANOVA, $* * * *=p<0.0001, * * *=p<0.001, *=p<0.05$. ROUT outlier analysis was performed prior to statistical analysis. Bars of central tendency represent averages, error bars represent standard deviation.

Figure 5: Heatmap and dendrograms showing hierarchical clustering of bacterial strains as well as secreted cytokines from infected macrophages. Hierarchical clustering was performed on an average of 4 biological replicates per strain, normalized against the average value from a non-infected macrophage culture. The average linkage computational method was used with Euclidean measurement distance between clusters.

Figure 6: Secretion of A) IL-6, B) GM-CSF and C) LIF from macrophages exposed to a panel of bacteria for 1 hour, followed by culture for 23 hours. Measurements were made from 4 biological replicates. Statistical significance was determined using one-way ANOVA, ****= $\mathrm{p}<0.0001, * * *=\mathrm{p}<0.001, * *-\mathrm{p}<0.01, *-\mathrm{p}<0.05$. Bars of central tendency represent averages, error bars represent standard deviation.

Figure 7: Internalization of intracellular Kan-resistant bacteria found in 1-hour secondary infections of RAW264.7 macrophages with K12 E. coli Experiments were performed in at least biological triplicate and statistical significance was assessed by non-parametric one-way ANOVA. ROUT outlier analysis was performed prior to statistical analysis. Bars of central tendency represent averages, error bars represent standard deviation. 
Figure 8: Internalization of intracellular secondary Kan-resistant K12 E. coli after 1.5 hours of exposure to RAW264.7 macrophages. Experiments were performed in biological triplicate. Statistical significance was determined using individual one-way ANOVA tests for each MOI. Error bars represent standard deviation.

Figure 9: Internalization of intracellular secondary Kan-resistant K12 E. coli after 24 hours of exposure to RAW264.7 macrophages. Experiments were performed in at least biological triplicate. Statistical significance was determined using one-way ANOVA, ${ }^{* *}-p<0.01$. ROUT outlier analysis was performed prior to statistical analysis. Bars of central tendency represent averages, error bars represent standard deviation.

Figure 10: Internalization of intracellular primary after 24 hours of macrophage infection compared to intracellular levels after $\mathbf{2 4}$ hours of primary plus $\mathbf{2 4}$ hours of secondary infection. 4 biological replicates were performed. Bars of central tendency represent averages, error bars represent standard deviation. .36

Figure 11: Internalization of intracellular Kan-resistant K12 E. coli in RAW264.7 macrophages after 40, 30 and 24 hours of primary followed by 8, 18 and 24 hours of secondary exposure respectively. Experiments were performed in at least quadruplicate. Statistical significance was determined using a non-parametric one-way ANOVA, $*=p<0.05$. ROUT outlier analysis was performed prior to statistical analysis. Bars of central tendency represent averages, error bars represent standard deviation.

Figure 12: Internalization of intracellular Kan-resistant K12 E. coli in RAW264.7 macrophages pre-treated for $\mathbf{2 4}$ hours with either with live or heat-killed bacteria before the addition of secondary bacteria. Experiments were performed biological triplicate with two technical replicates per experiment.. Statistical significance was determined using a non-parametric one-way ANOVA, $*=p<0.05, * *=p<0.01$. ROUT outlier analysis was performed prior to statistical analysis. Bars of central tendency represent averages, error bars represent standard deviation.

Figure 13: Internalization of intracellular Kan-resistant K12 E. coli in RAW264.7 macrophages pre-treated for $\mathbf{4 8}$ hours with either primary bacteria or conditioned supernatant from a 48hour primary infection. Experiments were performed in biological triplicate. Statistical significance was determined using a non-parametric two-way ANOVA. ${ }^{* *}=p<0.01, * * *=$ $p<0.001$. Bars of central tendency represent averages, error bars represent standard deviation.

Figure 14: Percent intracellular survival of bacteria after 24 hours in RAW264.7 macrophages. Statistical significance was determined using a two-way ANOVA. Bars of central tendency represent averages, error bars represent standard deviation. 
Figure 15: Corrected total cell fluorescence of the lysosomal marker LAMP1 in HM605 or K12infected RAW264.7 macrophages after normalizing to cells containing no bacteria after A) 1 hour and B) 6 hours. At least three biological replicates are represented for each strain from slides stained on different days. Statistical significance was assessed using an unpaired twotailed t-test, $* *=\mathrm{p}<0.01, * * * *=\mathrm{p}<0.001$. ROUT outlier analysis was performed prior to statistical analysis. Bars of central tendency represent averages, error bars represent standard deviation.

Figure 16: Representative images of 1-hour GFP-K12 and GFP-HM605-infected RAW264.7 macrophages. Bacteria are represented in green, extracellular bacteria are stained with antiE.coli in blue and LAMP1 is represented in green. Closeups are channel-merged images from A) K12 infection and B) HM605 infection. All images were subjected to artificial contrast enhancement to $0.3 \%$ pixel saturation for clarity.

Figure 17: Corrected fluorescence of the lysosomal marker LAMP1 on endosomes of HM605 or K12-infected RAW264.7 macrophages after 1 hour and 6 hours. At least three biological replicates are represented for each strain from slides stained on different days. Statistical significance was assessed using an one-way ANOVA, $* *=p<0.01$. ROUT outlier analysis was performed prior to statistical analysis. Bars of central tendency represent averages, error bars represent standard deviation.

Figure 18: A model of how internally persistent HM605 might influence macrophage activity towards an infection with a secondary bacterial strain. Constant stimulation of a putative paracrine signal might be required in order to condition non-HM605-infected cells for increased activity towards secondary bacteria. 53

Figure 19: A summary of LAMP1 expression and intracellular bacterial survival of A) K12 E. coli or B) HM605 AIEC. Panel i) shows the initial interaction between the bacteria and the host cell. Panel ii) represents internalized bacteria with phagosome-associated LAMP1 expression that is similar, regardless of bacterial strain. In K12-infected cells there is a significant increase in total-cell expression of LAMP1 as seen in panel iii), followed by elimination of the bacteria. In HM605 infection, there is a suppression of total-cell LAMP1, as well as decreased levels of phagosome-associated LAMP1, correlating with increased intracellular survival.

Figure 20: Secretion of IL1- $\alpha$ from macrophages exposed to a panel of bacterial for 1 hour, followed by culture for 23 hours. Measurements were made from 4 biological replicates. Statistical significance was determined using one-way ANOVA, * ${ }^{-p<0.05 . ~}$

Figure 21: Secretion of KC from macrophages exposed to a panel of bacterial for 1 hour, followed by culture for 23 hours. Measurements were made from 4 biological replicates. Statistical significance was determined using one-way ANOVA, $*_{-} p<0.05$. 
Figure 22: Secretion of MCP-1 from macrophages exposed to a panel of bacterial for 1 hour, followed by culture for 23 hours. Measurements were made from 4 biological replicates. Statistical significance was determined using one-way ANOVA, $*_{-}-p<0.05$.

Figure 23: Absorbance units representing LDH levels in supernatant taken from RAW264.7 macrophages infected for $\mathbf{2 4}$ hours with bacterial strains. Biological $\mathbf{n}$ of $\mathbf{3}$ with two technical replicates each. Error bars represent standard deviation. ............................................64 


\section{LIST OF APPENDICIES}

Appendix 1 - Cytokines analyzed from 24-hour infections ............................................60

Appendix 2 - Supplementary 24-hour cytokine data ......................................................62

Appendix 3 - Lactate dehydrogenase data .......................................................................64 


\section{INTRODUCTION}

\subsection{INFLAMMATORY BOWEL DISEASE}

Inflammatory bowel disease (IBD) is a condition that affects over 200,000 Canadians, and costs approximately $\$ 1.2$ billion annually in direct medical costs ${ }^{1}$. Characterized by chronic inflammation of the gastrointestinal (GI) tract, the two most common types of the disease are ulcerative colitis (UC), affecting the colon, and Crohn's disease (CD) principally affecting the ileum or caecum ${ }^{1}$. Patients with IBD present with symptoms such as abdominal pain, fever, weight loss, fatigue and frequent loose diarrhea ${ }^{2}$. Treatments are available to treat the various IBDs, including the use of antibiotics, corticosteroids, immunomodulators, antibody mediated anti-TNF- $\alpha$ (tumor necrosis factor alpha), anti-IL12/IL23 or anti-integrin therapy and surgery ${ }^{3}$. Despite the use of these treatments, occurrence of IBD is increasing globally ${ }^{4}$ and, with no cure, many patients experience bouts of the disease throughout their entire lives ${ }^{1}$.

IBD is a multifactorial disease that can develop due to a number of different influences. Patient genetics, environmental influences and gut microbiological composition can all contribute to the development of chronic Gl inflammation ${ }^{5}$. Several genome-wide association studies have been performed to look for genetic differences between IBD patients and healthy individuals. These studies look for single-nucleotide polymorphisms (SNPs) within coding regions that are associated with the disease condition. In a 2012 study, Jostins and colleagues identified 163 risk loci that had a statistically significant association with either UC or CD condition $s^{6}$ and other studies in different populations have continued to add to the list of genes that are associated with $\mathrm{IBD}^{7-9}$. These groups identified several SNPs in genes associated with Tcell function and immune system signaling, autophagy and intestinal barrier function. SNPs with the highest association levels with IBD include those found in the pattern recognition receptor NOD2, core autophagy proteins ATG16L1 and IRGM, as well as immune response receptors such as interleukin (IL)23R. SNPs in genes that encode intestinal mucins (MUC proteins) have also been associated with $\mathrm{IBD}^{10}$. These lead to alterations in the extracellular secretions of the intestinal epithelium, which affect barrier function and could lead to increased host susceptibility. Many SNPs are found in genes associated with host-microbe interactions, therefore, it stands to reason that disruption in either the host or the microbial population 
could potentiate disease. While existing studies offer a high-level view of host genetic influences, very few SNPs have been directly and mechanistically investigated to confirm their contribution to the disease state.

Environmental correlates that may contribute to IBD are often crudely referred in publications by the catch-all term "Western lifestyle". Few large meta-analyses of the contributory risks of various lifestyle elements have been performed until very recently. In 2016, the European Crohn's and Colitis Organization published an extensive review of over 200 original research publications and meta-analyses that investigated environmental risk factors for $\mathrm{IBD}^{11}$. For the purposes of issuing clinical practice guidelines, the group concluded that high animal fat and protein diets increase the risk for developing IBD, while omega-3 fatty acids, short triglycerides and some carbohydrates may be protective. Interestingly, smoking was determined to be a risk factor for developing CD but was possibly protective for UC. The use of antibiotics was also correlated with increased risk of developing disease. Several factors such as air pollution and birth by caesarian section correlated with IBD risk, however these, as well as many other factors, did not show enough evidence to rule out a common underlying cause. Of note, the authors confidently described a disruption in mucosal barrier homeostasis and changes in the intestinal mucosal microbiota as driving factors behind IBD development but did not find enough evidence that environmental factors were sufficient to independently drive these changes.

Microbial populations in the GI tract are another contributing factor to IBD. Several studies have demonstrated that the fecal and gut microbial communities are significantly altered in individuals with IBD when compared to healthy individuals ${ }^{12,13}$. These studies take a broad approach by looking at differences in the bacterial communities in the gut of diseased or healthy patients at the phylum or family level and do not show strong associations of specific bacterial groups with disease. A more recent, large-scale study of 668 patients associated increases in Enterobacteriaceae and Pasteurellaceae in rectal microbiota samples with earlystage Crohn's disease, especially in cases where antibiotics were administered ${ }^{14}$. The authors were also able to associate increases in Escherichia, Veillonella, Haemophilus and Fusobacterium in ileal samples to the disease state. As these alterations were observed in 
treatment-naïve patients, this supports the idea that alterations in the microbiota are a cause, rather than a consequence of prolonged IBD.

As previously stated, IBD is a multifactorial disease. Experimental evidence suggests a multimodal model of disease initiation whereby combinations of host risk factors, environmental priming and bacterial phenotypes are sufficient to cause a tipping point with respect to host immune system control. Infectious gastroenteritis has been linked to a greatly elevated risk of developing IBD in several large studies ${ }^{15-17}$. Furthermore, experimental evidence supporting this model has been recapitulated using animal models of infection. In a mouse model of disease, Small et al. showed that when previously colonized with Adherentinvasive Escherichia coli (AIEC), a bout of acute gastroenteritis caused by Salmonella enterica or Citrobacter rodentium led to the onset of highly increased inflammation in a tissue-specific manner ${ }^{15}$. Contextualized in a human setting, environmental and host-genetic factors could allow for the persistence of AIEC in healthy individuals until the pathobiont-mediated disease is triggered by an acute bout of gastroenteritis.

The study of individual species or strains of bacteria and their relation to IBD have been the focus of a more significant body of research, including the above study. While a single bacterium has not been identified as the single cause of IBD, there is evidence that AIEC are associated with the onset and/or maintenance of disease $\mathrm{e}^{18}$.

\subsection{THE IMMUNE ENVIRONMENT OF THE GUT}

The point of contact between intestinal pathogens and the host in the epithelial cell layer. As such, the cell types that make up this interface are important for bacterial sensing and response. At homeostasis, there is continual cross talk that occurs on a cellular level that enables the bacterial community of the gut to persist without eliciting an inappropriate immune response. Secretion of mucus by goblet cells generates the physical barrier that limits direct bacterial contact with the host and production of Host-defence peptides (HDPs) by Paneth cells helps to limit and control populations of both commensal and pathogenic bacteria. As stated earlier, disruption of these functions can predispose an individual to develop IBD, but 
the maladaptation and/or incorrect response of the immune system to a microbial population can contribute to chronic disease.

The intestine contains a variety of specialized immune cells that contribute to both inflammation and resolution of response. Studies using macrophage-dendritic precursor cells from the lamina propria have revealed that a variety of monocyte populations exist in the intestine, that are distinct based on both surface protein expression as well as cellular interactions ${ }^{19}$. Further mechanistic studies have demonstrated that dendritic cells (DCs) respond to microbial challenges through the signaling and polarization of Th1 and Th17 Tcells ${ }^{20,21}$. The sensing of bacteria by DCs occurs via Toll-like receptors (TLRs) $1^{22}, 2^{23}, 4^{24}$ and $5^{20}$ while different DC subtypes sense in a MyD88-independent manner ${ }^{25}$. The most wellcharacterized downstream signal of the polarized T-cells in the intestine is IL23. The Th17/IL-23 pathway is an important regulator of mucosal immunity and is involved in the coordinated response of both intestinal epithelial cells and leukocytes to infection. It has been studied in relation to IBD since 2006, with mechanistic evidence demonstrating that it is a strong driver of intestinal inflammation ${ }^{26}$. IL-23 along with separate bacterial sensing systems, also triggers further inflammatory cytokine secretion from other monocytes in the form of IL-1 $\beta^{27}$, IL- $6^{24}$, and TNF- $\alpha^{28}$.

Intestinal tissue-resident macrophages reside in the lamina propria where they play a major role in both sensing and responding to intestinal bacteria. Sensing of bacteria occurs through NOD proteins (as well as TLR4 and 5) and the importance of regulation of this function is underscored by the fact that NOD2 mutations are one of the more well-studied genetic markers for $\mathrm{IBD}^{29}$. The classical view of macrophage function in intestinal immunity is that sensing of a pathogen (either due to invasion or damage to the epithelial tissue) elicits a TNF- $\alpha$ response through the NF-KB pathway ${ }^{30}$ as well as secretion of prostaglandin $E_{2}{ }^{31}$. These signals recruit neutrophils to the site of infection and also trigger responses of other, now activated monocytes.

The identification of an inflammatory cytokine "fingerprint" that is IBD specific has been difficult to fully elucidate. This is likely due the diversity in IBDs between patient groups, expression difference between active and inactive IBD, and the difficulty associated with tissue 
sampling bias. Experimentally, IL-10 is an anti-inflammatory cytokine and important regulator of intestinal inflammation. IL-10 knockout mice have been shown to spontaneously develop colitis $^{32}$ and a macrophage-specific IL-10 receptor (IL-10R $\alpha$ ) deficiency also causes this phenotype ${ }^{33}$. This observation aligns with patient-derived data where specific IL-10 promoter polymorphisms that lead to low production also correlate with IBD disease state and IL-10R deficient patients develop very early-onset IBD, a particularly aggressive form of the disease ${ }^{34}$. Transforming-growth factor (TGF)- $\beta$ is another important immunoregulatory cytokine that has been associated with IBD. A transgenic TGF- $\beta$ receptor II-mutant mouse model has been developed to study IBD, which will develop spontaneous colitis ${ }^{35}$, although unlike IL-10, a complete removal of TGF- $\beta$ expression is fatal ${ }^{36}$. Experiments to reduce IL-10 and TFG- $\beta$ reveal that they operate by preventing the upregulation TNF- $\alpha$, IL-17 and Interferon (IFN)- $\gamma$, all of which are pro-inflammatory signals.

The importance of TNF- $\alpha$ and its role in IBD is revealed by the fact that anti-TNF- $\alpha$ antibody therapies are very effective at treating a subset of patients ${ }^{37,38}$. The problem with these treatments is that they appear to have no positive effect in other patient groups. Indeed, the various treatments for IBD (corticosteroids, immunomodulators, antibiotic treatment, antibody therapy) on appear to affect certain subsets of the patient population and many patients often relapse ${ }^{39}$. This once again leads to the idea that IBDs are very heterogenous in their nature, and that each patient may have a unique combination of genetic, environmental and microbial contributors that lead to incorrect immune function in the gut.

\subsection{ADHERENT-INVASIVE ESCHERICHIA COLI}

E. coli are part of the commensal microbiota in the digestive tract, forming symbiotic relationships with other species of bacteria but also competing for resources. They are the principle facultative anaerobe of the intestinal tract and they colonize the mucosal surface at the oxic-anoxic interface. Their principle metabolic role is to consume the oxygen that diffuses into the intestinal lumen, thereby contributing to the anaerobiosis that permits the growth of strict anaerobes like Bacteroides or Firmicutes ${ }^{40}$. Humans are colonized by $E$. coli shortly after birth and at any individual time, an individual may be colonized by multiple strains of $E$. coli ${ }^{41}$. 
They are a metabolically flexible species that competes with others by either metabolizing different substrates, growing at a faster rate, or entering into symbiotic relationships ${ }^{42}$. Strain to strain differences in carbon metabolism have been shown to affect relative fitness of $E$. coli strains $^{43}$ and during infection pathogenic $E$. coli can alter the types of carbon sources produced in the gut, thereby promoting their own fitness ${ }^{44}$. Disruptions in gut homeostasis have been shown to alter the monosaccharide availability in IBD patients versus healthy controls ${ }^{45}$. This metabolic flexibility has led to wide inter-strain variation in E. coli.

Initially characterized as adherent E. coli, AIEC were first isolated by Darfeuille-Michaud et al. from the ileal lesions of Crohn's disease patients ${ }^{46}$. Further characterized by Boudeau et al. in 1999, AIEC are subset of E. coli strains that are phenotypically and genetically distinct from other groups such as enterohemorrhagic, enteropathogenic or enterotoxigenic $E$. coli ${ }^{47}$. As their name suggests, AIEC are able to adhere to and invade host epithelial cells, as demonstrated in vitro on HEp-2, Caco-2, Intestine-407 and HCT-8 cell lines ${ }^{47}$ as well as the macrophage cell lines RAW264. $7^{18}$ and $7774^{48}$. Although HEp-2 and Intestine-407 cell lines have subsequently been confirmed to be contaminated by HeLa cells, this body of evidence still robustly demonstrates the ability of AIEC to adhere to and invade cell lines relevant to disease.

AIEC have been described as a distinct $E$. coli pathovar. Animal studies demonstrated that infection with an AIEC strain can cause the chronic intestinal inflammation that mimics some features of that observed in IBD. Human carcinoembryonic antigen-related cell adhesion molecule 6 (CEACAM6) is a known receptor for AIEC adhesion ${ }^{49}$. In a 2009 study, a transgenic mouse model in which mice express human CEACAM6 was used to successfully establish an animal model of chronic intestinal inflammation using the clinical AIEC strain LF82 ${ }^{50}$. The presence of CEACAMs and a treatment with $0.25 \%$ dextran sodium sulfate allowed for AIEC internalization within host epithelial cells and infected animals developed severe colitis, leading to significantly decreased survival. In comparison to a non-pathogenic K12 strain, LF82 caused significantly more damage to the colonic mucosa in CEACAM-expressing animals, again highlighting the role of this bacterium in disease.

In a more recent study, a model of Crohn's disease was established in conventional mice using a treatment with streptomycin and colonization with AIEC strain NRG857 ${ }^{51}$. A chronic 
infection with AIEC over a period of 7 days in mice allowed for evaluation of the IBD-like phenotype in these animals. The authors found that persistent inflammation, mucosal ulceration, sloughing of the epithelial layer and intestinal fibrosis were evident along with cellular invasion by AIEC. Additional immune system responses were detected including upregulation of IL-17 and Monocyte chemoattractant protein (MCP)-1, both signaling molecules associated with increased inflammation and altered T-cell responses. Both this study and the 2009 study by Carvalho et al. demonstrate that AIEC can contribute to the development of an IBD-like disease state in vivo when the gut is subjected to other pro-inflammatory insults, like exposure to a low concentration of DSS ${ }^{50}$.

Adaptations by AIEC to survive and colonize in a stressful environment represent an important aspect of their biology. More specifically, in the setting of the inflamed intestinal mucosal barrier, AIEC have adapted to adhere to intestinal epithelial cells, to resist innate immune mechanisms such as host-defense peptides, and to survive intracellularly. These are discussed further below.

\subsection{ADHESION}

Since the 1990s it has been recognized that IBD was associated with thinning of the extracellular mucus layers of the intestine ${ }^{52}$. This mucus layer represents the point of contact between bacteria and the host, and its abundance and composition are both important for homeostatic maintenance. Changes to the sugar composition of the mucosal layer have associated inflammation and disease phenotypes ${ }^{53,54}$, while thinning of the mucus layer and increased bacterial interaction with the underlying epithelial cells have been linked in animal models ${ }^{55}$. These changes could allow for a pathogen, adapted to adhere to the intestinal epithelium, to fill this newly-available niche.

Mechanisms of pathogenicity have been identified in AIEC that help to explain their adherent phenotype and which could contribute in part to the IBD state. The fimH gene encodes the type I fimbral adhesin, and is important for binding to the bladder epithelial surface in uropathogenic $E$. coli ${ }^{56}$. AIEC are enriched in unique fimH SNPs that may reflect altered host-interaction properties compared to non-pathogenic strains of $E$. coli ${ }^{57}$. 
Furthermore, experiments have shown that when $\triangle$ fimH AIEC were complemented with the $\mathrm{K} 12 \mathrm{fimH}$ gene, they were reduced in their ability to adhere to CEACAM6-expressing host cells in vitro. AIEC also express long polar fimbrae (LPF), which are encoded by the Ipf operon. Similar to other E. coli pathovars, AIEC use LPF to bind to and invade host cells. Experiments using Ipfdeletion mutants have shown that LPF are required for AIEC invasion into M cells, a specialized cell type that are found in the Peyer's patches of the intestinal epitheium ${ }^{58}$. The same study screened a panel of AIEC isolates from CD patients and found that Ipf genes had a higher carriage rate in disease-associated strains compared to controls. This points to the potential importance of these genes in allowing AIEC to establish intimate contact with the host epithelium.

E. coli contain a number of uncharacterized chaperone-usher like adhesin systems that may alter the level and specific cell tropism of bacterial binding and invasion. CEACAM6 is the best-characterized target for AIEC interaction with the host epithelium, but it is not likely to be the only one. Further study is required to characterized both these adhesion systems and their host targets in order to better understand the adhesion phenotype.

\subsection{HOST-DEFENSE PEPTIDES}

Host-defense peptides are ubiquitously expressed by animals and are an important part of innate immunity. Expressed by many cell types, HDPs are commonly found at the epithelial and mucosal layers of the human body ${ }^{59}$. Table 1 below adapted from Hancock, Haney and Gill outlines a subset of HDPs that have been identified in humans and the milieu in which they are expressed $^{60}$.

Table 1: A subset of host-defense peptides that have been identified in the human intestine. Adapted from Hancock, Haney and Gill.

\begin{tabular}{|l|l|}
\hline Peptide Class & Common Expression Sites \\
\hline Cathelicidin - LL-37 & $\begin{array}{l}\text { Epithelial cells, macrophages, monocytes } \\
\text { neutrophils }\end{array}$ \\
\hline$\alpha$-defensins - HNP1, HNP2, HNP3, HNP4 & Neutrophils, monocytes, lymphocytes \\
\hline
\end{tabular}




\begin{tabular}{|l|l|}
\hline$\alpha$-defensins - HD5, HD6 & $\begin{array}{l}\text { Paneth cells, female reproductive epithelium, } \\
\text { airway epithelium }\end{array}$ \\
\hline$\beta$-defensins - HBD1, HBD2, HBD3, HBD4 & $\begin{array}{l}\text { Epithelial cells, monocytes, macrophages, } \\
\text { dendritic cells }\end{array}$ \\
\hline
\end{tabular}

LL-37 is of particular interest due to its expression in a variety of cell types and its relative structural simplicity. It is positively charged and amphipathic, characteristics that are shared with other HDPs that allow for interaction with membranes and extracellular structures such as bacterial lipopolysaccharide (LPS) ${ }^{61}$. As a short alpha-helical peptide, LL-37 is proposed to operate via activity related to membrane disruption and the most likely mechanism of action is through membrane pore formation induced by membrane curvature ${ }^{62}$. The activity of LL-37 has been found to be altered by the lipid composition of its target. As such, several HDPresistance genes in bacteria are involved in modifications of the lipid structures on the cell surface.

Found at many epithelial sites, defensins are an important part of the innate immune system. Their up- or down-regulation in various disease states correlates with the absence or presence of infection ${ }^{63}$. Divided into several sub-classes, defensins are diverse in their structures and sites of expression ${ }^{64}$. Human $\beta$-defensin 3 (HBD3) is a beta-defensin that has $3 \beta$ sheets that are stabilized by disulfide bonds. While HBD3 self-dimerizes, dimerization is unnecessary for the antimicrobial activity of the peptide ${ }^{65}$. Activity of HBD3 as an antimicrobial has been observed against several bacterial species, but it also functions as a chemoattractant for different immune system cell types ${ }^{63}$. Expression of HBD3 has been found in a number of different parts of the body and is known to be expressed by epithelial cells and macrophages. As with other defense peptides, HBD3 is suspected to function via membrane disruption. A study in Campylobacter jejuni used scanning electron microscopy to demonstrate that exposure to HBD3 caused membrane blebbing and peeling further supporting the membrane as the site of interaction between this molecule and gram-negative bacteria ${ }^{66}$.

The intestinal mucosa is protected from the high bacterial concentration in the lumen by a series of physical and chemical barriers the keep the normal concentration of bacteria at 
the epithelial surface low. Consequently, it has been demonstrated that an increased mucosal bacterial load is correlated with severity of disease ${ }^{67}$. The presence of extracellular mucus secreted by epithelial and goblet cells that forms distinct layers that provide physical and chemical protection from the luminal contents of the intestine ${ }^{68}$. In addition, there is selection for mucus-adherent phage in the intestinal tract that protect the epithelial surface from incoming microbes ${ }^{69}$. Finally, there is the presence of a concentration gradient of HDPs that are secreted by the intestinal epithelium that prevent colonization of the epithelial surface by bacteria. In the presence of mucolytic bacteria, or other physical or chemical disruptions to the mucus layers of the intestine, IBD is a possible consequence ${ }^{70}$.

During an inflammatory episode that occurs after mucosal disruption, HDP levels increase dramatically. This has been demonstrated in both infectious colitis ${ }^{71}$ as well as it $C^{72}$ and $\mathrm{UC}^{73}$ conditions and is an important selective pressure for the intestinal bacteria that are exposed to such an environment. Interestingly, it has also been demonstrated that certain SNPs in NOD2 are linked to decreases in the $\alpha$-defensins HD5 and $\mathrm{HD6}^{29}$. While this seems contradictory, it is possible that the lower basal levels of HDPs in individuals with mutant NOD2 alleles pre-dispose for development of a disease condition. The subsequent inflammatory response in these individuals would still see a global increase in HDP production as a response. Alternatively, it is possible that decreases in defensin expression and NOD2 mutations are found in separate IBD patient populations. Increased expression of HBD3 in the terminal ileum of Crohn's disease patients has been demonstrated experimentally, though low level expression is detected even in healthy individuals ${ }^{72}$.

Work in the McPhee lab has demonstrated that peptide resistance is a conserved phenotype among different groups of AIEC. In screens of isolates from UC, CD and healthy control patients, LL-37 and HBD3 resistance was found to be increased in UC and CD isolates respectively compared to controls (unpublished). Figure 1 below shows represents two examples of conserved disease-specific peptide-resistance phenotype. HBD3 resistance $(A)$ is significantly higher in CD-associated AIEC isolates compared to strains isolate from healthy patients, whereas resistance to LL-37 (B) is higher in isolates from UC patients (Cho, 2017 unpublished). 

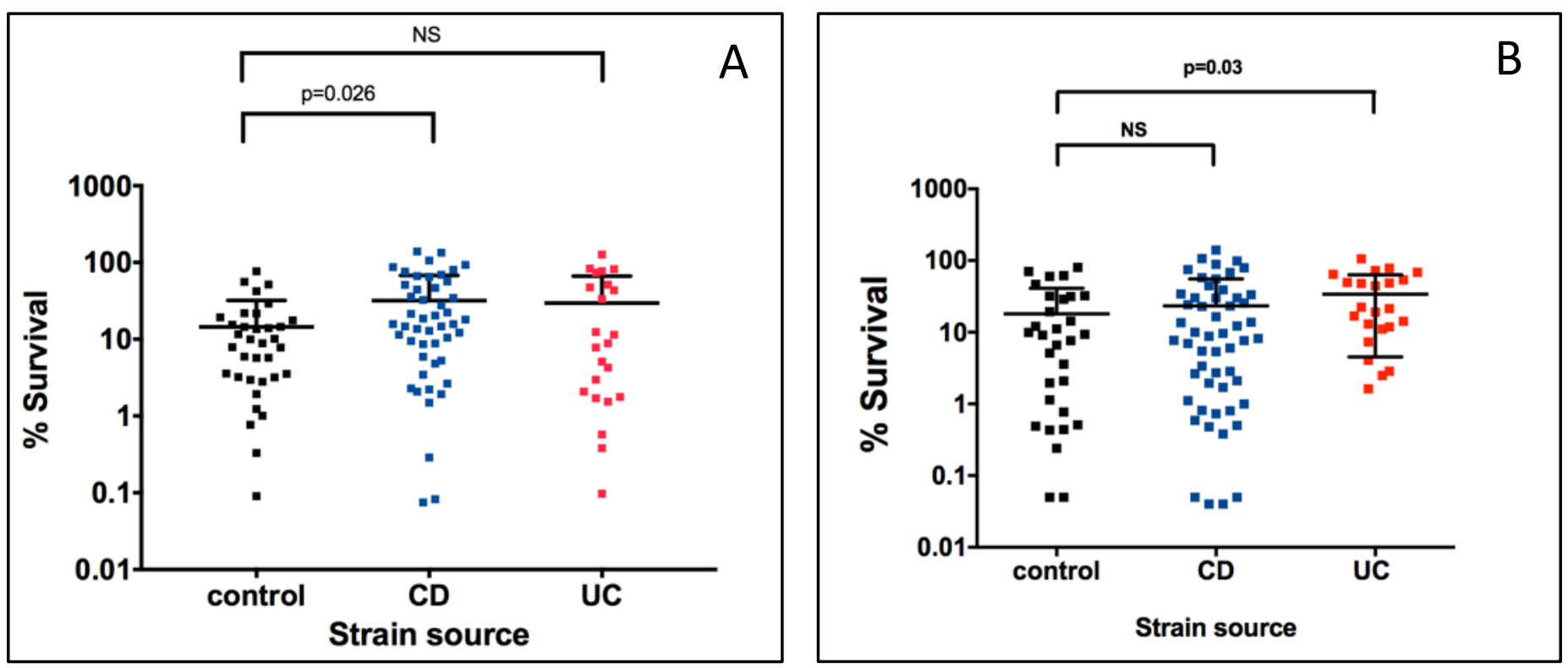

Figure 1: Percent survival of AIEC strains exposed to: A) $2 \mu \mathrm{g} / \mathrm{mL}$ of HBD3 or B) $50 \mu \mathrm{g} / \mathrm{mL}$ of LL-37 for 10 minutes compared to an unexposed control. 4 biological replicates were performed. Statistical significance was determined using a one-way ANOVA. Bars of central tendency represent the average, error bars represent standard deviation (Cho, 2017 unpublished).

Although one animal study has shown the importance of HDP resistance to potentiating virulence $^{74}$, previous work has failed to identify genetic determinants of HDP resistance ${ }^{75}$, suggesting that AIEC possess unique molecular mechanisms to achieve resistance. Taken together, this evidence suggests that HDP resistance is an important bacterial phenotype that allows AIEC to persist in the inflamed gut and, along with other virulence mechanisms, cause disease.

\subsection{AVOIDING HOST-CELL XENOPHAGY}

The ability of AIEC to adhere to and to invade has been established but the mechanisms by which they persist intracellularly have not been well characterized. It is possible that, similar to Salmonella species, AIEC are able to alter the host-cell endosomal pathway to promote intracellular survival. Other enteric pathogens like Salmonella enterica can stabilize an intracellular compartment within the host cell through well-characterized mechanisms involving specialized III secretion system (T3SS) and associated effectors ${ }^{76}$. Other enteric 
pathogens also modify macrophage autophagy, providing a model for the function by which AIEC could survive intracellularly ${ }^{77}$.

As stated above, several genetic defects in macrophage function have been strongly associated with high risk for developing IBD. SNPs in NOD2, IRGM and ATG16L1 are all wellestablished and mechanistically explained risk factors for the disease. NOD2 is known to coordinate with IRGM ${ }^{78}$ and $\mathrm{ATG} 16 \mathrm{~L} 1^{79}$ as an intracellular sensor of bacterial muramyl dipeptide ${ }^{80}$. Work performed in macrophages isolated from IBD patients has demonstrated that in the disease cohort, there is a deficiency in the ability to clear bacteria compared to healthy controls $^{81}$. Furthermore, Chu and colleagues have shown that immune cells from individuals with ATG16L1 mutations have defective $T_{\text {reg }}$ responses when exposed to outer membrane vesicles from commensals ${ }^{82}$. More recently, ATG16L1 was shown to directly interact with complement C3 and that ATG16L1 knockout epithelial cell lines lost the ability to limit intracellular replication of the AIEC strain LF82 in a C3-dependent manner ${ }^{77}$. From these studies, it is clear that host-cell xenophagy and immune system signaling both up and downstream of this response are important in the context of IBD pathogenesis.

AIEC appear not only to be able to take advantage of these known risk factors, but to also have mechanisms which allow for some degree of intracellular survival within host macrophages. Several groups have studied this phenomenon using different experimental models. Glasser and colleagues were the first to identify this phenotype in an in vitro cell culture model using J774-A1 cells ${ }^{83}$. Using the LF group of AIEC strains, this work demonstrated robust intracellular replication that was strikingly similar to what is seen with Salmonella spp. In a separate study, Sepehri et al. used isolates from UC patients to infect RAW264.7 macrophages and demonstrated intracellular bacterial survival ${ }^{18}$. This group did not report the same explosive bacterial replication as Glasser and colleagues, but they did demonstrate that AIEC persisted after a 24-hour infection. Subramanian et al. have independently assessed AIEC invasion and survival in a cell culture model and showed that some strains demonstrate intracellular replication after 3 hours of infection ${ }^{84}$. This work included the HM group of AIEC strains as well as the strain LF82 which has been well studied and was included in the work by Glasser and colleagues. 
In the AIEC field, there is little agreement on either the ubiquity or the magnitude of the intracellular macrophage survival phenotype expressed by these bacteria. Some groups have reported that it is a defining characteristic of AIEC, while others suggest that it is a phenotype that exists on a continuum and is not robustly expressed by all strains. Additionally, very little work has been performed to identify the mechanism or mechanisms by which AIEC are able to persist and, in some cases, replicate within macrophages. Furthermore, it is not known how any such mechanism would affect downstream macrophage function in the context of the bacterial community of the gut containing both pathogenic and commensal species. While it is clear that this phenotype, in combination with host-cell defects in bacterial sensing and/or clearance could allow for a bacterium which is already fit to survive in an inflammatory milieu (i.e. peptide resistance, adhesion) to persist and contribute to the chronic inflammatory storm that is characteristic of IBD.

\subsection{KNOWN ALTERATIONS TO ENDOSOMAL TRAFFICKING CAUSED BY E. COLI}

Trafficking of intracellular cargo within macrophages has been well-studied due to their importance as innate immune cells. Several complex events must occur in a coordinated fashion in order for internalized material to be trafficked to the appropriate endpoint. Comprehensive reviews by Luzio et al. and Pauwels et al. describe endosome-lysosome as well as phagosome-lysosome biology in great detail ${ }^{85,86}$. In the case of bacterial uptake, phagocytosis and subsequent phagosome maturation is required in order for phagolysosomal fusion followed by bacterial breakdown. As is common in host-pathogen interactions, bacteria have evolved mechanisms in order to disrupt this process.

Phagocytosis is the process by which large particles are internalized within a cell. This requires substantial remodeling of the membrane in order to surround and encapsulate the cargo that is to be internalized by the cell. Touret and colleagues have demonstrated that remodeling of the membrane to form pseudopods is dependent mainly on actin remodeling and contributions of material directly from the plasma membrane ${ }^{87}$. Others have argued that different subcellular compartments, such as the endoplasmic reticulum, contribute to this 
process $^{88}$, although this hypothesis appears controversial or at least context-dependent ${ }^{89}$. The formation of the phagosomal cup and eventual engulfing of a bacterium is succeeded by a series of maturation steps that are required in order for eventual phagolysosomal fusion.

Maturation of the phagosome relies on a family of GTPases called Rab proteins. An early phagosome will acquire Rab5 ${ }^{90}$ followed by Rab7 and Rab7-interacting lysosomal protein $(\mathrm{RILP})^{91}$ before eventually acquiring the lysosomal markers Lysosome-associated membrane protein (LAMP)1 and LAMP2. This dynamic requires interaction with other intracellular compartments including early and late endosomes and also relies heavily on actin polymerization $^{92}$. Importantly, it has been demonstrated that phagosomes that fail to acquire LAMP1 and/or LAMP2, or those with lower level expression, do not progress through lysosomal fusion $^{93,94}$. Fusion of phagosomes with lysosomes is a relatively well-studied phenomenon and is generally broken into four steps: Tethering, docking, consolidation and fusion. Tethering and docking are described in literature as two distinct steps that are both actin and calmodulindependent, whereas consolidation is $\mathrm{Ca}^{2+}$-dependent ${ }^{92}$. The direct interaction between phagosome and lysosome that is maintained through consolidation helps mediate fusion of the two compartments. Fusion requires Soluble N-ethylmaleimide-sensitive factor attachment protein receptor (SNARE) proteins on both compartments that form a trans-SNARE complex ${ }^{85}$. These act to form the initial pore that leads to fusion between the lysosome and phagosome. Many bacterial pathogens disrupt this pathway and the way in which they do so is very diverse. The best characterized microbe that disrupts the system is probably Salmonella enterica, which is a facultative intracellular pathogen that is able to replicate inside macrophages. This pathogen is able to hijack and activate the host focal adhesion kinase (FAK) to arrest normal xenophagy through activation of the Akt-mTOR pathway ${ }^{95}$. This allows for actin remodeling, arrest of phagosome maturation and stabilization of the Salmonella-containing vacuole (SCV) within the cell. Salmonella have also been shown to modulate host-cell interferon signaling which has causes downstream deficiencies in chemokine-mediated host response ${ }^{96}$. These mechanisms are mediated by the Salmonella pathogenicity islands (SPIs), SPI1 and SPI2, which encode for two type three secretion systems as well as several other effector proteins ${ }^{97}$. 
The closest genetically related group to AIEC are extraintestinal pathogenic $E$. coli (EXPEC). The ExPEC group includes a number of important pathogens, including those associated with urinary tract infection, neonatal meningitis and invasive infections of birds. To date the only functional comparison between the two that has been performed is one of adherent and invasive phenotypes ${ }^{98}$. It is notable also, that at least one AIEC strain, NC101, has been shown to form aggregates in an iron-dependent manner similar to the EXPEC subset of strains uropathogenic $E$. coli (UPEC) ${ }^{99}$. Studies of UPEC strains have found a number of different mechanisms that allow for intracellular survival of these bacteria, which may offer insight into how AIEC achieve this same goal. In a 2006 paper by Eto and colleagues, the authors used an ex vivo model of mouse bladder infection to elucidate how UPEC are trafficked and eventually come to infect and re-infect a given host ${ }^{100}$. They show through co-localization fluorescence microscopy that internalized UPEC in immature bladder cells are trafficked to the late endosome and acquire LAMP1 (a finding confirmed by others ${ }^{101}$ ), suggesting interaction with lysosomes, although the bacteria persist with low-level replication. Once bladder cell differentiation occurs, a redistribution of actin around the vacuoles containing the UPEC contributes to the release of the bacteria into the cytosol where it begins to extensively replicate. This suggests that these bacteria have the ability to resist the low $\mathrm{pH}$ environment associated with the phagolysosome.

More recent work has identified the requirement of the host GTPase Rab35 for intracellular UPEC survival. Through mechanistic experiments, Dikshit et al. show that Rab35 is recruited to the UPEC-containing vacuole. This allows for interaction with TfR1, the transferrin receptor 1 to allow iron uptake and ultimately bacterial survival ${ }^{102}$. This is an example of an intracellular $E$. coli strain hijacking a host Rab protein to benefit itself, although a caveat must be made that these infections are performed in bladder epithelial cells and not macrophages.

These pathogens offer some insight into the way that bacteria have evolved to avoid killing by host cells. Disruption of some part of the phagocytic pathway via secreted effectors usually plays a role in intracellular stability. Knowing that certain strains of AIEC persist within macrophages for at least 24 hours, it would be informative to look for potential disruptions in phagosomal maturation and/or lysosomal fusion as ways to explain this phenotype. 


\subsection{SUMMARY AND EXPERIMENTAL RATIONALE}

In summary, a number of different virulence phenotypes have identified and explored experimentally in AIEC. This diversity of phenotypes mirrors the many possible host defects that could contribute to the onset and/or maintenance of IBD. It is therefore likely that there are many host-pathogen combinations that can lead to a disease state. Although no one single bacterial phenotype may be necessary or sufficient to cause disease, focusing on individual phenotypes is important for understanding these interactions.

Very little is known about how AIEC are able to mediate interactions with host macrophages. Several genetic risk factors for IBD are related to either bacterial sensing or processing by these cells. These factors, combined with the apparent ability of AIEC to persist intracellularly are a possible a host-pathogen interaction that could contribute to the development of IBD. To date, no studies have been performed to correlate disease state with the ability of a clinical isolate to invade and/or persist intracellularly in macrophages, instead these screens have focused on quantifying a panel of disease-associated strains. Developing an experimental system that allows an evaluation of AIEC strains with respect to macrophage processing will allow for elucidation of possible novel phenotypes. Extending this system using a co-infection with non-pathogenic bacteria will allow for identification of any changes to macrophage function after interaction with AIEC. Putting this information into context with the other risk factors for IBD could help to improve to ability to predict risk for developing disease. With this context, the research that is the focus of this thesis will address the following hypotheses:

\section{Hypothesis I}

\section{AIEC show a diversity of invasion and intracellular survival phenotypes towards macrophages.}

\section{Objective I}

Establish an in vitro macrophage infection model using RAW264.7 cells and strains of AIEC. 
Macrophages isolated from CD patients have been shown to be defective in their ability to clear intracellular bacteria ${ }^{81}$. Since AIEC are known to interact with macrophages, experiments will focus on this host-pathogen interaction.

RAW264.7 murine macrophages will be cultured and used for bacterial infections using AIEC strains. This objective will focus on narrowing the timing of infections, the multiplicity of infection (MOI) as well as the methods for cell lysis and bacterial quantification. Data from this objective will be used to generate standard infection conditions in order to assess AIEC uptake and intracellular survival in RAW264.7 cells.

Objective II

Quantify uptake and survival phenotypes of AIEC strains in comparison to non-virulent K12 E. coli and the intracellular pathogen Salmonella SL1344 as controls.

A panel of AIEC strains isolated from CD, UC and healthy control patients, as well as K12 E. coli and Salmonella SL1344 will be used to infect RAW264.7 cells with standard conditions as determined in objective 1. Bacterial uptake will be assessed by quantifying total intracellular bacteria at 1 hour and comparing to total bacteria inoculated into the culture. Survival will be assessed by quantifying intracellular bacteria after a gentamicin treatment followed by culture for 23 hours. Survival will be determined as total intracellular bacteria at 23 hours postGentamicin treatment compared to intracellular bacteria after 1 hour of invasion.

\section{Hypothesis II}

Some AIEC strains have the ability to alter macrophage function as a virulence strategy. Objective I

Determine if a primary infection with AIEC strains alters macrophage killing of a secondary nonpathogenic strain.

Downstream effects on macrophage function will be assessed by adding a non-virulent antibiotic-resistant K12 strain after the primary strain (AIEC or control strain) has already been 
established intracellularly. Experiments will focus on determining changes in the uptake and/or killing of secondary bacteria after pre-treatment with the test strain.

Objective II

Use fluorescence microscopy to co-localize Green fluorescent protein (GFP)-expressing AIEC strains in macrophage endosomal pathway using antibody staining.

GFP-expressing strains of AIEC or control bacteria will be used in conjunction with antibody staining for the lysosomal marker LAMP1. Co-localization of bacteria with LAMP1, as well as quantification of fluorescence will be used to compare macrophage response to AIEC and control strains. 


\section{METHODS}

\subsection{BACTERIAL CULTURE METHODS \& LIST OF BACTERIAL STRAINS USED}

Bacterial strains were routinely grown in lysogeny broth (LB) composed of $10 \mathrm{~g} / \mathrm{L}$ tryptone (Bioshop cat. \#TRP402.1), $5 \mathrm{~g} / \mathrm{L}$ yeast extract (Bioshop cat. \#YEX401.1) and $10 \mathrm{~g} / \mathrm{L} \mathrm{NaCl}$ (Bioshop cat. \#SOD002.205) in deionized water. Cultures were grown overnight at volumes of 3 $\mathrm{mL}$ and were subcultured prior to use. All growth occurred at $37^{\circ} \mathrm{C}$ while shaking at $200 \mathrm{rpm}$. Direct quantification of bacteria on plates was performed on LB agar plates supplemented with $15 \mathrm{~g} / \mathrm{L}$ of agar (Bioshop cat. \# AGR001.500) and antibiotic(s) where indicated. The list of bacterial strains used is in Table 2 below.

Table 2: List of bacterial strains used.

\begin{tabular}{|c|c|c|}
\hline Strain Name & Description & Source \\
\hline E. coli NRG857c & CD-associated clinical isolate & Eaves-Pyles et al. ${ }^{103}$ \\
\hline E. coli LF82 & CD-associated clinical isolate & Darfeuille-Michaud et al. ${ }^{46}$ \\
\hline S. enterica SL1344 & Clinical isolate & Hoiseth and Stocker ${ }^{104}$ \\
\hline E. coli DK K12 & Non-virulent lab strain & Sepehri et al. ${ }^{18}$ \\
\hline E. coli DK18 & CD-associated clinical isolate & Sepehri et al. ${ }^{18}$ \\
\hline E. coli DK28 & $\begin{array}{l}\text { Clinical isolate from healthy } \\
\text { patient }\end{array}$ & Sepehri et al. ${ }^{18}$ \\
\hline E. coli DK33 & $\begin{array}{l}\text { Clinical isolate from healthy } \\
\text { patient }\end{array}$ & Sepehri et al. ${ }^{18}$ \\
\hline E. coli DK35 & $\begin{array}{l}\text { Clinical isolate from healthy } \\
\text { patient }\end{array}$ & Sepehri et al. ${ }^{18}$ \\
\hline E. coli HM605 & CD-associated clinical isolate & Martin et al. ${ }^{105}$ \\
\hline E. coli BW25113 & Keio-collection parent strain & Baba et al. ${ }^{106}$ \\
\hline E. coli BW25113 + pCR2.1 & N/A & This study \\
\hline E. coli DK K12 + pCR2.1-GFP & N/A & This study \\
\hline E. coli HM605 + pCR2.1-GFP & N/A & This study \\
\hline S. enterica SL1344 + pCR2.1-GFP & N/A & This study \\
\hline
\end{tabular}




\subsection{CREATION OF ANTIBIOTIC RESISTANT AND GFP-EXPRESSING BACTERIA}

Bacterial strains were made chemically competent and transformed with either empty pCR2.1 TOPO vector (ThermoFisher Scientific cat. \# K451020) or one containing a stable GFP gene. Briefly, bacterial cells were grown overnight in LB broth before subculturing in $100 \mathrm{~mL}$ of LB and grown to an optical density (OD) between 0.4 and 0.6. Cells were then centrifuged at $2000 \times g$ for 10 minutes at $4^{\circ} \mathrm{C}$ and pellets were resuspended in $40 \mathrm{~mL}$ of ice-cold TFB1 solution, composed of $30 \mathrm{mM}$ potassium acetate (Bioshop cat. \#POA301), $10 \mathrm{mM} \mathrm{CaCl}_{2}$ (Bioshop cat. \#CCL302), $50 \mathrm{mM} \mathrm{MnCl}_{2}$ (Bioshop cat. \#MAN222), $100 \mathrm{mM} \mathrm{RbCl}$ (Bioshop cat. \# RUB123.25) and 15\% glycerol (Bioshop cat. \# GLY002.4) in deionized water. Cells were incubated on ice in TFB1 for 5 minutes before pelleting by centrifugation at $2000 \times g$ for 5 minutes at $4^{\circ} \mathrm{C}$. Pellets were resuspended in $4 \mathrm{~mL}$ of TFB2 solution composed of $10 \mathrm{mM}$ MOPS (Bioshop cat. \# MOP001), 75 $\mathrm{mM} \mathrm{CaCl}_{2}, 10 \mathrm{mM} \mathrm{RbCl}$ and $15 \%$ glycerol in deionized water. Cells were incubated on ice for 1 hour before the addition of vector and heat shock at $42^{\circ} \mathrm{C}$ for 30 seconds. Cells were recovered on ice for 5 minutes before the addition of SOC media, composed of $20 \mathrm{~g} / \mathrm{L}$ tryptone, $5 \mathrm{~g} / \mathrm{L}$ yeast extract, $10 \mathrm{mM} \mathrm{NaCl}, 2.5 \mathrm{mM} \mathrm{KCl}$ (Bioshop cat. \#POC308), $10 \mathrm{mM} \mathrm{MgCl}$ (Sigma-Aldrich cat \# M8266) and 20 mM glucose (Bioshop cat. \# GLU501.500) in deionized water. Cells were recovered at $37^{\circ} \mathrm{C}$ shaking at $200 \mathrm{rpm}$ for 2 hours before plating on LB agar containing $50 \mu \mathrm{g} / \mathrm{mL}$ kanamycin (Kan) (Bioshop cat. \# KAN201.5). After overnight incubation, individual colonies were picked and placed in $3 \mathrm{~mL}$ overnight cultures in LB broth containing $50 \mu \mathrm{g} / \mathrm{mL}$ Kan. Cultures that grew successfully were assessed visually for fluorescence. Plasmid-containing strains were frozen in a 1:1 mix of overnight culture with $50 \%$ glycerol solution in LB media and stored at $-80^{\circ} \mathrm{C}$.

\subsection{ROUTINE CULTURE OF RAW 264.7 CELLS}

RAW264.7 cells were obtained frozen at passage 4 from the Botelho lab, thawed at $37^{\circ} \mathrm{C}$ and centrifuged at $400 \times \mathrm{g}, 4^{\circ} \mathrm{C}$. Pellets were resuspended and cultured in Dulbecco's modified Eagle's medium (DMEM, Sigma-Aldrich cat. \# D5796-500ML) with 10\% fetal bovine serum (FBS, Sigma-Aldrich cat. \# F1051-500ML), $100 \mathrm{U} / \mathrm{mL}$ penicillin and 100 gg/mL streptomycin (Sigma- 
Aldrich cat. \# P4333-100ML). Cultures were maintained in a $37^{\circ} \mathrm{C}$ incubator with $5 \% \mathrm{CO}_{2}$ up to $80 \%$ confluence and media was exchanged every 3-4 days. Subculturing of cells was performed using mechanical detachment with a cell scraper and cells were passaged using a 1:10 dilution of the original culture in fresh culture media. Cells were used between passages 4 and 11 .

\subsection{QUANTIFICATION OF UPTAKE AND SURVIVAL PHENOTYPES OF AIEC}

Infections of RAW264.7 macrophages were performed in 24-well plates with a cell density of approximately 68,000 cells $/ \mathrm{cm}^{2}\left(1.3 \times 10^{5}\right.$ cells per well). Bacterial strains were grown overnight in LB medium and sub-cultured to mid-log growth phase $\left(\mathrm{OD}_{600}\right.$ of $\left.0.6-0.8\right)$ before normalizing inoculum concentrations in $1.5 \mathrm{~mL}$ microcentrifuge tubes by diluting in $1 \mathrm{X}$ phosphate buffered saline (Bioshop cat. \# PBS405.4).

To prepare for infection, antibiotics were removed from cell cultures by washing three times with Dulbecco's phosphate buffered saline with no calcium or magnesium (DPBS, Gibco cat \# 14190250) and fresh culture media was added with no antibiotics. Bacterial strains were

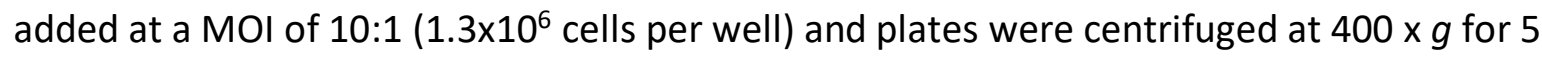
minutes at room temperature to synchronize infections. Plates were then placed in a $37^{\circ} \mathrm{C}$ incubator with $5 \% \mathrm{CO}_{2}$.

After 1 hour of incubation, plates were washed again three times with 1X PBS before the addition of $200 \mu \mathrm{g} / \mathrm{mL}$ of gentamicin (Gent) (Bioshop cat \# GTA202.10) in DMEM in order to eliminate extracellular bacteria. Gent exposure was performed for 15 minutes at $37^{\circ} \mathrm{C}$ with $5 \%$ $\mathrm{CO}_{2}$ after which plates were once again washed with $1 \mathrm{X}$ DPBS three times. Culture wells that were left for the assessment of 24-hour survival were maintained in DMEM with $10 \%$ FBS and $15 \mu \mathrm{g} / \mathrm{mL}$ of gentamicin.

Harvest of wells for the assessment of 1-hour uptake of bacteria was performed by adding $0.1 \%$ Triton X-100 (Bioshop cat \# TRX777.500) in DPBS. Aliquots of $250 \mu \mathrm{L}$ were added to each well and a $1 \mathrm{~mL}$ micropipette was used to thoroughly wash each well. Cell lysates were collected into $1 \mathrm{~mL}$ titer tubes before a second aliquot of $250 \mu \mathrm{L}$ of Triton X-100 solution was added to each well. Wells were again washed thoroughly before cell lysate was collected. Lysate was serially diluted in 1X DPBS and spot plated on LB agar. Plates were dried before 
incubating either at room temperature or at $37^{\circ} \mathrm{C}$. Bacterial colonies were enumerated by eye. This procedure was repeated on a separate subset of wells after 24 hours for assessment of intracellular survival.

\subsection{INFLAMMATORY CYTOKINE SAMPLE COLLECTION AND ANALYSIS}

In order to investigate the effect of different bacterial strains on macrophages, quantification of secreted inflammatory cytokines was performed. Aliquots of $800 \mu \mathrm{L}$ of culture media from 24-hour infections were collected into $1.5 \mathrm{~mL}$ microcentrifuge tubes. These were centrifuged at $18,000 \times g$ for 1 minutes to remove cells and debris. Subsequently, $500 \mu \mathrm{L}$ of the supernatant was removed into a fresh microcentrifuge tube and stored at $-80^{\circ} \mathrm{C}$. Multiplex assays for 32 murine inflammatory cytokines were performed by Eve Technologies on $55 \mu L$ of supernatant per sample. All samples were performed in biological quadruplicate. Analysis was performed using Heatmapper and Prism. The full list of quantified cytokines can be found in Appendix 1.

\subsection{QUANTIFICATION OF SECONDARY BACTERIAL SURVIVAL PHENOTYPE}

Assessments of macrophage function downstream of 24-hour primary bacterial infection performed by infecting with a secondary, non-virulent bacterial strain. E. coli BW25113 $\mathrm{Kan}^{\mathrm{R}}$ was cultured overnight in LB containing $50 \mu \mathrm{g} / \mathrm{mL}$ of Kan before being subcultured and grown to mid-log growth phase (OD of 0.5-0.8). Bacteria was prepared for the addition to macrophage cultures at a $\mathrm{MOI}$ of 100:1 (1.3 x 107 bacteria per well).

Macrophages were cultured and infected according the procedure outlined in section 2.4 above. Instead of lysing cells to assess intracellular bacteria, primarily infected cultures were grown for 24 hours before removing Gent-containing media and washing three times with 1X DPBS. Fresh culture media with no antibiotics was added to the previously-infected cells, followed by BW25113 $\mathrm{Kan}^{\mathrm{R}}$. Cultures of infected cells were centrifuged at $400 \times \mathrm{g}$ for 5 minutes before incubating at $37^{\circ} \mathrm{C}$ with $5 \% \mathrm{CO}_{2}$ for either 1 hour of 24 hours.

After incubation, these cultures were then treated with $200 \mu \mathrm{g} / \mathrm{mL}$ of Gent for 15 minutes at $37^{\circ} \mathrm{C}$ with $5 \% \mathrm{CO}_{2}$ and then washed three more times with $1 \mathrm{X}$ PBS. Macrophage 
cultures were then lysed with $0.1 \%$ Triton X-100 solution and lysate was serially diluted and plated on LB agar containing $50 \mu \mathrm{g} / \mathrm{mL}$ Kan to enumerate secondary Kan-resistant bacteria.

\subsection{INTERROGATION OF SECONDARY BACTERIAL SURVIVAL PHENOTYPES}

Subsequent uptake experiments used secondary bacterial MOls of 100:1, 1,000:1, 10,000:1 and 100,000:1 for a 1.5-hour exposure before gentamicin killing, lysis and plating. Secondary infection time course experiments used three different infection timings: 24 hours primary with 24 hours secondary, 30 hours primary with 18 hours secondary and 40 hours of primary with 8 hours of secondary.

Experiments were also performed using the same procedure as described in 2.4 and 2.6 to compare inoculation of either live or heat-killed primary bacterial strains on the survival of the secondary non-virulent strain. All procedures remained the same with the exception of heat-killing treatment. Primary strains were split into two groups, the first was kept at room temperature while the second was expose to $90^{\circ} \mathrm{C}$ for 5 minutes before inoculate in to macrophage cultures. Samples of live and heat-killed bacteria were plated on LB agar to ensure that heat-killing was effective.

Experiments using conditioned tissue-culture media were performed in the following manner. Infections of macrophages were performed using primary strains according to the procedure outlined in section 2.4. Culture media from 24 and 48-hour infections was collected into $15 \mathrm{~mL}$ centrifuge tubes. A plate of naïve macrophages was then treated either with live primary bacterial strains or conditioned culture media and cultures were allowed to incubate for 24 hours at $37^{\circ} \mathrm{C}$. The remaining infection procedure was performed as outlined above in order to quantify the uptake and survival of the secondary non-virulent strain.

\subsection{QUANTIFICATION OF LACTATE DEHYDROGENASE FROM 24-HOUR PRIMARY INFECTIONS}

Lactate dehydrogenase (LDH) assays were performed using a commercial kit from Roche (Sigma-Aldrich cat \# 11644793001). Briefly, $100 \mu \mathrm{L}$ of sample medium (cell culture medium from infections) was added to wells of a 96-well plate. Samples were diluted 1:10 and 1:100 in 
order to create a range of analyte concentrations. Plates were incubated at $37^{\circ} \mathrm{C}, 5 \% \mathrm{CO}_{2}$ for 10 minutes before $2.5 \mu \mathrm{L}$ of catalyst was added to $112.5 \mu \mathrm{L}$ of dye solution was added. Reactions were left in the dark at room temperature for 5 minutes before $50 \mu \mathrm{L}$ of stop solution was added to each well. A plate reader was used to read absorbance values at $490 \mathrm{~nm}$.

\subsection{VISUAL QUANTIFICATION OF INTRACELLULAR BACTERIA AND LAMP1 FLUORESCENCE}

To interrogate the effects of primary infection on macrophage function, infections of RAW264.7 macrophages were performed using GFP-expressing bacterial strains. Fluorescence microscopy was performed in order to visualize and co-localize bacteria with the lysosomal marker LAMP1.

Infections were performed as described previously but with the following changes. Cells were cultured on $12 \times 12 \mathrm{~mm}$ glass coverslips in order to perform antibody staining and microscopy. Bacterial exposures were performed for 1 hour before being fixed with paraformaldehyde (PFA). A second set of experiments included a 1-hour bacterial exposure, gentamicin killing and then incubation of cultures for an additional 5 hours prior to fixing.

Cell cultures were fixed with 4\% PFA at room temperature for 15 minutes. Cultures were washed three times with $0.5 \%$ bovine serum albumin (BSA, Bioshop cat. \# ALB005.100) solution in DPBS before blocking for 20 minutes at room temperature in BSA solution. While blocking, 50 $\mu \mathrm{L}$ drops of rabbit-anti-E. coli antibody (Bio-Rad cat. \# 4329-4906) diluted 1:200 in DPBS were placed on a piece of parafilm. Coverslips were removed from blocking solution using tweezers and gently dried before being placed culture-side down on antibody drops. Coverslips were then placed in the dark at room temperature for 30 minutes for staining. Following primary staining, coverslips were replaced in their culture wells and washed three times with BSA solution before secondary staining with $500 \mu \mathrm{L}$ of Dylight 650 goat anti-rabbit secondary antibody (Bethyl Laboratories cat. \#A120-201D5) and incubated in the dark for 30 minutes at room temperature.

Staining of extracellular bacteria was succeeded by permeabilization of macrophages with $100 \%$ ice-cold methanol for 3 minutes, followed by three washes with BSA solution. LAMP1 staining was performed using the same flip-staining technique, with staining incubations 
of 1 hour each in order to reach an intracellular target. Primary staining was performed with rat-anti-LAMP1 antibody (Developmental Studies Hybridoma Bank 1D4B) and secondary staining of was performed with Dylight 550 goat anti-rat antibody (Bethyl Laboratories cat. \#A110-337D3). After LAMP1 staining, coverslips were mounted onto glass slides using Dako fluorescence mounting media (Agilent cat. \# S302380-2) and stored in the dark at room temperature overnight to dry.

Imaging was performed using a Quorum spinning disk imaging system and image analysis was performed in ImageJ. Corrected total cell fluorescence (CTFC) of LAMP1 was measured by taking average pixel intensity through a Z-stack of images and subtracting the average background intensity of an adjacent region adjusted for cell area. Measurements of total cellular LAMP1 fluorescence of cells containing bacteria were normalized cells from the same field of view that contained no intracellular bacteria. Additional measurements were performed on bacterial-containing endosomes in order to assess the specific acquisition of LAMP1 to these intracellular structures. 


\section{RESULTS}

\subsection{ESTABLISHING THE RAW264.7 INFECTION MODEL}

RAW264.7 cells have been used by other groups to assess macrophage interactions with AIEC. As stated previously, Sepehri and colleagues screened 65 AIEC strains for their ability to survive intracellularly in RAW264.7 cells ${ }^{18}$. They used 24 -well plates at a cell density of $5 \times 10^{5}$ cells per well. Knowing this, it seemed reasonable that we would be able to replicate similar work using small-scale infections in 12 or 24 well plates. In addition, a similar infection protocol from the Botelho lab was used as a starting point in order to quickly generate data and determine if the model was working as expected. In contrast to the Sepehri publication, a lower cell seeding density of $1.3 \times 10^{5}$ cells was used. The justification for this change was that, instead of a 24-hour assay, cells would remain in culture for a total of 48 hours, allowing for some additional cell division and the lower seeding density might be conducive to this.

Figure 2 below shows an example of an MOI optimization experiment using either BW25113 (K12) or SL1344 (Salmonella) as a pre-treatment for 1 hour, followed by 1 hour of exposure to Kan-resistant K12. A significant difference was found between groups only when both primary and secondary bacterial MOls were 100:1.

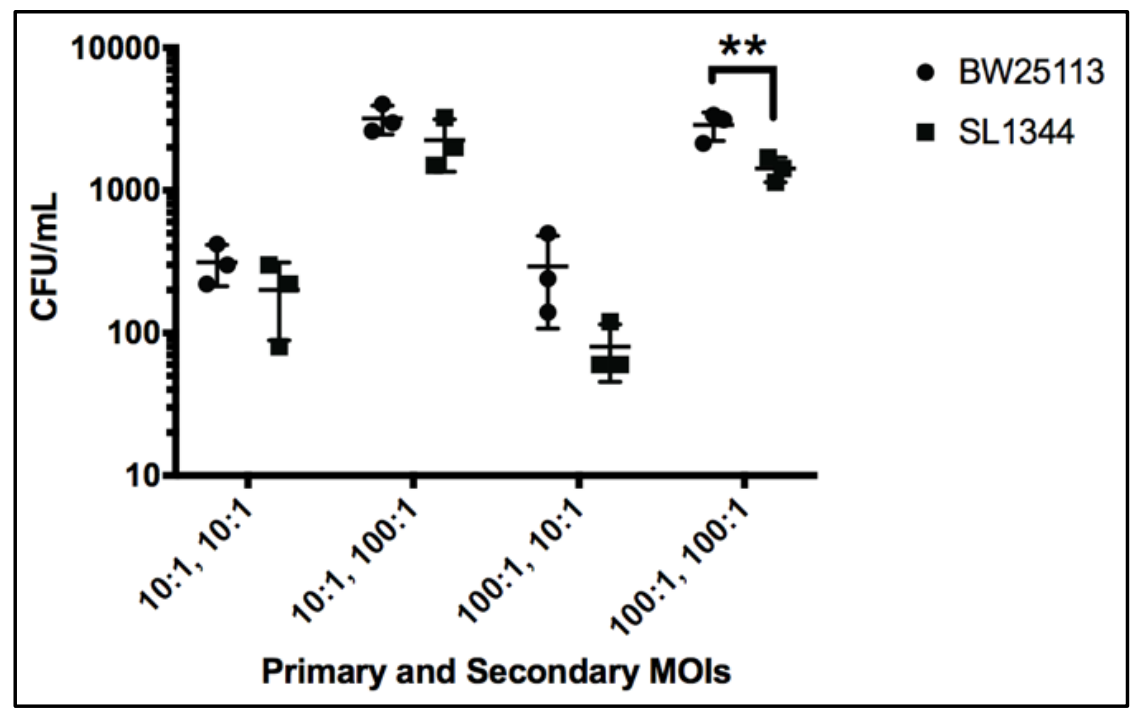

Figure 2: Internalization of Kan-resistant K12 after 1 hour of infection in pre-treated RAW264.7 macrophages. $\mathrm{MOI}$ ratios represent ratio of primary bacteria to macrophages, followed by ratio of secondary bacteria to macrophages. Experiment was performed in biological triplicate. Statistical significance was determined via two-way ANOVA **=p<0.01. Bars of central tendency represent averages, error bars represent standard deviation. 
These optimization experiments led to the development of an infection protocol whereby primary infections used an MOI of 10:1 for 1 hour, followed by Gent treatment. Cultures were then allowed to grow in fresh culture media containing $15 \mu \mathrm{g} / \mathrm{mL}$ gentamicin to prevent any bacteria released from dead or lysed cells to re-infect. Intracellular bacterial survival was assessed at 24 hours post-infection. Subsequent secondary infections were performed with an MOI of 100:1.

\subsection{DISEASE-ASSOCIATED AIEC STRAINS DEMONSTRATE HIGHER UPTAKE AND INTRACELLULAR SURVIVAL IN RAW 264.7 MACROPHAGES}

Using the optimized infection protocol developed above, a number of AIEC strains isolated from either IBD patients or healthy individuals were used to infect RAW264.7 macrophages for 1 hour in order to quantify bacterial uptake followed by maintenance of culture for 23 additional hours to quantify intracellular survival. These experiments were performed in conjunction with a K12 strain as a negative control for intracellular survival and Salmonella SL1344 as a positive control.

Figure 3 below, shows the diversity of uptake phenotypes among different AIEC strains. It is important to note that the descriptor of "Adherent-Invasive" is based on a phenotype towards epithelial cells, therefore it is not surprising that strains such as NRG857c show no significant increase in 1-hour uptake over the K12 negative control. Three disease-associated strains - LF82, DK18 and HM605 - all demonstrate statistically significant increased uptake by macrophages over the non-pathogenic control. SL1344, the positive control for intracellular survival, does not have a significantly different uptake phenotype from K12. Within the cohort of clinical isolates from healthy patients, only strain DK33 showed a significant increase in bacterial uptake compared to K12. This diversity in uptake was expected as the genetics of different AIEC strains tend to be diverse, with no single virulence factor explaining their ability to cause disease. Overall, AIEC strains isolated from patients with IBD do appear to be taken up by macrophages to a higher degree compared with those strains isolated from healthy individuals. 


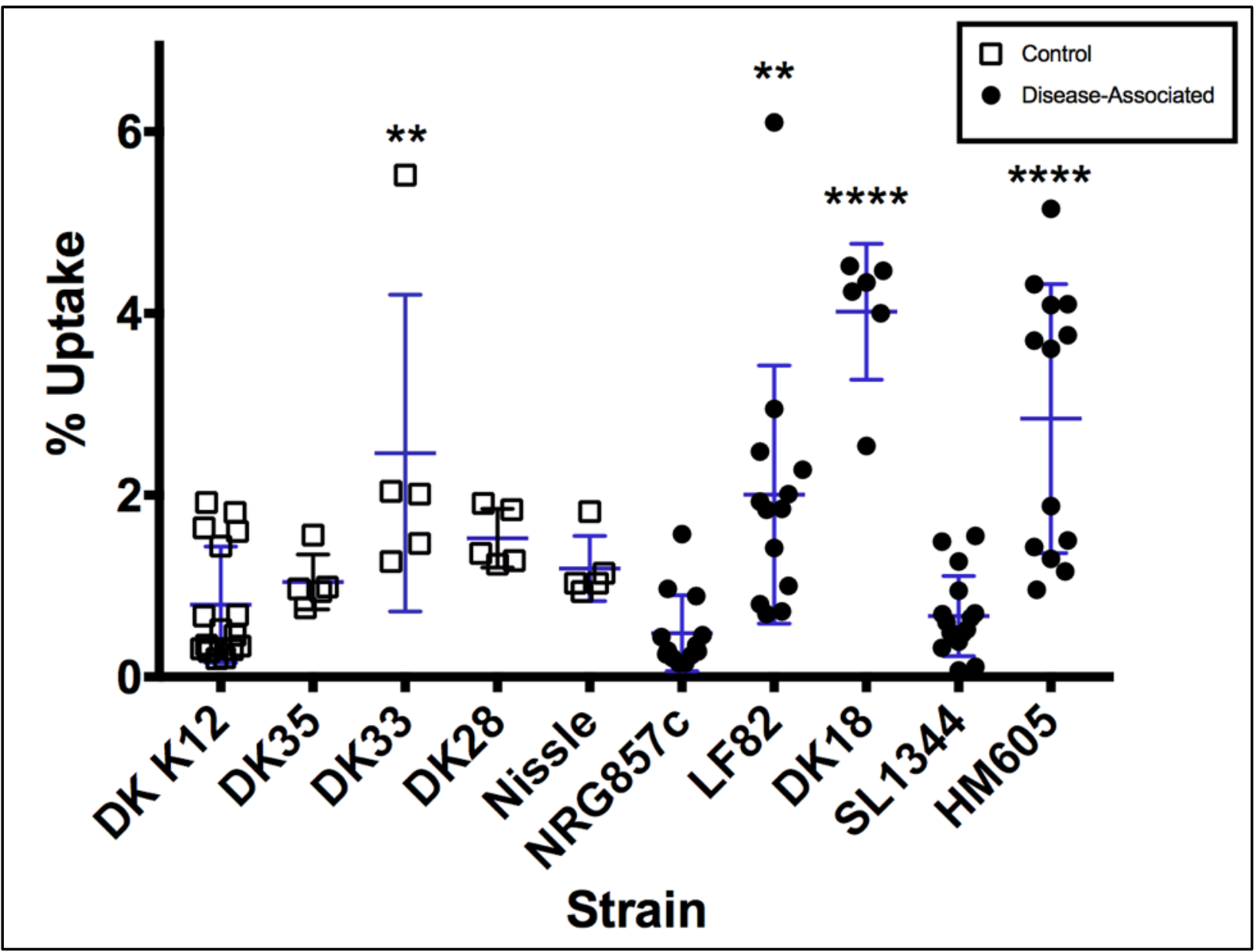

Figure 3: Percent uptake of bacteria after a 1-hour exposure to RAW264.7 macrophages normalized to inoculum. Experiments were performed in technical duplicate and biological replicates of at least 3. Statistical significance was determined using a one-way ANOVA, $* * * *=p<0.0001, * *=p<0.01$. ROUT outlier analysis was performed prior to statistical analysis. Bars of central tendency represent averages, error bars represent standard deviation.

After the 1-hour exposure followed by 23 hours of additional incubation, a different pattern was observed for bacterial survival. Figure 4 below shows this different, but still diverse pattern in intracellular bacterial survival. As expected, the $\mathrm{K} 12$ control was eliminated almost entirely from the intracellular macrophage environment, with survival ranging between 0.5 and 9\% compared to levels measured after 1-hour uptake. One disease-associated AIEC strain, LF82, demonstrated a moderate survival phenotype, maintaining survival between 5 and $50 \%$ of baseline. NRG857c and HM605 both showed higher rates of survival, between 10 and 100\%, while SL1344 robustly replicated intracellularly in almost all replicates. From the panel of 
control strains, only DK33 reached a significant level of intracellular survival compared to K12. No other control strains showed any significant differences from this control.

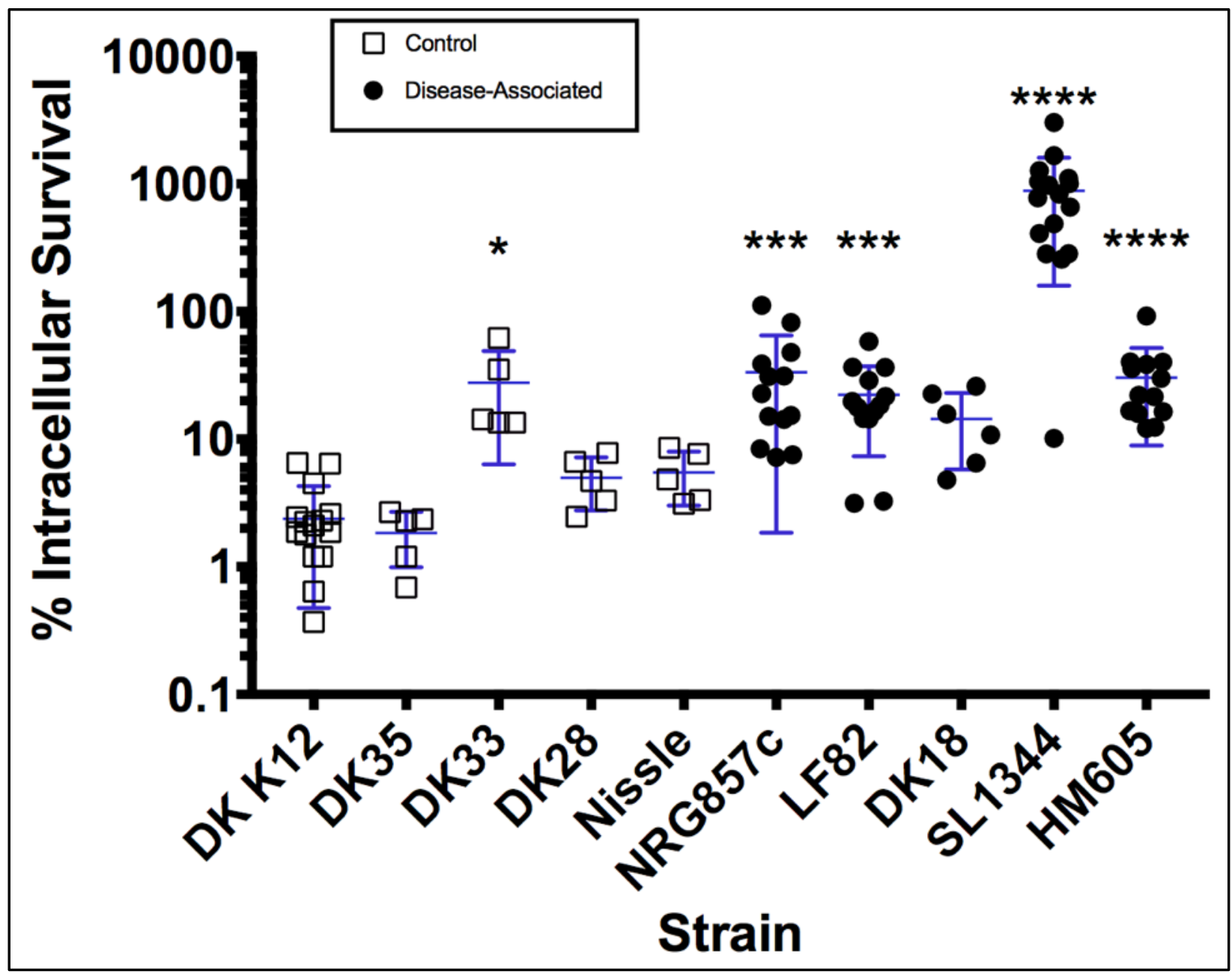

Figure 4: Percent survival of intracellular bacteria after 24 hours in RAW264.7 cells normalized to intracellular levels after 1 hour of uptake. Experiments were performed in technical duplicate with at least 3 biological replicates. Statistical significance was determined using a non-parametric ANOVA, $* * * *=p<0.0001, * * *=$ $p<0.001,{ }^{*}=p<0.05$. ROUT outlier analysis was performed prior to statistical analysis. Bars of central tendency represent averages, error bars represent standard deviation.

These results are interesting because while they do show intracellular persistence of some AIEC, they contradict other groups' findings that AIEC robustly replicate intracellularly within macrophages. In this model of infection, SL1344 shows robust intracellular replication, therefore it is expected that any similar ability to do so by AIEC strains would also be demonstrable within this 24-hour time course. Nonetheless, taken together with the uptake 
data, an overall variety of phenotypes can be seen among these different strains with the general pattern of increased uptake and survival among disease-associated strains. Table 3 below summarizes these phenotypes.

Table 3: The phenotypic diversity of invasion and survival phenotypes of AIEC in macrophage infections. Control strains are in blue, while disease-associated strains appear in red.

\begin{tabular}{|l|l|l|}
\hline Strain & Uptake Phenotype & Survival Phenotype \\
\hline DK K12 & - & - \\
\hline DK35 & - & - \\
\hline DK33 & ++ & + \\
\hline DK28 & - & - \\
\hline Nissle & - & - \\
\hline NRG857c & - & ++ \\
\hline LF82 & ++ & ++ \\
\hline DK18 & ++++ & - \\
\hline SL1344 Salmonella & - & ++++ \\
\hline HM605 & +++ & ++++ \\
\hline
\end{tabular}

\subsection{INFLAMMATORY CYTOKINE EXPRESSION OF 24-HOUR INFECTED MACROPHAGES IS STRAIN-SPECIFIC}

In an attempt to identify potential mechanisms of cellular response to AIEC infection, a panel of secreted inflammatory cytokines was quantified from the cell culture media of 24-hour infections. A sample from infections with a subset of strains - K12, SL1344, LF82, NRG857c and HM605 - were sent to a third-party company and quantified using a multiplex cytokine assay.

Of the 32 cytokines assayed, 31 generated output levels within the range of the assay. IL-13 was consistently below the range of detection for all samples, therefore it was excluded from analysis. Analysis of the panel was performed by running individual one-way ANOVA tests 
with the K12 strain as a control for baseline expression. This was done in order to differentiate between a general response to LPS and a more strain-specific response.

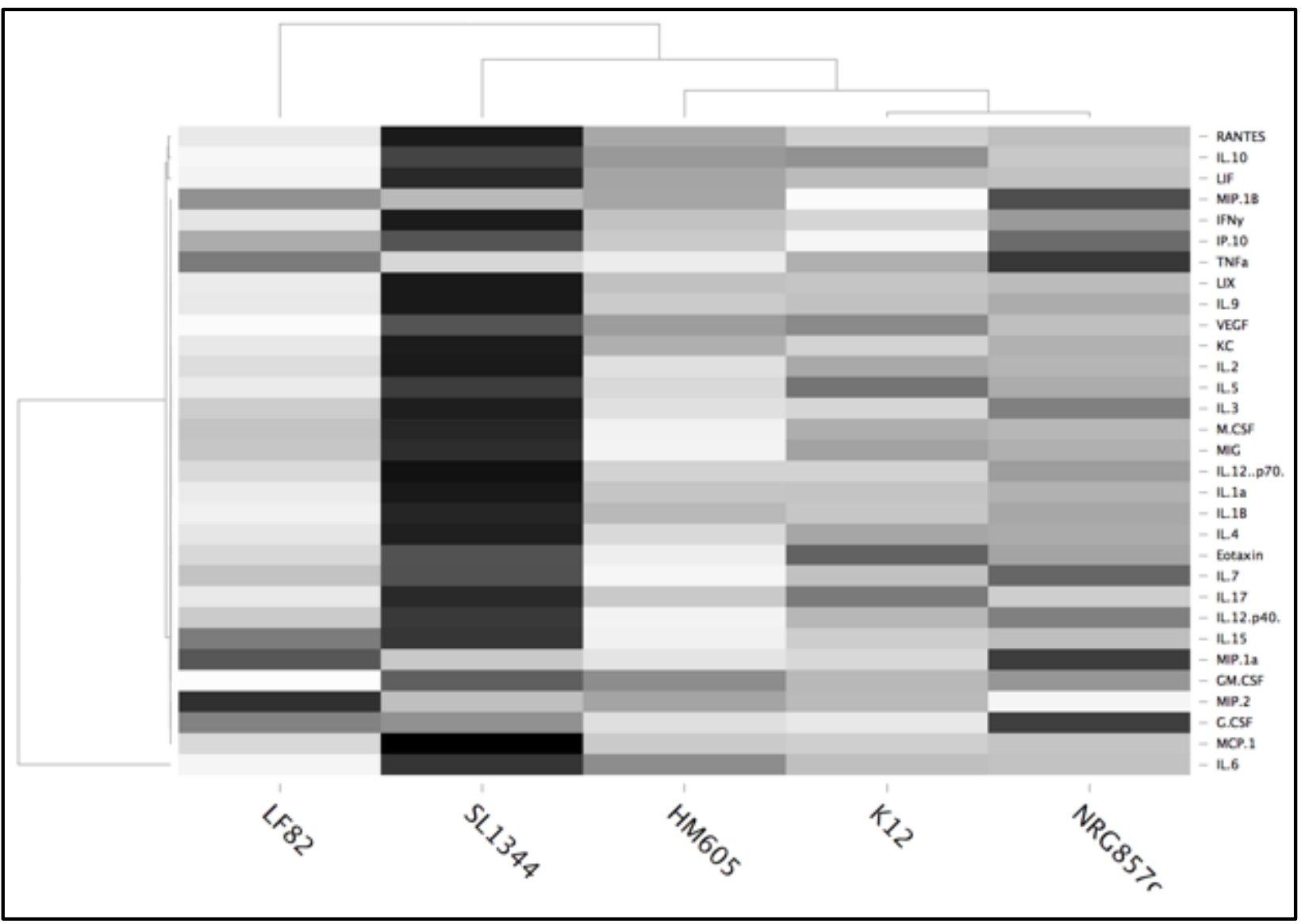

Figure 5: Heatmap and dendrograms showing hierarchical clustering of bacterial strains as well as secreted cytokines from infected macrophages. Hierarchical clustering was performed on an average of 4 biological replicates per strain, normalized against the average value from a non-infected macrophage culture. The average linkage computational method was used with Euclidean measurement distance between clusters.

Figure 5 above shows the output of a cluster analysis of inflammatory cytokine secretion from macrophages infected with various bacterial strains. It can be seen that all bacteria are very distinct with respect to the differences in the cytokine expression that they induce. SL1344 induces a very distinct expression pattern when compared to all other strains. Based on clustering, LF82 is the outgroup, whereas NRG857c has the most similar expression pattern to K12 among the strains tested. This data suggests that LF82 induces a different response from host macrophages, but it is clear that each AIEC strain seems to illicit a unique cytokine profile. 
Looking at individual analytes, Figure 6 below shows that there are patterns that can be found in the expression levels induced by both LF82 and SL1344. In measurements of IL-6, granulocyte monocyte colony stimulating factor (GM-CSF) and leukemia inhibitory factor (LIF), infection with LF82 caused a statistically significant increase in expression while infection with SL1344 caused a statistically significant decrease. The full panel of cytokine expression data can be found in Appendix 2.
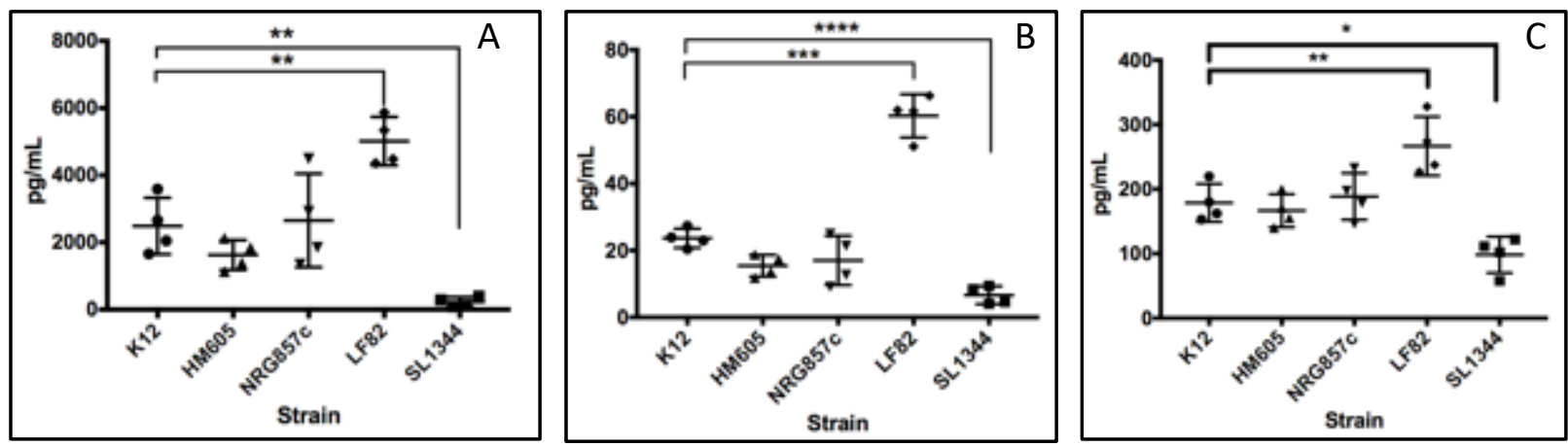

Figure 6: Secretion of A) IL-6, B) GM-CSF and C) LIF from macrophages exposed to a panel of bacteria for 1 hour, followed by culture for 23 hours. Measurements were made from 4 biological replicates. Statistical significance was determined using one-way ANOVA, ${ }^{* * * *}=p<0.0001,{ }^{* * *}=p<0.001,{ }^{* *}-p<0.01,{ }^{*}-p<0.05$. Bars of central tendency represent averages, error bars represent standard deviation.

Additionally, SL1344 induced statistically significant decreases in IL-1 $\alpha$, keratinocyte chemoattractant (KC), and MCP-1 (see Appendix 2 for figures). No other statistically significant differences were observed.

\subsection{PRIMARY INFECTION WITH AIEC DOES NOT AFFECT 1-HOUR UPTAKE OF SECONDARY BACTERIA}

Secondary infections using a Kan-resistant K12 E. coli were used in order to probe any effects of individual AIEC strains on downstream macrophage function. 24-hour AIEC infections were challenged with a higher $\mathrm{MOI}$ of $\mathrm{K} 12$ in order make evident any differences between treatments in either macrophage uptake or killing.

Figure 7 below shows the uptake phenotypes of pre-infected macrophages after 1 hour of exposure to Kan-resistant K12. While there is variation in some groups among replicates, no 
significant differences were observed among any primary bacterial pre-infections. All groups of macrophages show the same levels of secondary bacterial uptake. This includes cells pretreated with disease-associated bacteria and those that were treated with control bacteria. This result indicates that primary infection over 24 hours has no effect on the uptake of secondary bacteria. Of note, some experimental replicates performed on higher-passage cells generated lower uptake values. These, however did not alter the statistical significance of the finding.

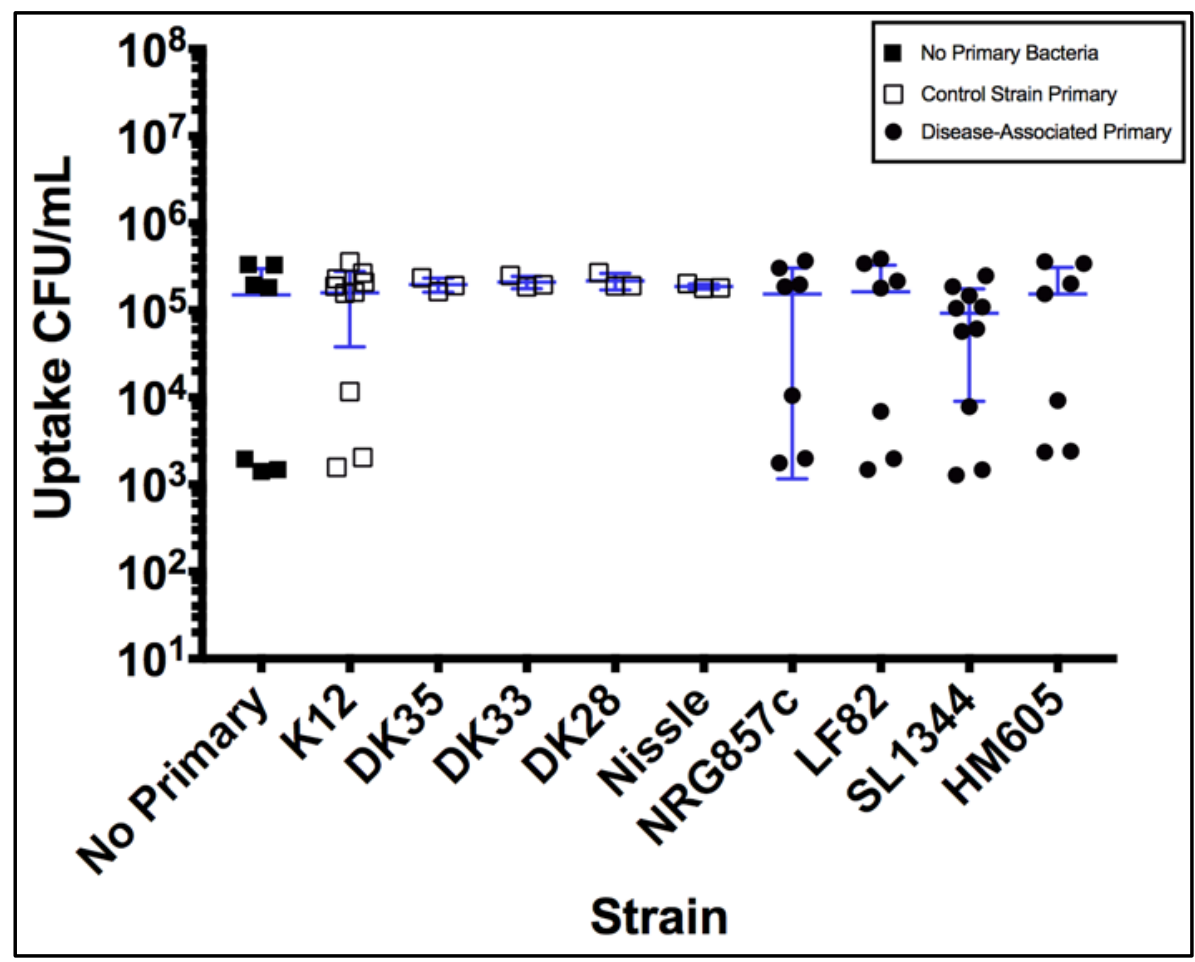

Figure 7: Internalization of intracellular Kan-resistant bacteria found in 1-hour secondary infections of RAW264.7 macrophages with $K 12 \mathrm{E}$. coli Experiments were performed in at least biological triplicate and statistical significance was assessed by non-parametric one-way ANOVA. ROUT outlier analysis was performed prior to statistical analysis. Bars of central tendency represent averages, error bars represent standard deviation.

In order to determine if secondary uptake is concentration-dependent, and to see if differences were evident at higher MOls, an additional series of experiments was performed to probe any potential defects in uptake. Secondary bacteria were added, again to 24-hour primary-exposed macrophage cultures, but at MOls ranging from 100:1 to 100,000:1 for 1.5 hours. This was intended to probe the ability of pre-treated macrophages to take up large 
amounts of secondary over a short period. Figure 8 below shows the results of this series of experiments.

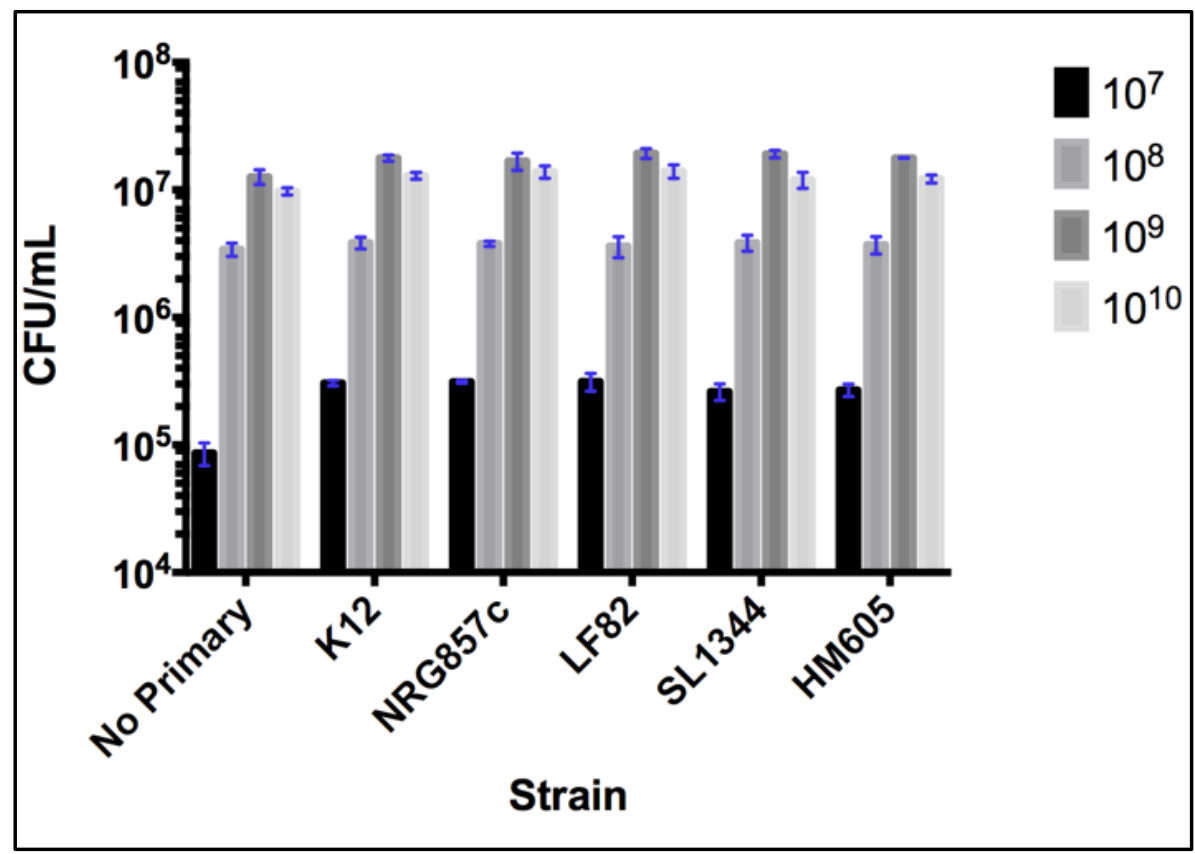

Figure 8: Internalization of intracellular secondary Kan-resistant $K 12$ E. coli after 1.5 hours of exposure to RAW264.7 macrophages. Experiments were performed in biological triplicate. Statistical significance was determined using individual one-way ANOVA tests for each MOI. Error bars represent standard deviation.

The only significant difference found in the data represented by Figure 8 is an increase in uptake in all strains treated with primary bacteria compared to the control group with no primary for the $10^{7}$ (MOI 100:1) group. No defects in uptake were detected for any primarytreated group at any MOI. Figure 6 also shows that a plateau was reached for bacterial uptake by the RAW264.7 macrophages. Increases can be seen in all groups between the different MOI treatments up to $10^{9}$ bacteria. The $10^{10}$ group did not demonstrate this same increase and in fact showed a slight decrease in intracellular bacteria (possibly due to cell death). This shows that the capacity of these macrophages to take up bacteria is on the order of $10^{9} / \mathrm{mL}$ for a 1.5 hour exposure.

In combination, figures 7 and 8 clearly demonstrate that infection with primary bacteria for 24 hours is not sufficient to affect the ability of macrophages to take up a secondary nonvirulent strain. 


\subsection{PRE-TREATMENT WITH SL1344 OR HM605 LEADS TO A DECREASE IN INTRACELLULAR}

\section{SURVIVAL OF SECONDARY K12 AFTER 24 HOURS}

Following uptake experiments, an assessment was made of 24-hour pre-treated

macrophages exposed to secondary bacteria for 24 hours. This allowed for observations to be made about the longer-term dynamics of macrophage function. Figure 9 below shows the results of this experiment.

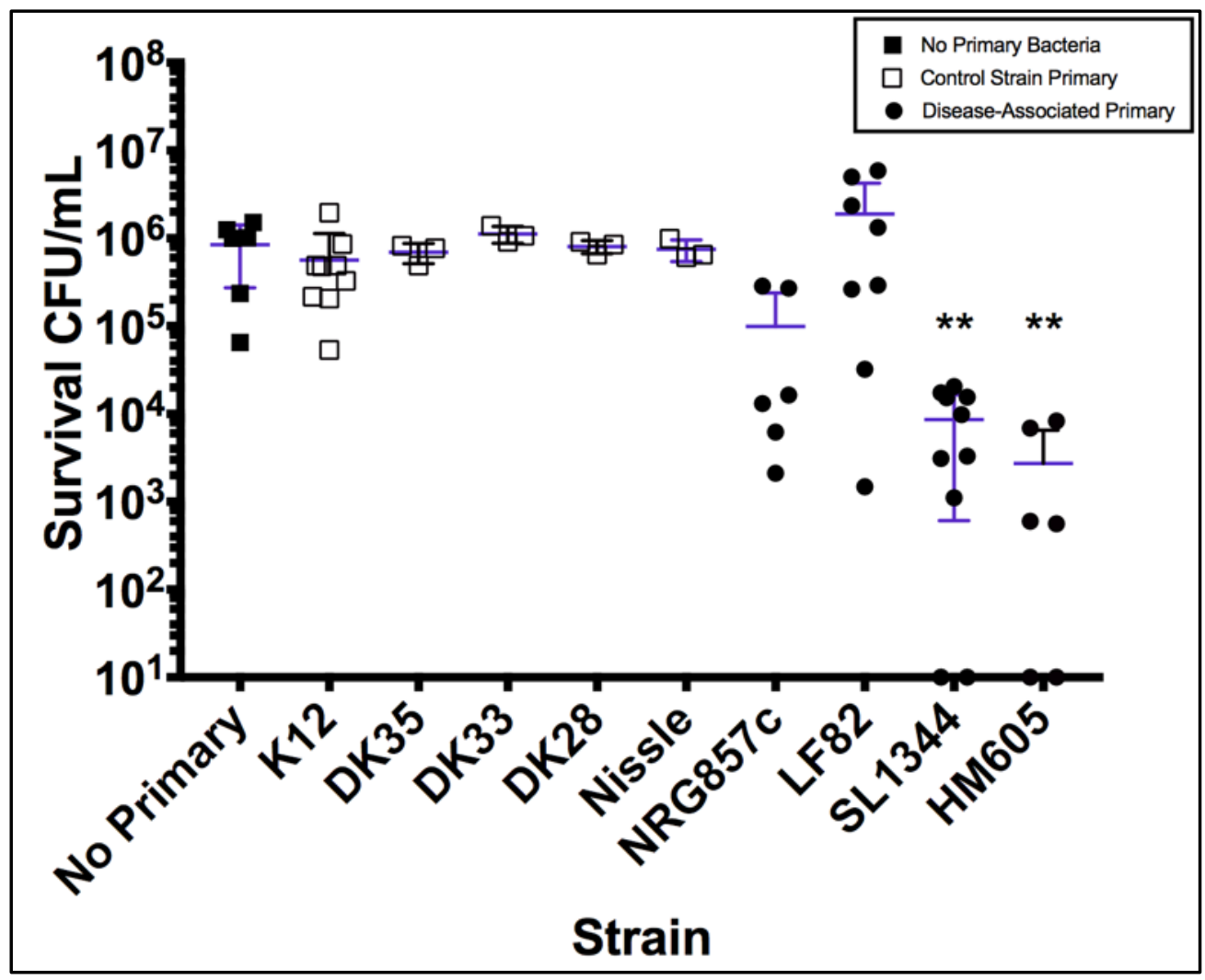

Figure 9: Internalization of intracellular secondary Kan-resistant K12 E. coli after 24 hours of exposure to RAW264.7 macrophages. Experiments were performed in at least biological triplicate. Statistical significance was determined using one-way ANOVA, ${ }^{* *}$ - $p<0.01$. ROUT outlier analysis was performed prior to statistical analysis. Bars of central tendency represent averages, error bars represent standard deviation.

Figure 9 shows that the level of intracellular secondary K12 is significantly reduced after 24 hours of exposure in both the SL1344 and HM605 pre-treatment compared to both a naïve macrophage culture as well as one pre-treated with K12. This difference was not due to 
significant macrophage death, as determined both visually and through the use of an LDH assay (See Appendix 3). This result indicates that there are changes in the way that macrophages in these groups are processing non-pathogenic bacteria and that changes are specific to the strain causing the primary infection.

In a subset of experiments, streptomycin-containing LB agar plates were used to select for the primary strains HM605 and SL1344 from the lysate of macrophages subjected to 24 hours of primary followed by 24 hours of secondary infection (i.e. 48 hours of total infection). Figure 10 below shows that both strains can be detected at similar levels to those found after 24 hours of primary infection.

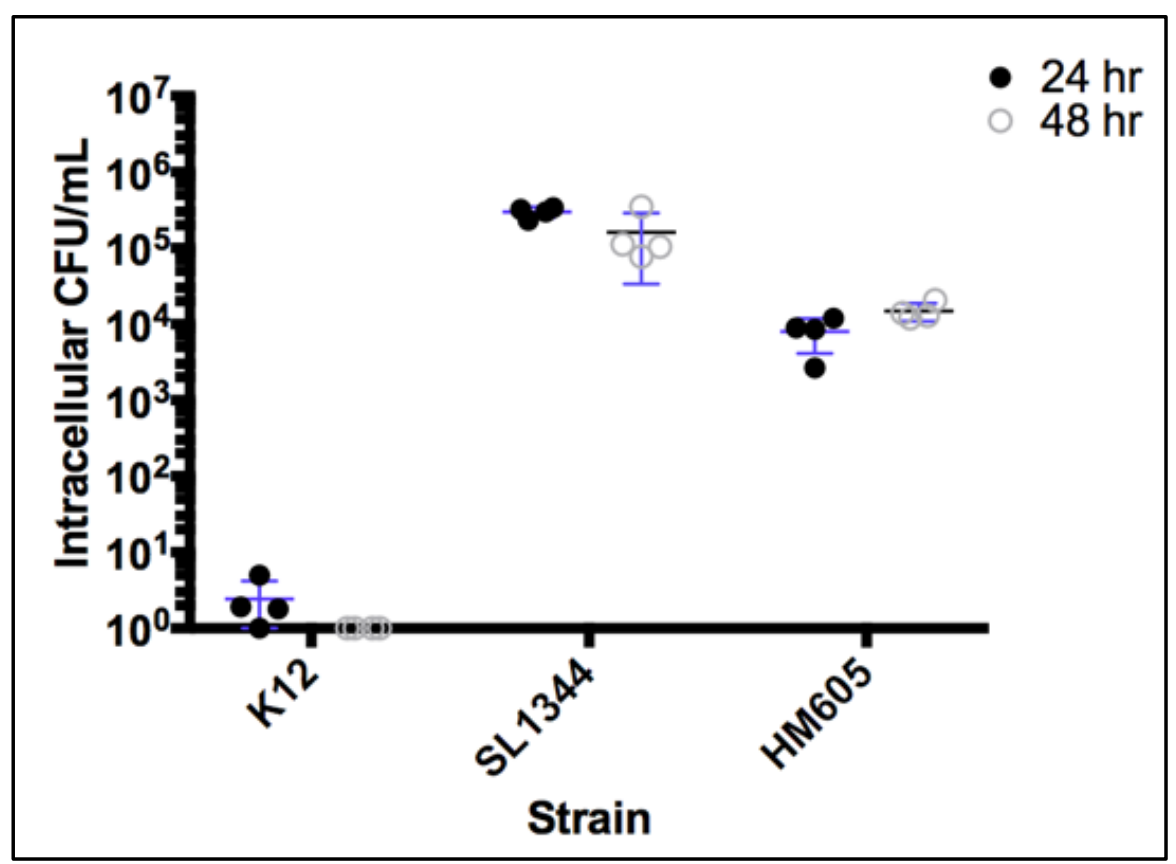

Figure 10: Internalization of intracellular primary after 24 hours of macrophage infection compared to intracellular levels after 24 hours of primary plus 24 hours of secondary infection. 4 biological replicates were performed. Bars of central tendency represent averages, error bars represent standard deviation.

Together, figures 9 and 10 demonstrate that primary and secondary bacteria are treated differently by the intracellular macrophage environment. It is clear that both HM605 and SL1344 are surviving for the full 48 hours of the experiment, while the secondary bacteria in these infections is being eliminated more efficiently. 


\subsection{EEFFECTS ON SECONDARY BACTERIAL SURVIVAL ARE TIME-DEPENDENT}

The next set of experiments was performed in order to determine whether the differences seen at 24 hours of secondary exposure were time-dependent. In order to test this, the total exposure time of 48 hours was maintained, but exposure to the primary and secondary strains was shifted from 24 and 24 hours to 30 and 18 hours as well as 40 and 8 hours. Figure 11 below shows the results the outcome of this experiment.

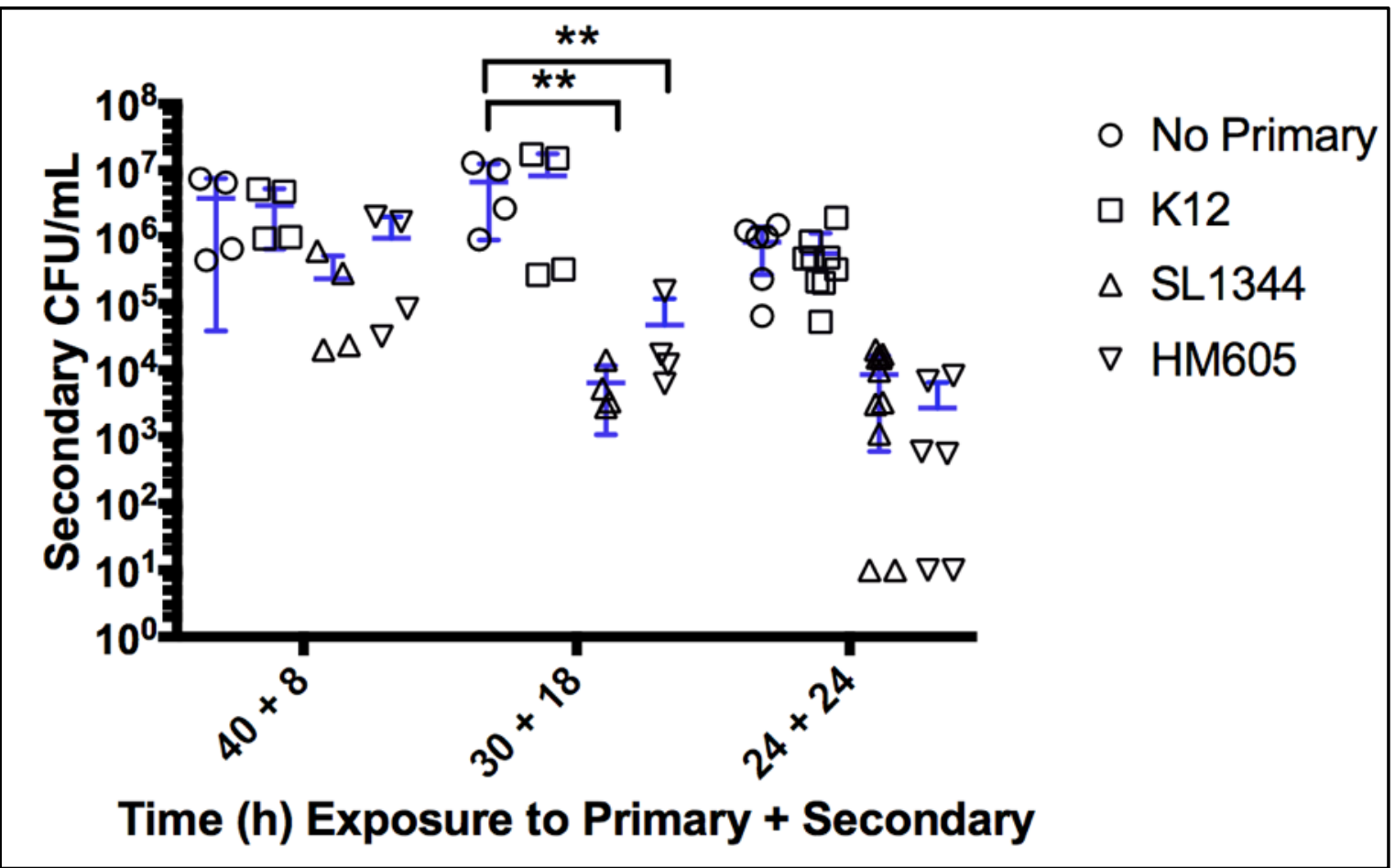

Figure 11: Internalization of intracellular Kan-resistant K12 E. coli in RAW264.7 macrophages after 40, 30 and 24 hours of primary followed by 8,18 and 24 hours of secondary exposure respectively. Experiments were performed in at least quadruplicate. Statistical significance was determined using a non-parametric one-way ANOVA, ${ }^{*}=p<0.05$. ROUT outlier analysis was performed prior to statistical analysis. Bars of central tendency represent averages, error bars represent standard deviation.

No significant differences in secondary intracellular bacteria were observed after 40 hours of primary and 8 hours of secondary exposure, as can be seen in Figure 8 . After 30 hours of primary exposure, followed by 18 hours of secondary, both HM605 and SL1344 pre-treated groups reach statistical significance. This significance is maintained at 24 hours of primary followed by 24 hours of secondary. This indicates that any alterations in macrophage function 
caused by primary infections with SL1344 or HM605 decrease secondary bacteria in a timedependent manner.

\subsection{EFFECTS ON SECONDARY BACTERIAL SURVIVAL REQUIRE DIRECT CONTACT OF LIVE PRIMARY BACTERIA WITH MACROPHAGES}

Next, in order to probe the nature of the bacterial interaction that causes the change in secondary bacterial survival, an experiment was performed using heat-killed primary strains to determine whether the effect requires a living primary strain. Figure 12 below shows that indeed living HM605 or SL1344 are required to recapitulate the altered secondary survival phenotype. The level of secondary bacteria in the heat-killed HM605 or SL1344 groups is the same as a pre-treatment with K12 (living or killed). This confirmation that living bacteria is required indicates that $\mathrm{HM} 605$ and SL1344 are an active participant in changes that are occurring in macrophage function.

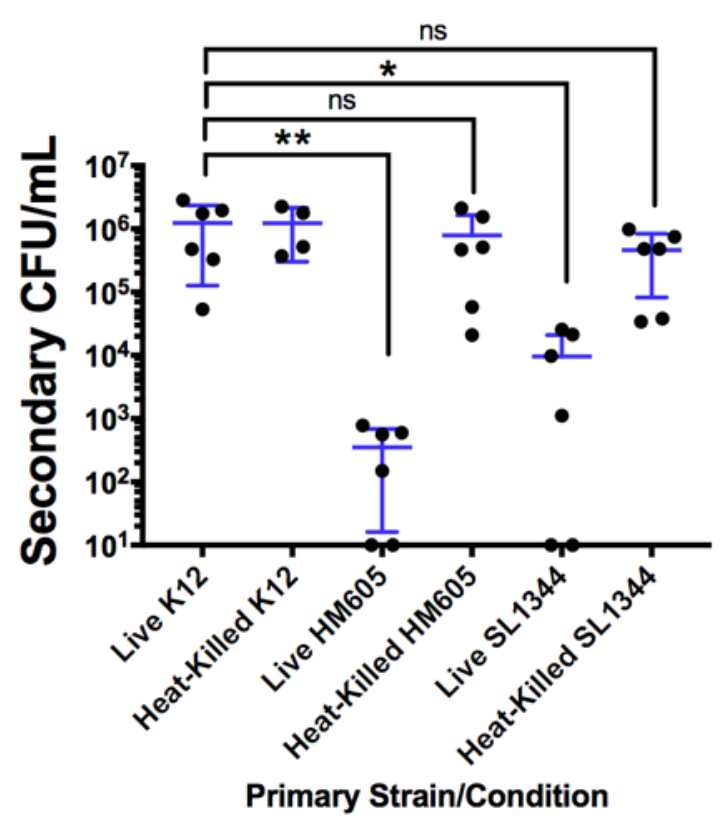

Figure 12: Internalization of intracellular Kan-resistant K12 E. coli in RAW264.7 macrophages pre-treated for 24 hours with either with live or heat-killed bacteria before the addition of secondary bacteria. Experiments were performed biological triplicate with two technical replicates per experiment.. Statistical significance was determined using a non-parametric one-way ANOVA, ${ }^{*}=p<0.05, * *=p<0.01$. ROUT outlier analysis was performed prior to statistical analysis. Bars of central tendency represent averages, error bars represent standard deviation. 
Another possible contributor to alterations in macrophage function is paracrine signaling between cells. As indicated above in the 24-hour inflammatory cytokine analysis, it is clear that there are changes intracellular survival that are primary infection-specific. In order to test the contributions of these signals to alterations in secondary bacterial processing, pretreatment of naïve macrophages with sterile-filtered conditioned cell-culture supernatant from 24-hour infections was tested against pre-treatment with bacteria. Figure 13 below shows the results from this comparison.

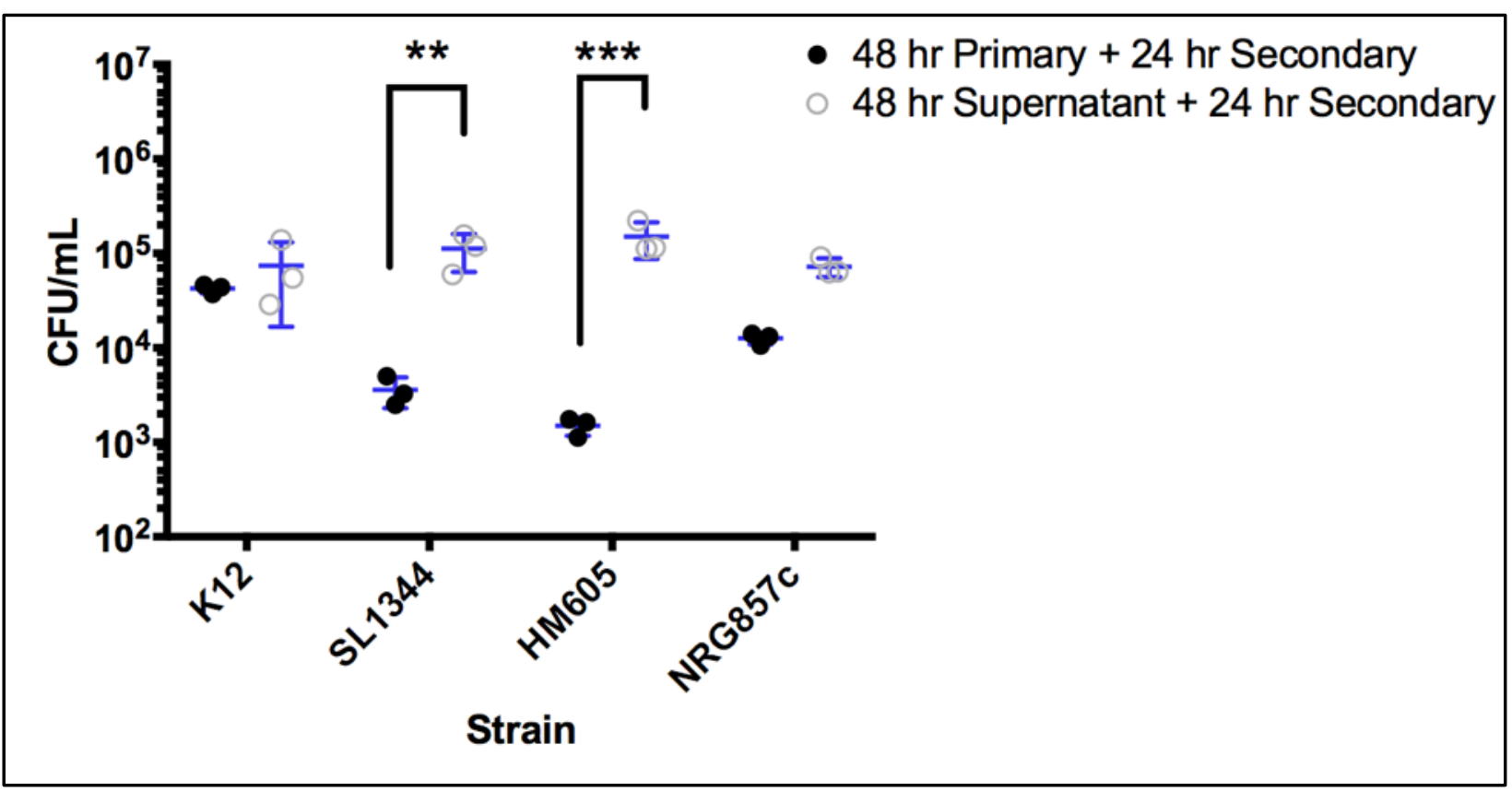

Figure 13: Internalization of intracellular Kan-resistant K12 E. coli in RAW264.7 macrophages pre-treated for 48 hours with either primary bacteria or conditioned supernatant from a 48-hour primary infection. Experiments were performed in biological triplicate. Statistical significance was determined using a non-parametric two-way ANOVA. ${ }^{* *}=p<0.01,{ }^{* *}=p<0.001$. Bars of central tendency represent averages, error bars represent standard deviation.

It is clear from Figure 13 that conditioned supernatant from primary macrophage infections does not cause the same change to secondary bacterial processing as the bacteria themselves. Killing phenotypes are lost in both HM605 and SL1344 groups when conditioned supernatant is used, as secondary bacterial levels rise in a statistically significant fashion. We 
therefore conclude that inflammatory cytokines are not sufficient to pre-condition macrophages to better process a secondary bacterial challenge.

This series of experiments provides several lines of evidence to suggest that alterations in macrophage processing of the secondary bacterial strain are directly mediated by contact between the primary strain and the macrophage. The requirement for direct contact with a live strain of bacteria suggests that HM605 possesses one or more effectors that are able to alter host-cell function.

\subsection{MACROPHAGES CONTAINING HM605 EXPRESS LOWER LEVELS OF LAMP1}

Bacterial strains were transformed with a GFP expression vector and infections of macrophages were performed in a similar fashion to primary infection experiments described previously. Cell cultures were fixed and stained in order to visualize both the bacteria (intracellular with GFP, extracellular with GFP and anti-E.coli) and the lysosomal marker LAMP1. We hypothesized that changes that were observed in previous experiments in macrophage function may be quantified by observing changes either in LAMP1 intensity or distribution. Such an observation would represent direct evidence of a change in macrophage function mediated by a bacterial strain.

Prior to assessing LAMP1 expression in infected macrophages, a control experiment was performed to demonstrate that the addition of the plasmid-encoded GFP did not affect the previously-observed phenotypes with respect to intracellular bacterial survival. Figure 14 below shows this comparison between wildtype and GFP-expressing strains after 24 hours of infection. 


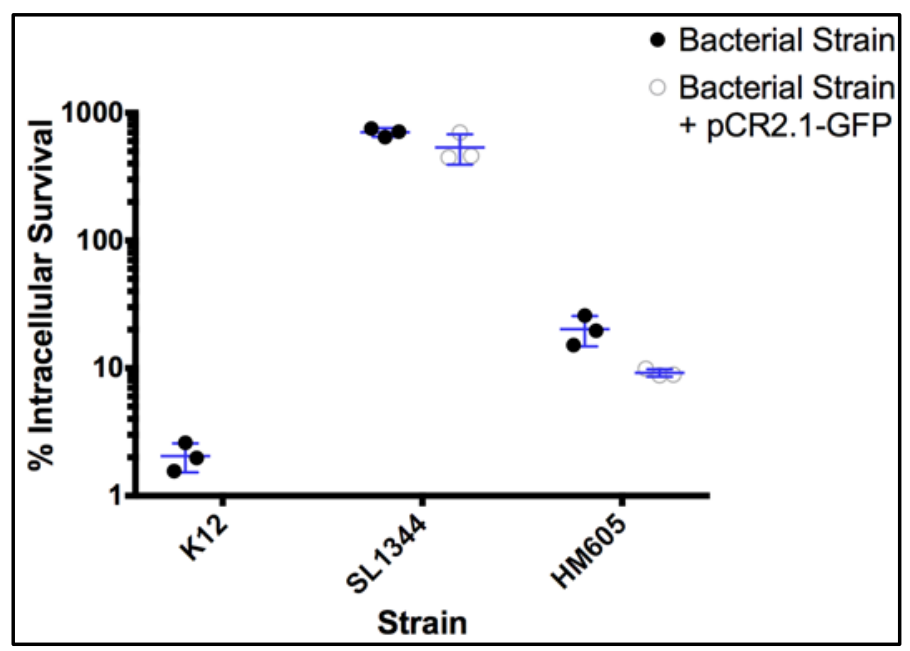

Figure 14: Percent intracellular survival of bacteria after 24 hours in RAW264.7 macrophages. Statistical significance was determined using a two-way ANOVA. Bars of central tendency represent averages, error bars represent standard deviation.

Figure 14 shows that the addition of the GFP vector did not change the intracellular survival phenotypes of any of the test strains in a statistically significant manner. This provided confidence that any effect seen in visualizations using GFP-tagged bacteria would also be applicable to the corresponding wildtype strain.

Total cell LAMP1 intensity was quantified and comparisons were made by normalizing CTFC of cells containing bacteria to the CTFC of cells with no bacteria within the same field of view. This provided internal controls for each field of view and allowed for normalization between cultures stained on different days. Figure 15 below shows the normalized LAMP1 CFTC after A) 1 hour and B) 6 hours, while Figure 16 shows representative images of 1-hour infections. 

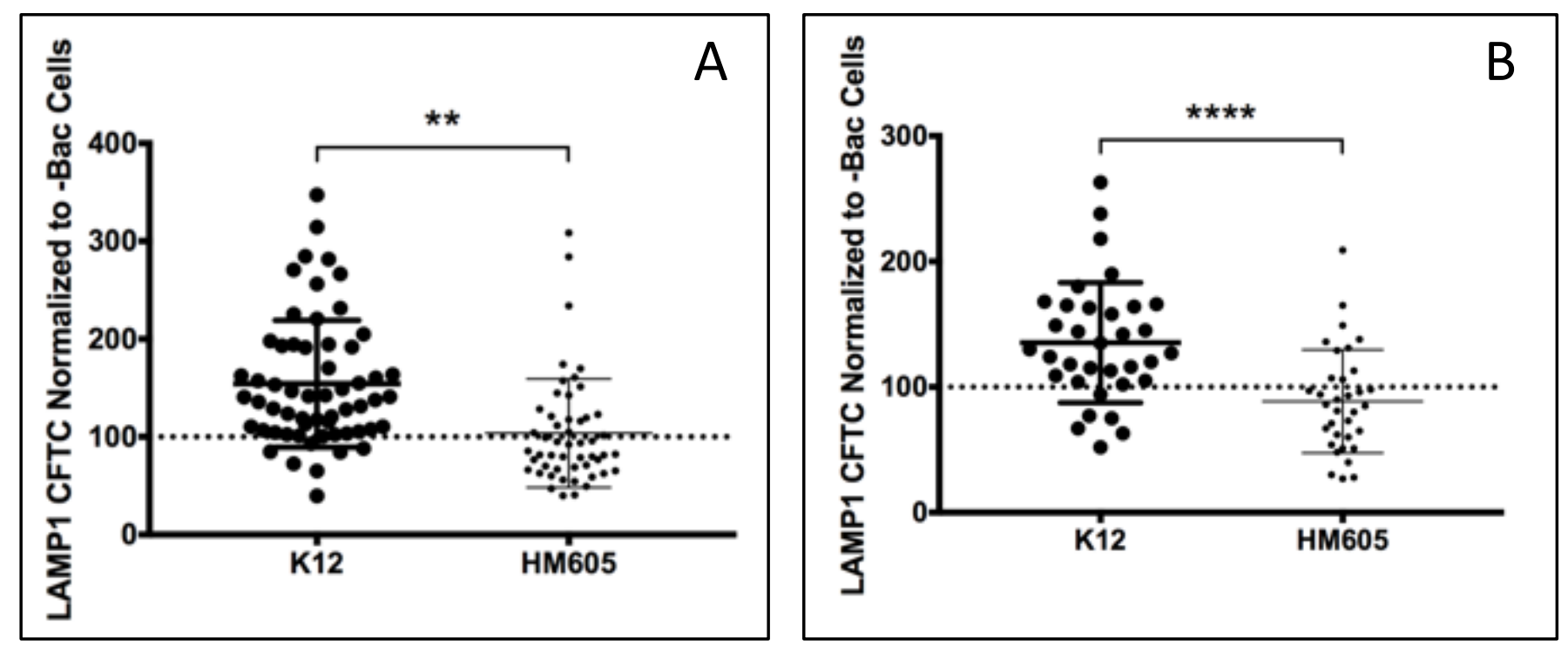

Figure 15: Corrected total cell fluorescence of the lysosomal marker LAMP1 in HM605 or K12-infected RAW264.7 macrophages after normalizing to cells containing no bacteria after A) 1 hour and B) 6 hours. At least three biological replicates are represented for each strain from slides stained on different days. Statistical significance was assessed using an unpaired two-tailed t-test, $* *=p<0.01, * * * *=p<0.001$. ROUT outlier analysis was performed prior to statistical analysis. Bars of central tendency represent averages, error bars represent standard deviation.

From Figure 15 I draw two conclusions. The first is that within a population of macrophages exposed to K12 bacteria, those that had internalized bacteria had increased LAMP1 expression when compared to those that had no internalized bacteria. Conversely, in the HM605-infected population, there was no difference in LAMP-1 expression between cells that had internalized bacteria and those that did not. These are clear differences in the patterns of LAMP1 expression between the test and control groups and allows for further inference about the nature of the HM605 infection. 

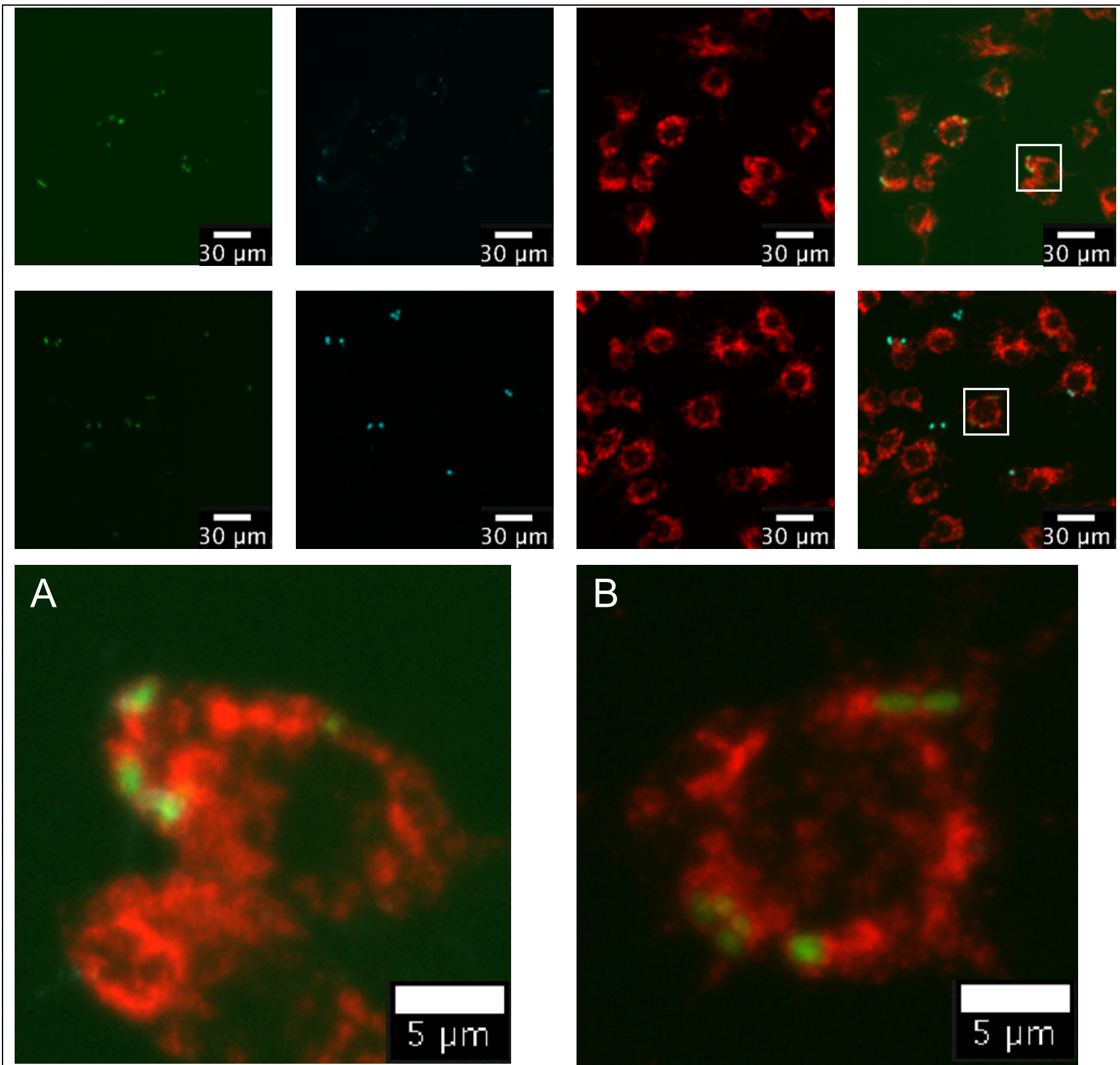

Figure 16: Representative images of 1-hour GFP-K12 and GFP-HM605-infected RAW264.7 macrophages. Bacteria are represented in green, extracellular bacteria are stained with anti-E.coli in blue and LAMP1 is represented in green. Closeups are channel-merged images from A) K12 infection and B) HM605 infection. All images were subjected to artificial contrast enhancement to $0.3 \%$ pixel saturation for clarity. 
In addition to quantifying total cell fluorescence of LAMP1, individual endosomes containing either HM605 or K12 from 1 and 6-hour infections were measured. Figure 18 shows that between 1 and 6 hours of infection, HM605-containing endosomes have significantly decreased LAMP1 fluorescence.

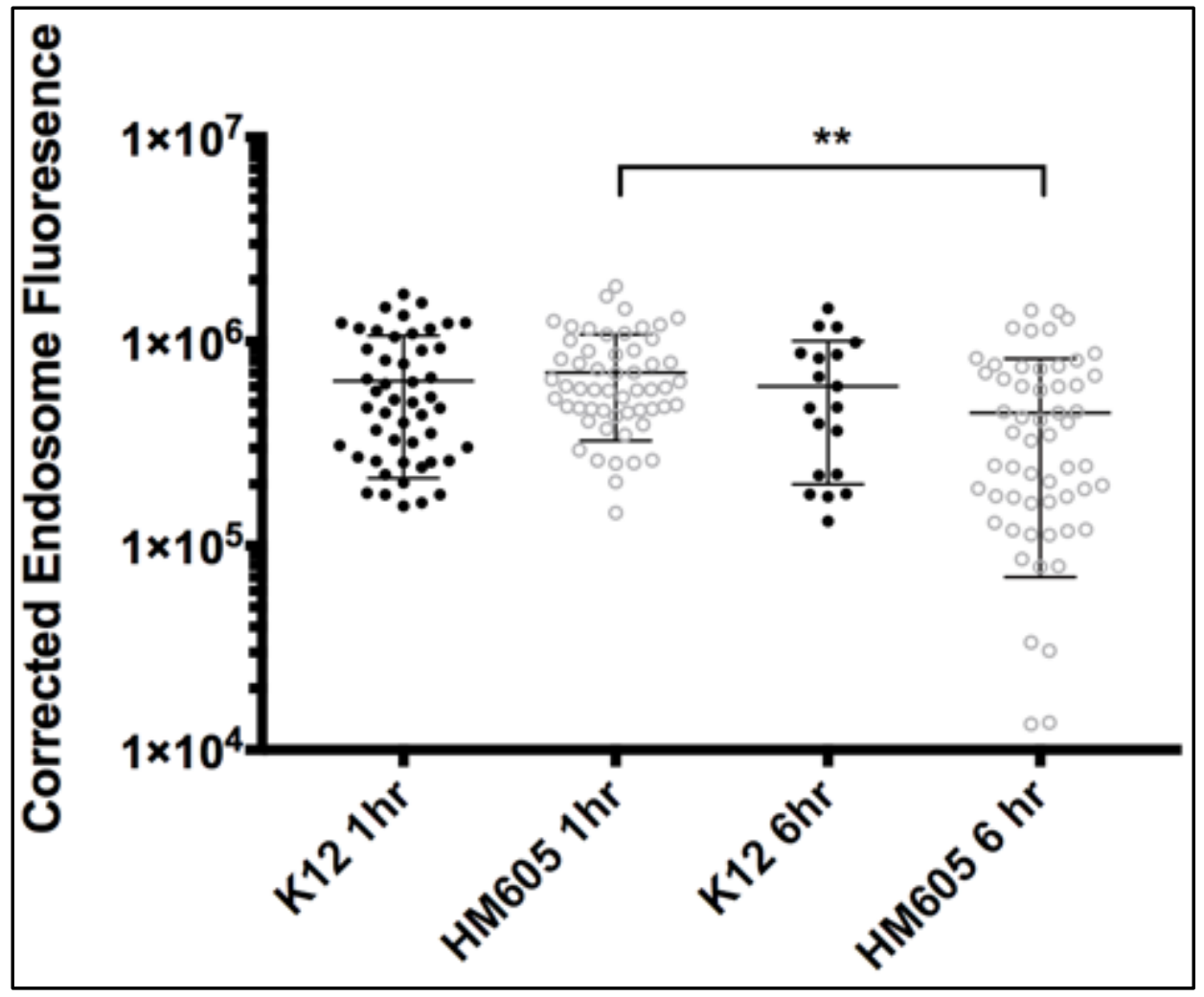

Figure 17: Corrected fluorescence of the lysosomal marker LAMP1 on endosomes of HM605 or K12-infected RAW264.7 macrophages after 1 hour and 6 hours. At least three biological replicates are represented for each strain from slides stained on different days. Statistical significance was assessed using an one-way ANOVA, ** = $p<0.01$. ROUT outlier analysis was performed prior to statistical analysis. Bars of central tendency represent averages, error bars represent standard deviation.

Taken together with previous experiments, this data suggests that HM605 is an active participant in the disruption of macrophage function. The decreased total cell expression of LAMP1 suggests that HM605 has the ability to mask or protect itself from the host macrophage by altering the way that the macrophage processes bacteria and this mechanism requires internalized bacteria. A significant decrease in LAMP1 on HM605-containing endosomes from 1 hour to 6 hours suggests that, while there is a macrophage response to the bacteria, this 
response is abrogated in comparison to K12-infected macrophages. The correlation between decreased LAMP1 expression and increased bacterial survival seen in HM605 suggests that this is a phenotype that is meaningful in the context of an opportunistic intracellular pathogen.

\section{DISCUSSION}

\subsection{OVERVIEW}

Perturbation to the host microbiome can lead to an increased risk for development of IBD. Several phenotypes have been identified in AIEC in particular, that could mechanistically contribute to this increased risk. The body of work presented here suggests that intracellular survival within macrophages is one of these phenotypes, but that our understanding of how individual strains might accomplish this remains limited.

Fundamentally, there are two ways that a bacterium can influence its ability to survive within a host cell. The first is by altering itself to become more resistant to the environment that is created within the host cell. In the case of an endolysosomal compartment, this would involve resistance to proteolysis and low $\mathrm{pH}$. The second path that a bacterium could use is actively interacting with the host cell in order to create a more favorable environment for itself. It is likely that different intracellular pathogens (as well as different strains within a single species) might use a combination of these two strategies. As discussed in detail below, our body of work suggests that, while variation exists in the ability of AIEC strains to survive intracellularly within macrophages, disease associated strains appear to be more successful.

It is our belief that each individual host represents a different set of selection pressures to a given bacterial strain. As such, different AIEC strains from different hosts might achieve survival using different mechanisms. The Crohn's-associated strain HM605 appears to demonstrate substantially different behaviour from the other strains tested, even though - as seen in Figures 3 and 4 -it does not behave differently from other disease-associated strains with respect to uptake and survival. The changes in expression of the lysosomal marker LAMP1 that appear to be induced by HM605, as well as the conditioning of a larger macrophage population to become more lethal towards a secondary bacterium, are two phenotypes that set this strain apart from the others tested. 


\subsection{AND 24-HOUR PRIMARY INFECTION PHENOTYPES OF AIEC}

Prior to initiating an investigation into AIEC uptake and survival phenotypes, a standardized, repeatable assay had to be developed. Based on the work performed by Sepehri and colleagues $^{18}$, we performed classical gentamicin protection assays in RAW264.7 macrophages at several timepoints up to 24 hours in order to assess bacterial uptake and survival. Figure 2 demonstrates that after 1 hour of bacterial exposure, statistically significant differences can be observed between SL1344 and E. coli BW25113 at MOIs of 100:1. This data supported performing further experiments using this 1-hour timepoint as a baseline for bacterial uptake by macrophages.

The 24-hour timepoint was chosen to compare to survival phenotypes that have been previously reported by other groups. In our hands, we observed near-complete elimination of $E$. coli K12 after 24 hours while also observing many-fold replication of SL1344 (Figure 4). These two strains were used throughout the course of experimentation as negative and positive controls for intracellular survival respectively.

Uptake of primary strains of bacteria is shown in Figure 3, with disease-associated clinical isolates demonstrating significantly higher uptake by macrophages than the K12 control strain or clinical strains isolated from non-IBD patients. This result is consistent with what is known about IBD-associated E. coli. As shown in section 1.4, at least one other phenotype - hostdefense peptide resistance - is also conserved in a disease-specific manner (Cho, 2017 unpublished). Although intramacrophage survival was tested in only a small number of strains, it appears that disease-specific selection is found with respect to phagocytosis. What is less clear from this finding is whether differential levels of bacterial uptake are a consequence of differences in macrophage response, or alternatively, differences in the ability of strains to actively mediate cellular invasion. AIEC do not have the well-defined virulence factors that other intracellular pathogens possess that might allow them to resist phagosomal killing, so it is not clear whether they are able to perform this function. It is possible that AIEC may express surface proteins that promote macrophage uptake. Previous reports have identified a protein, IbeA, with invasin activity in AIEC isolate NRG857c that also contributes to intramacrophage survival ${ }^{107}$, but it is unclear whether this function is conserved in other AIEC strains or whether 
other proteins may possess invasin activity. Nonetheless, further investigation is required in order to identify which of these two mechanisms (or a combination) is at play.

Figure 4 shows the levels of intracellular survival at 24 hours post-infection of each strain normalized to cellular uptake after 1 hour. Similar to the 1-hour uptake, these phenotypes appear to occur in a disease-specific manner with higher intracellular survival in diseaseassociated strains. Figure 10 shows that the level of intracellular bacteria does not change significantly between 24 and 48 hours for two strains of interest, HM605 and SL1344. Comparing these results to survival values found in previous investigations, Bringer and colleagues found that LF82 reached up to $400 \%$ at 24 hours of the intracellular levels found at 1 hour, though their infections were performed in $\mathrm{J774}$ macrophages and used and $\mathrm{MOI}$ of $100: 1^{48}$. This is quite different from our finding which showed that LF82 only persisted at levels between 5 and $50 \%$ out to 24 hours. The work by Sepehri and colleagues showed intracellular survival after 20 hours in RAW264.7 cells ranged between 17 and $172 \%$ depending on the strain. Similar to our experiments, an MOI of 10:1 was used, but they infected with stationaryphase bacteria ${ }^{18}$. Although there are some similarities between all three groups of experiments, the small differences make it difficult to compare outcomes. What is clear is that there is wide strain-to-strain variation in the level of intracellular survival, meaning that this is not a ubiquitous phenotype among AIEC.

At a higher-level view, since it is clear that at least some AIEC strains can survive intracellularly for 24 and up to 48 hours, the question arises as to whether this is sufficient to cause or contribute to disease. Under a multi-hit model of disease where many contributing factors converge to tip the balance of homeostasis within a patient, it seems reasonable that intra-macrophagic survival would be a key contributor to IBD. Macrophages would be present at a site of infection and an inability to effectively clear an intracellular pathogen could lead to abnormal intracellular signaling as well as altered levels of expression of pro-inflammatory cytokines that could initiate or contribute to persistent inflammation. Elliot and colleagues have found that macrophages isolated from CD patients are deficient in handling of both adherentinvasive as well as commensal E. coli ${ }^{108}$. Subsequently, the same group showed using microdissection that LP macrophages isolated from CD patients commonly contained an 
intracellular E. coli burden ${ }^{109}$. These findings support the idea that both the host and bacterial phenotypes can contribute to the onset and/or maintenance of disease. This is further supported by the fact that several host-genetic risk factors for IBD are related to both bacterial sensing ${ }^{29}$ and clearance ${ }^{110}$. Our work clearly shows that even healthy, non-conditioned macrophages can be susceptible to perturbation by AIEC strains that were isolated from a diseased condition. Coupled with other physical or chemical insults, the inflammation caused by the persistence of intracellular bacteria could lead to tissue damage and ultimately symptoms of IBD. It is likely, therefore, that while a combination of host and bacterial factors play a role in the development of disease, intracellular survival may be especially important.

\subsection{4-HOUR EXTRACELLULAR CYTOKINE EXPRESSION}

Looking at a panel of secreted inflammatory cytokines after 24 hours of infection, there are a number of interesting observations that are found. Figure 5 shows a cluster analysis of all 31 analytes, while Figure 6 highlights three individual analytes (IL-6, GM-CSF and LIF) and represents statistical significance compared to the expression levels found in K12-infected cultures. It is clear that SL1344 causes the most dramatic shift in cytokine expression by macrophages and from Figure 6 we can see that this is in fact due to a decrease in the levels of several analytes compared to K12. This aligns with what is known about the ability of Salmonella to modify extracellular signaling of macrophages while in the SCV. Salmonella are able to suppress IFN- $\beta$ expression by the host cell ${ }^{96}$ and this may explain the decrease seen in several other inflammatory cytokines. Some Salmonella serovars have evolved the ability to induce IL-10 expression by macrophages via activation of STAT3, which in turn has been shown to decrease pro-inflammatory cytokine production ${ }^{111}$. We did not see this increase in IL-10 levels with our strain SL1344, however decreases in other cytokines may be indicative of an anti-inflammatory phenotype.

IL-6 can act as either a pro- or anti-inflammatory signal in a context-dependent manner. A detailed review by Hunter and Jones discusses IL- 6 in the context of disease ${ }^{112}$. In the context of innate immunity, IL-6 induces monocyte differentiation away from the dendritic lineage towards macrophages ${ }^{113}$. It has also been reported that in Mycobacterium tuberculosis 
infections, an induction of IL- 6 inhibits the IFN- $\gamma$ response of uninfected macrophages, blocking an inflammatory response. Conversely, IL-6R knockout mice or anti-IL6 treatment in conventional animals leads to an attenuated phenotype in a model of colitis ${ }^{114}$, suggesting that IL-6 is at least involved in the inflammation characteristic of colitis. In relation to our cytokine data, a decrease in the overall pool of secreted IL- 6 by Salmonella-infected macrophages may indicate that there is inhibition or disruption of some factor upstream of IL-6 signaling. This has not, to our knowledge, been previously reported in Salmonella literature, but would seem to agree with the known role of IL- 6 in the context of macrophage differentiation.

GM-CSF is a cytokine that triggers the recruitment of neutrophils, monocytes and leukocytes to infected tissue and is a robust inflammatory signal ${ }^{115}$. Additionally, defective expression of the GM-CSF receptor, CD116, has been correlated with IBD in human patients ${ }^{116}$. This may seem counter-intuitive, since a defect in innate immunity should lead to a subdued inflammatory response, although others have suggested that defects in the innate response are compensated by a highly inflammatory adaptive immune response in IBD ${ }^{117}$. Our data show that in Salmonella infections, there is a marked decrease in GM-CSF secretion by macrophages, a finding that suggests a suppression of the normal acute inflammatory immune response. LIF is a far less well studied cytokine but is classified as an IL-6-like protein. LIF is secreted by injured nerve cells as a chemoattractant to macrophages ${ }^{118}$. Macrophage-derived LIF has also been identified as a regulator of fut 2 expression in a murine model ${ }^{119}$. Mutations that cause defects in FUT2 secretion have been identified as a risk factor for IBD ${ }^{120}$, so it is possible that there is a link between LIF and IBD. It is possible that LIF is functioning in our infection assays as an autocrine signal, and that a decrease in the amount of secreted protein is once again a manipulation of the inflammatory response caused by Salmonella.

Elliot et al. assessed the expression of several inflammatory cytokines from LP macrophages isolated from CD patients and found that those cells that had a pre-existing intracellular bacterial burden generated expressed higher IL-10 and lower IL-6, TNF- $\alpha$ and iNOS regardless of macroscopic assessment of inflammation ${ }^{109}$. We did not see the similar associated decreases in our in vitro assessment of AIEC infection. It is clear that the overall disease state is far more complex than what is represented by reducing infections to a single bacterial species 
interacting with one cell type. Considering that the inflammation that is characteristic of IBDs is complex in etiology, we can be assured that multiple host cell types are playing a role in the response to any bacterial insult. It is also possible that the changes in cytokine secretion cannot be captured by looking at a single timepoint (in our case 24 hours post-infection). IBD is a chronic condition that expresses in bouts of active inflammation interspersed by clearance. It is possible that longer-term infection experiments looking at multiple cell types could yield more useful information about the inflammasome associated with AIEC infection.

\subsection{SECONDARY BACTERIAL INFECTION PHENOTYPES}

When macrophages undergo phagocytosis, they increase in their ability to successfully phagocytose subsequent bacteria/viruses ${ }^{121}$. This suggests that during inflammation, when there is a decrease in the mucosal barrier and elevated recruitment of neutrophils and macrophages to the site of infection, the interaction between AIEC and host-macrophages may alter the interactions between those macrophages and other components of the microbiota. Thus, the objective of infecting with a secondary non-pathogenic bacterial strain was to use it as a tool to probe macrophage function. Prior to initiating this line of investigation, we expected that infections with disease-associated strains of AIEC would cause defects in either uptake or processing that would be seen as either decreases in secondary bacterial uptake or increases in survival. What we found contradicted this hypothesis.

No differences were found in secondary uptake after 1 hour of exposure between any primary bacterial pre-treatments. Figure 7 shows very clearly that there are no significant differences between pre-treatment groups indicating that any effects observed downstream of infection are not due to altered uptake. In order to ensure that this result was not due to an insufficient $\mathrm{MOI}$, another experiment was performed at 10 -fold higher MOls to see if increased loads of secondary bacteria would make obvious any defects in macrophage uptake. Figure 8 shows the result from this experiment, where no significant differences were found between pre-treatment groups at any MOI up to 100,000:1. This second experiment gave us confidence to conclude that primary infection with a virulent or disease-associated strain does not cause 
defects in macrophage uptake. We then went on to interrogate secondary bacterial survival at 24 hours.

Secondary bacteria at 24-hours post-infection are no different from either the no-primary control or K12 pre-treatment control with the exception of two pre-treatment groups. These are pre-treatment with HM605 and SL1344 for 24 hours, where the level of secondary bacteria decreased significantly, which can be seen in Figure 9. This was unexpected since we anticipated that defects in intracellular processing would manifest as increases in secondary bacterial survival. Since this result did not agree with what was expected, LDH assays were performed on the cell culture media of these infections to look for increases in cell death. LDH has been used previously to assess cell culture health and viability so this seemed to be a valid approach $^{122}$. Our results in Appendix 3 show that no differences were found in the LDH levels of any groups. This implies that the decreases in secondary bacteria seen in the HM605 and SL1344 pre-treatment groups are a result of effects on cellular behaviour due to the primary infection and not from increased/altered macrophage cell death.

Next, we wished to characterize the nature of the priming effect of HM605 and SL1344 on secondary bacterial processing by macrophages. Figure 10 shows that a decrease in secondary bacteria requires the primary bacteria to be internalized for at least 18 hours, and that this effect is time-dependent. Figure 11 shows that a pre-treatment with either heat-killed HM605 or SL1344 causes a loss of the secondary decrease phenotype, as does pre-treatment with supernatant of cell cultures infected with either of these strains for up to 48 hours (Figure 12). These results indicate that direct contact with living HM605 or SL1344 is necessary to elicit this phenotype. This implies that this is an effect of active primary infection and not some nonspecific side-effect.

Our interpretation of this group of results is that there are likely two different effects that are at play on the pool of infected macrophages. It is clear from the 24-hour cytokine data that all macrophages populations show LPS-activation in response to bacterial exposure. Only a small subset of these macrophages have internalized primary bacteria once they are exposed to the secondary strain. As such, there is a large pool of macrophages in each infection with no internalized bacteria, but in the case of HM605 and SL1344 infections, these uninfected cells 
presumably clear secondary bacteria more efficiently. This is similar to the effect observed by Elliott and colleagues whereby infection of a subset of macrophages was sufficient to lead to decreased expression of inflammatory cytokines, but there was still a drive of uninfected cells towards a pro-inflammatory phenotype ${ }^{109}$. There are likely direct effects of the individual AIEC strains on the cells that they have internalized, but due to the relatively small population of macrophages that this represents, there must be a secondary effect.

We believe that there must be a paracrine effect from those cells that have internalized primary bacteria, since the number of cells that are co-infected with both primary and secondary strains would be very small relative to the total population of macrophages. Paradoxically the results of priming macrophages with the supernatant of primary infections shows that this cannot be recapitulated by exposure to 24 hour cultures of primary infected cells (Figure 12). This suggests either that a putative paracrine effector(s) must require constant stimulation from a primary bacterial source in order to maintain the level required in order to prime cells for increased killing, or that more than 24 hours of primary infection is required to observe the effect. In order to test this, experiments could be performed using selectively permeable membranes in order to isolate an infected macrophage population from one that is sterile. Figure 18 below shows a model of this hypothesis. Splitting a culture with such a membrane could allow for an effector molecule to continually interact with the unprimed cell population as it is infected with secondary bacteria. If a paracrine effector is responsible for this phenotype, we would expect to see a decrease in secondary bacterial survival in this type of treatment even without direct interaction with the primary HM605 strain. Nonetheless, it would still be unclear from these experiments what this effector might be and further chemical analysis would be required for identification. 


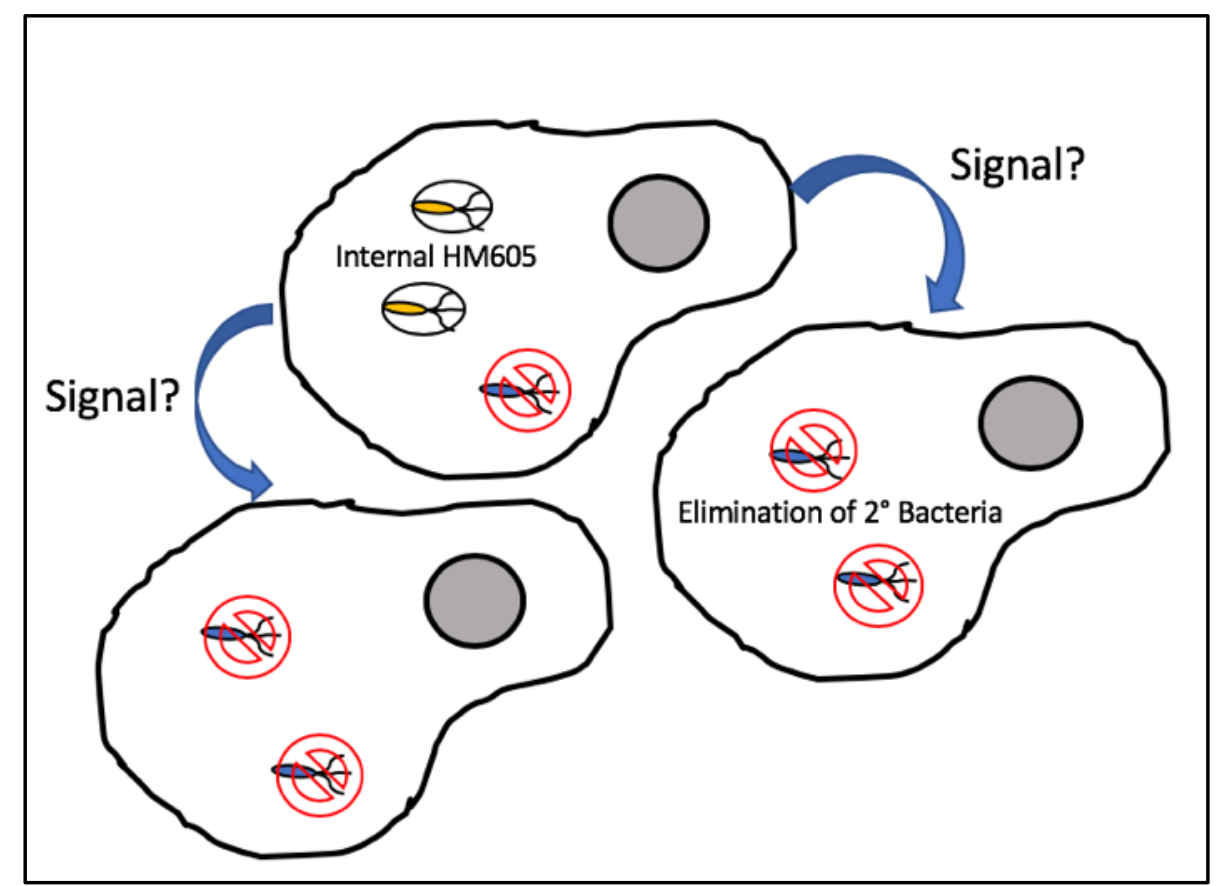

Figure 18: A model of how internally persistent HM605 might influence macrophage activity towards an infection with a secondary bacterial strain. Constant stimulation of a putative paracrine signal might be required in order to condition non-HM605-infected cells for increased activity towards secondary bacteria.

\subsection{LAMP1 EXPRESSION AS A PROXY FOR LYSOSOMAL ACTIVITY}

In order to further investigate the potential effects that primary infections with AIEC are having on macrophage cultures, co-localization fluorescence microscopy was performed using GFP-expressing bacteria. LAMP1 was used as a marker for phagolysosomal fusion, with the hypothesis that increased levels of LAMP1 would indicate more lysosomal fusion. Other groups have used LAMP1 as a proxy for lysosomal fusion with good success ${ }^{123,124}$ and based on our uptake and survival data, we expected that an infection with an AIEC strain would lead to reduced LAMP1 expression within the macrophage population.

Figures 14 shows that infections with GFP-expressing bacteria generates similar phenotypes to the wild-type strains used in previous experiments. The intracellular survival phenotypes as measured by both gentamicin protection assays are not significantly different. This gives us confidence that other data generated using these reflect that of wild-type infections and that addition of the GFP vector has not significantly altered their intracellular survival phenotypes. 
Figure 15 shows the total cell LAMP1 fluorescence of cells containing intracellular bacteria normalized to cells that did not have internalized bacteria, over A) 1 hour and B) 6 hours of infection. Based on this data, LAMP1 appears to have increased in cells containing internalized K12 but those that contain internalized HM605 show no increase. When looking at phagosomespecific fluorescence of LAMP1, Figure 17 shows that there is an overall decrease in the level of LAMP1 in HM605-containing phagosomes between 1 and 6 hours. In comparison K12-infected cells show no difference between 1 and 6 hours. A decrease in LAMP1 over time with concurrent bacterial survival suggests that HM605-containing phagosomes are either not fusing with lysosomes, or they are doing so at a decreased rate in comparison to K12-containing phagosomes. This is direct evidence that HM605 modulates macrophage function in a way that could benefit intracellular survival. Figure 19 below shows a summary of these findings.

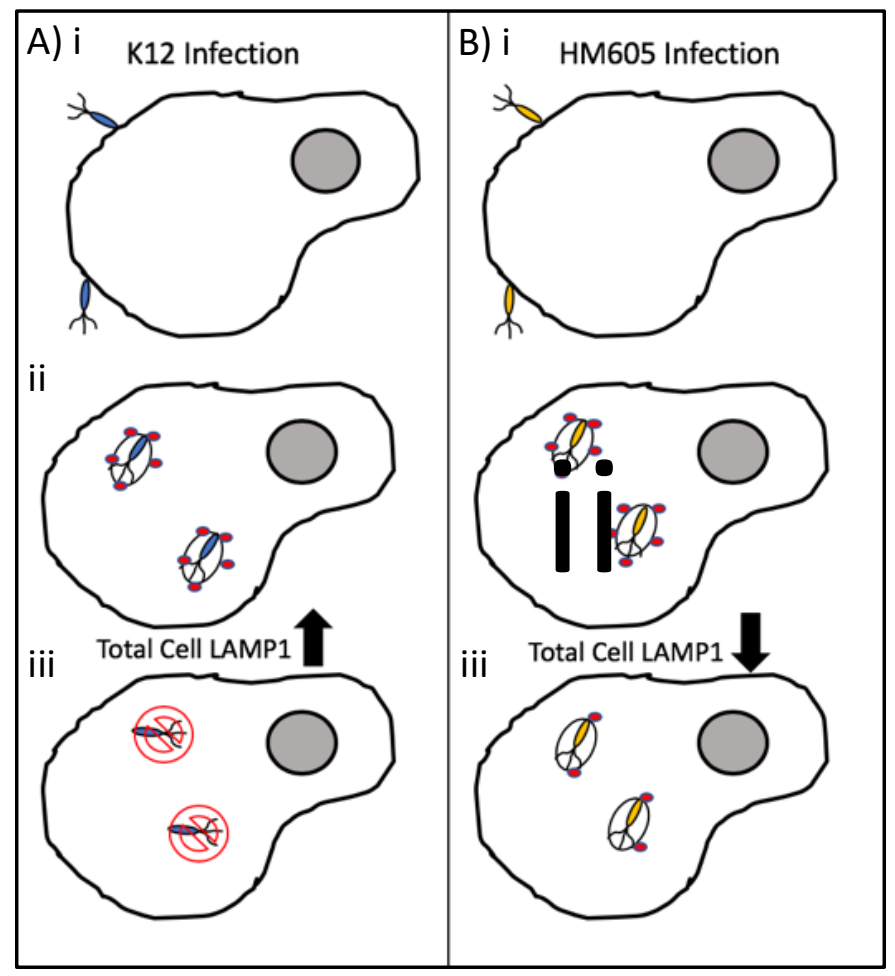

Figure 19: A summary of LAMP1 expression and intracellular bacterial survival of A) K12 E. coli or B) HM605 AIEC. Panel i) shows the initial interaction between the bacteria and the host cell. Panel ii) represents internalized bacteria with phagosome-associated LAMP1 expression that is similar, regardless of bacterial strain. In K12-infected cells there is a significant increase in total-cell expression of LAMP1 as seen in panel iii), followed by elimination of the bacteria. In HM605 infection, there is a suppression of total-cell LAMP1, as well as decreased levels of phagosome-associated LAMP1, correlating with increased intracellular survival.

These findings combine to generate a picture of a more favorable intracellular environment for HM605. Bringer and colleagues used the AIEC strain LF82 to infect J774 macrophages and 
demonstrated that, in their hands, bacterial-containing phagosomes underwent complete maturation, acquiring both LAMP1 and LAMP $2^{48}$. Our work shows that after initial acquisition of LAMP1, HM605-containing phagosomes appear to lose a significant amount, suggesting a different mechanism leading to intracellular survival. While these two outcomes seem contradictory, we know that AIEC are both genetically and phenotypically diverse and therefore it would not be unexpected that different strains that survive intracellularly accomplish this feat in different ways. Bringer and colleagues also used the $\mathrm{pH}$-sensitive dye LysoTracker to assess the acidity of the LF82-containing phagosolysosome. They concluded that LF82 survives in an acidified compartment, although their assessment is qualitative and they do not present control infections using non-virulent bacteria ${ }^{48}$. Future experiments using this infection model with $\mathrm{HM} 605$ will include the use of $\mathrm{pH}$-sensitive dyes to assess this aspect of phagolysosomal functionality.

Putting this into context of IBD and intestinal inflammation, we have clear evidence that disease-associated AIEC strains have an increased ability to survive within macrophages. Our work with HM605 shows that this strain has the ability to alter macrophages function in a way that allows for increased bacterial persistence and that this is a divergent phenotype from LF82 which has been reported to replicate within fully-mature phagolysosomes ${ }^{48}$ This latter statement is somewhat controversial as other groups have anecdotally been unable to replicate this result. Ultimately, this is an example once again of the variety of evolutionary paths that different AIEC strains have charted that have led to virulence potential.

\subsection{SIGNIFICANCE AND FUTURE WORK}

Investigating interactions between AIEC and macrophages is an important part of understanding the pathogenesis of IBD. While other groups have focused on the simple fact that AIEC can survive and/or replicate intracellularly, very little is known about the mechanisms by which AIEC persist within macrophages nor what the consequences of this intracellular survival are. Many pathogenic bacteria have evolved mechanisms to survive inside macrophages as these cells are a critical node in the primary innate immune response. Since several genetic risk factors for IBD, such as $A T G 16 L 1^{110}$ and IRGM ${ }^{8}$, affect macrophage function, 
it is reasonable to suggest that a bacterium that is able to take advantage of such deficiencies may significantly contribute to disease.

Several new questions have come about from this work. It is unclear why HM605-infected macrophages would have lower expression of LAMP1 but more efficiently eliminate a secondary bacterial infection. It is possible that, within a population of macrophages, those that contain a persistent HM605 population have a protective environment, while other cells in the population have been conditioned to clear secondary bacteria more efficiently. This potential divergence is consistent with altered responses observed in Elliott et al, in which cytokine responses from macrophages containing E. coli vs. those that do not, have altered innate immune responses, such that the cells containing bacteria are in a more immunotolerant state than others adjacent to them ${ }^{109}$. In our hands though, only HM605 exhibited the enhanced killing effect, while most AIEC strains tested showed enhanced intracellular survival. It is clear from this work that HM605 can persist as a stable intracellular population for at least 48 hours. This suggests that while survival itself is strongly selected for, the specific mechanisms by which this occurs are not.

Another question that remains is what specific proteins are required in order for an AIEC strain like HM605 to persist intracellularly and/or disrupt immune cell function. It is possible that these two phenomena are linked and that a bacterium that does not have these proteins might be more easily processed by the macrophage after what amounts to priming by HM605. This model of AIEC infection would align with the idea that abnormal host-bacterial interaction is at least partially responsible for chronic intestinal inflammation.

Future work on this project will focus on functional characterization of the endosomes containing HM605 bacteria as well as identifying the specific HM605 protein (or proteins) responsible for modifying the endosomal compartment. Salmonella is able to stabilize its intracellular compartment and prevent endosome-lysosome fusion, preventing acidification of the environment. An investigation could be made into whether HM605 is also able to mediate a similar response. This would contribute to the understanding of how HM605 survives as an intracellular pathogen. There are several different aspects of phagosomal biology that could be interrogated in order to identify specific effects. Co-localization of phagosomes with lysosomes 
over a time course of HM605 infection could elucidate whether there is in fact an overall decrease in fusions between these intracellular compartments, thereby explaining the intracellular survival phenotype that we observe. Using several other characteristic compartmental markers such as Rab5, Rab7 and LAMP2 could allow for a more complete characterization of both the HM605-containing compartments as well as the lysosomes of the cells containing these bacteria. Finally, functional assessments of the phagosomal environments to which HM605 are exposed would help to identify mechanisms of bacterial survival. Intracellular probes that are $\mathrm{pH}$-sensitive or that are activated based on proteolytic activity have been used in previous studies in order to assess mechanisms of intracellular pathogen survival and the application of these probes here would be beneficial.

It should also be noted that there is a possibility that the priming effect of HM605 and the alterations in LAMP1 acquisition could be unrelated phenotypes. As such it would also be informative to investigate other disease-associated strains that demonstrate at least some level of intracellular survival using the same panel of intracellular markers to see if there are conserved or divergent patterns of disruption to phagosomal processing by macrophages.

Another aspect of investigation that would be valuable would be to look at interactions between HM605-containing phagosomes and the autophagy pathway. Bringer and colleagues assessed this aspect of AIEC survival by co-localizing bacteria with the autophagy marker LC3. In their case there was no evidence that the AIEC strain LF82 was interacting with this pathway ${ }^{48}$, however, the authors could not rule out a transient interaction with LC3 that, to our knowledge, has never been followed up experimentally. More recently it was shown mechanistically that LF82 modifies microRNA levels in epithelial cells to impair autophagic response ${ }^{125}$. We also know that ATG16L1, an important autophagy protein, is a strong risk allele for CD and others have shown that intracellular pathogens such as Salmonella and Shigella disrupt autophagy by interrupting signaling through ATG16L177. For our part, we don't believe that any one specific cause and effect mechanism is at play with respect to AIEC mediating host-cell autophagy in all IBD contexts. Rather, different strains have likely evolved a variety of solutions to this problem, and that the host associated risk factors vary from patient group to patient group. As we have evidence that HM605 already appears to act in a different manner 
than LF82, additional experimentation to interrogate any interactions with the autophagy pathway would be informative.

A final avenue of investigation will focus on identifying and knocking out proteins in HM605 that may have the potential to cause changes in host cell behaviour, in order to assess whether or not they contribute to the distinctive phenotype that is observed characteristic of this strain. HM605 has a complete genome sequence ${ }^{126}$ and there is no evidence of a T3SS. There are some elements of a type six secretion system (T6SS), a nanomachine that is able to interact with both eukaryotic and prokaryotic cells in a contact-dependent manner. A detailed review by Alcoforado Diniz and colleagues outlines that diverse groups of both Gram positive and negative species possess this machinery and also the effectors that it secretes ${ }^{127}$. At least one known T6SS effector, haemolysin co-regulated protein (Hcp), has been shown to interact with macrophages in vitro and lead to increased uptake of Aeromonas hydrophila ${ }^{128}$. Hcp has been found in a T6SS-postive E. coli strain K1 RS218 and was shown to mediate pathogenesis of meningitis ${ }^{129}$. This makes a reasonable justification to interrogate a putative T6SS in HM605 using knockout studies of T6SS genes to look for attenuated uptake and/or survival phenotypes. HM605 also possesses several proteins that have significant sequence similarity to known autotransporters. Autotransporters are a class of protein that contain a signal sequence, passenger domain and translocator domain, many of which have been implicated in host cell toxicity $^{130}$. The Tat and Sec translocation systems have both been implicated in the transport of these proteins, but they do not require a dedicated effector secretion system such as the $\mathrm{T}_{3 S S^{131}}$. HM605 has a homologue for $\operatorname{tam} B$, a protein required for stabilization of the translocation and assembly module ${ }^{132}$, a protein complex involved in the secretion of some virulence factors. Homologues for $y f L^{133}$, vacuolating autotransporters ${ }^{130}$, as well as several other putative but poorly annotated autotransporters can be found in the HM605 genome. If a protein or group of proteins can be identified using knockout studies, that causes either increased intracellular survival and/or abnormal bacterial processing by macrophages, these could be screened for in other clinical AIEC isolates.

Ultimately, we believe that, in addition to host genetic and environmental factors, bacterial contributions to the IBD state are likely to be different on a patient to patient basis. The diverse 
mechanisms that IBD-associated strains have evolved serve as a means to a common goal of increased survival within a host. Identifying and characterizing these behaviours will allow for better understanding of the pathogenesis of the disease and potentially lead to better screening methods to assess individual patient risk. 


\section{Appendix 1 - Cytokines analyzed from 24-hour infections}

Table 4: List of full inflammatory cytokine names.

\begin{tabular}{|l|l|}
\hline G-CSF - Granulocyte-colony stimulating factor & IP-10 - IFNy-inducible protein 10 \\
\hline IFN-y - Interferon-gamma & KC - Keratinocyte chemoattractant \\
\hline IL-1a - Interleukin 1 alpha & LIF - Leukemia inhibitory factor \\
\hline IL-1B - Interleukin 1 beta & LIX - Lippolysaccharide-induced CXC chemokine \\
\hline IL-2 - Interleukin 2 & MCP-1 - Monocyte chemoattractant protein \\
\hline IL-3 - Interleukin 3 & M-CSF - Monocyte colony stimulating factor \\
\hline IL-4 - Interleukin 4 & MIG - Monokine induced by interferon gamma \\
\hline IL-5 - Interleukin 5 & MIP -1a - Macrophage inflammatory protein 1 alpha \\
\hline IL-7 - Interleukin 7 & MIP- 1B - Macrophage inflammatory protein 1 beta \\
\hline IL-9- Interleukin 9 & MIP-2 - Macrophage inflammatory protein 2 \\
\hline IL-10 - Interleukin 10 & $\begin{array}{l}\text { RANTES - Regulated on activation, normal T-cell } \\
\text { expressed and secreted }\end{array}$ \\
\hline IL-12(p70) - Interleukin 12 heterodimer & VEGF - Vascular endothelial growth factor \\
\hline IL-12(p40) - Interleukin 12 p40 subunit & TNFa - Tumor necrosis factor alpha \\
\hline IL-17 - Interleukin 17 & $\begin{array}{l}\text { GM-CSF - Granulocyte-monocyte colony stimulating } \\
\text { factor }\end{array}$ \\
\hline IL-15 - Interleukin 15 & IL-6 - Interleukin 6 \\
\hline
\end{tabular}

Table 5: Average 24-hour inflammatory cytokine values ( $\mathrm{pg} / \mathrm{mL}$ ) from RAW264.7 macrophages.

\begin{tabular}{|l|l|l|l|l|l|l|l|}
\hline \multicolumn{1}{|c|}{ Analyte } & Media & Primary & \multicolumn{1}{|c|}{ K12 } & \multicolumn{1}{c|}{ HM605 } & NRG857c & \multicolumn{1}{|c|}{ LF82 } & \multicolumn{1}{c|}{ SL1344 } \\
\hline Eotaxin & 0.560 & 1.103 & 2.288 & 2.803 & 2.433 & 2.665 & 2.253 \\
\hline G-CSF & 0.640 & 612.133 & 11247.133 & 11151.230 & 10319.038 & 10565.618 & 10619.450 \\
\hline GM-CSF & 1.550 & 2.320 & 23.663 & 15.445 & 17.040 & 60.248 & 6.648 \\
\hline IFN-y & 0.620 & 0.620 & 5.030 & 4.745 & 4.500 & 5.280 & 3.830 \\
\hline IL-1a & 0.710 & 11.070 & 64.913 & 65.263 & 61.940 & 75.715 & 47.380 \\
\hline IL-1B & 3.200 & 5.980 & 35.778 & 32.775 & 30.950 & 47.810 & 18.275 \\
\hline
\end{tabular}




\begin{tabular}{|c|c|c|c|c|c|c|c|}
\hline IL-2 & 0.125 & 1.330 & 5.783 & 7.015 & 5.900 & 6.930 & 4.293 \\
\hline IL-3 & 0.640 & 0.725 & 3.215 & 3.325 & 2.745 & 3.125 & 2.390 \\
\hline IL-4 & 0.075 & 0.205 & 0.510 & 0.558 & 0.513 & 0.575 & 0.448 \\
\hline IL-5 & 0.650 & 1.890 & 7.113 & 8.045 & 7.455 & 8.373 & 6.783 \\
\hline IL-6 & 0.640 & 0.738 & 2488.783 & 1625.175 & 2653.775 & 5014.948 & 225.823 \\
\hline IL-7 & 1.120 & 2.400 & 5.930 & 7.535 & 4.913 & 6.003 & 4.690 \\
\hline IL-9 & 0.990 & 3.903 & 40.478 & 43.908 & 37.068 & 54.065 & 19.728 \\
\hline IL-10 & 0.640 & 3.765 & 369.780 & 396.643 & 623.605 & 1078.075 & 110.720 \\
\hline IL-12(p70) & 0.640 & 0.600 & 1.215 & 2.065 & 0.928 & 1.468 & 0.558 \\
\hline IL-12(p40) & 0.330 & 4.625 & 28.505 & 28.510 & 23.785 & 29.740 & 16.518 \\
\hline IL-15 & 0.640 & 10.545 & 39.323 & 50.480 & 34.620 & 27.523 & 20.143 \\
\hline IL-17 & 0.660 & 1.285 & 3.678 & 3.995 & 4.045 & 4.293 & 3.425 \\
\hline IP-10 & 0.640 & 458.940 & 5575.913 & 4182.330 & 2912.650 & 3605.435 & 2671.595 \\
\hline $\mathrm{KC}$ & 0.640 & 5.590 & 29.130 & 25.270 & 25.368 & 32.078 & 17.940 \\
\hline LIF & 0.545 & 2.228 & 178.780 & 166.640 & 188.653 & 266.563 & 98.330 \\
\hline LIX & 17.300 & 29.260 & 334.503 & 325.403 & 313.523 & 430.150 & 173.068 \\
\hline MCP-1 & 6.070 & 742.858 & 13785.568 & 13360.785 & 12894.335 & 14595.920 & 7047.363 \\
\hline $\mathrm{M}-\mathrm{CSF}$ & 0.640 & 1.445 & 5.318 & 6.925 & 5.405 & 5.628 & 4.035 \\
\hline MIG & 0.390 & 0.563 & 2.588 & 3.855 & 2.685 & 2.945 & 1.793 \\
\hline MIP -1a & 8.990 & 6085.643 & 8736.415 & 9249.863 & 5762.885 & 6132.413 & 8100.398 \\
\hline MIP- 1B & 17.360 & 2403.643 & 24265.875 & 17859.748 & 15084.118 & 17189.490 & 18460.753 \\
\hline MIP-2 & 13.860 & 1128.558 & 16771.653 & 16332.423 & 20095.760 & 14006.428 & 16940.388 \\
\hline RANTES & 0.610 & 6.563 & 1093.463 & 892.243 & 966.800 & 1294.748 & 497.115 \\
\hline TNFa & 0.440 & 71.725 & 806.073 & 899.610 & 731.990 & 773.923 & 861.988 \\
\hline VEGF & 0.115 & 6.785 & 50.333 & 57.060 & 70.960 & 132.763 & 31.030 \\
\hline
\end{tabular}




\section{Appendix 2 - Supplementary 24-hour cytokine data}

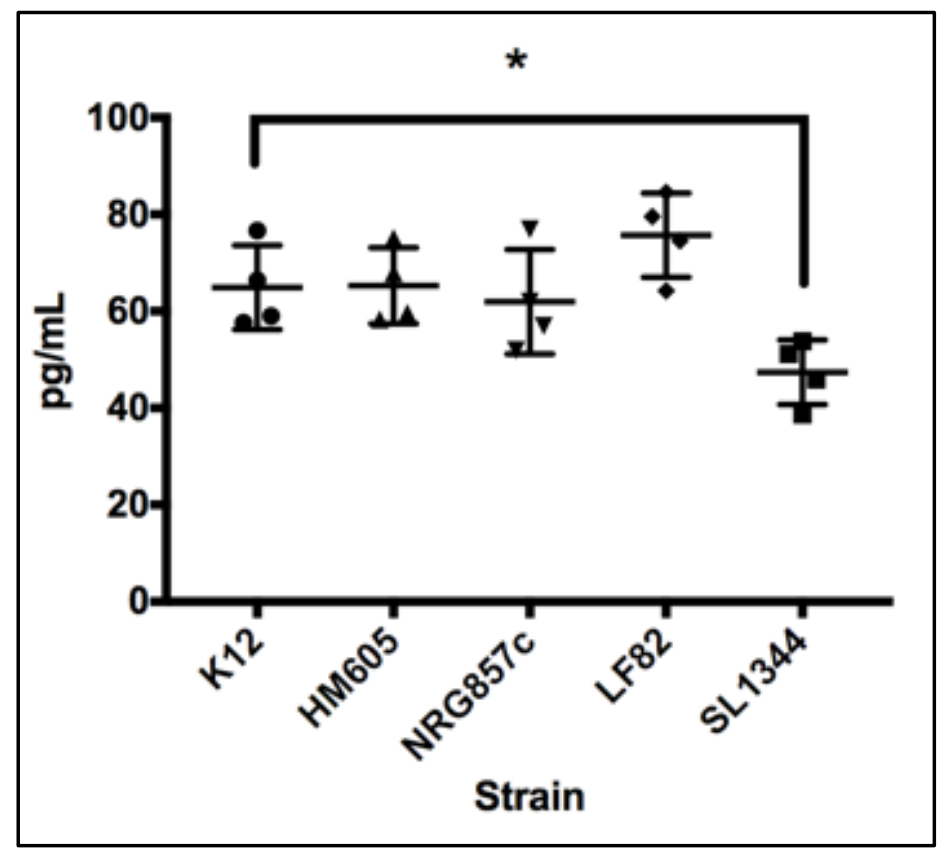

Figure 20: Secretion of IL1- $\alpha$ from macrophages exposed to a panel of bacterial for 1 hour, followed by culture for 23 hours. Measurements were made from 4 biological replicates. Statistical significance was determined using one-way ANOVA, *-p<0.05.

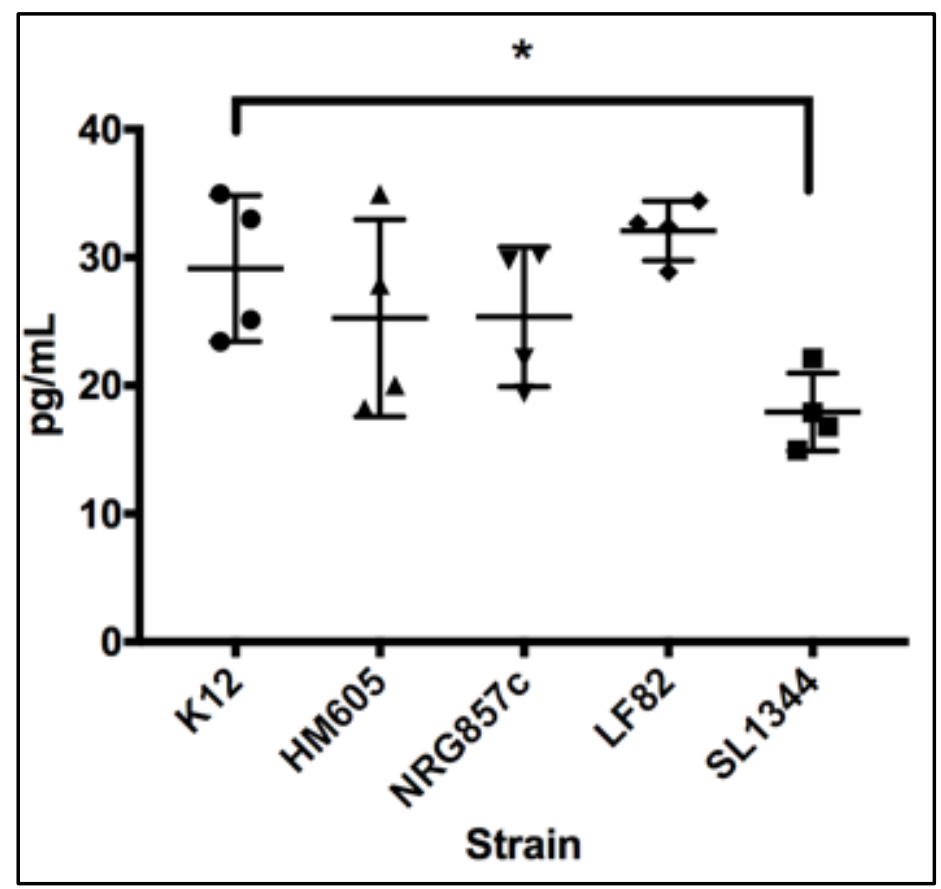

Figure 21: Secretion of KC from macrophages exposed to a panel of bacterial for 1 hour, followed by culture for 23 hours. Measurements were made from 4 biological replicates. Statistical significance was determined using one-way ANOVA, *-p<0.05. 


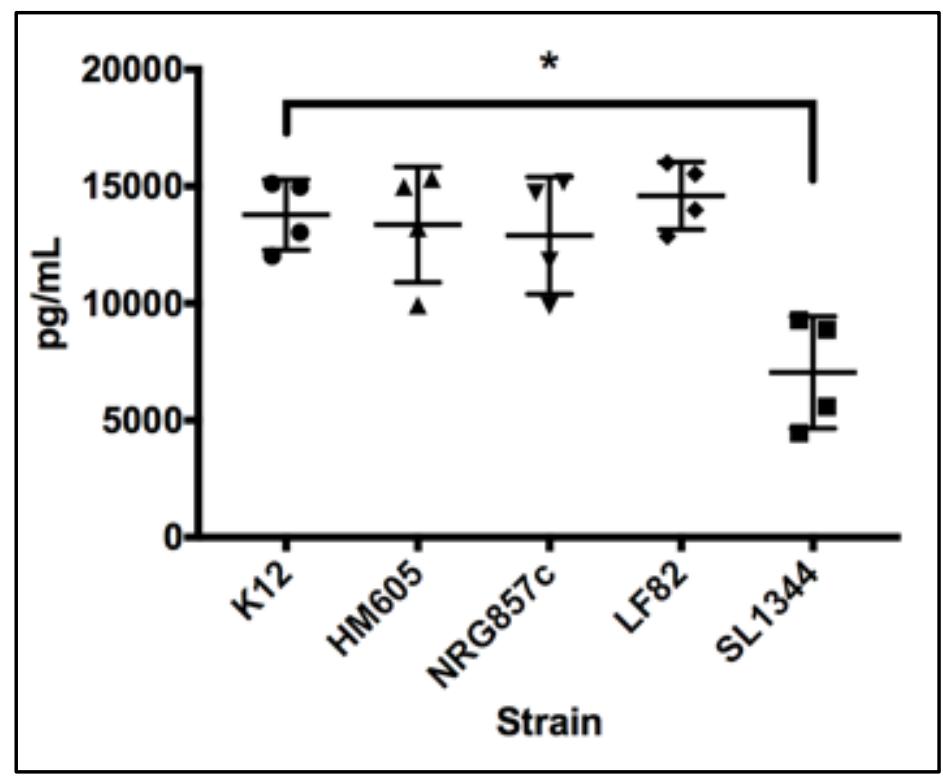

Figure 22: Secretion of MCP-1 from macrophages exposed to a panel of bacterial for 1 hour, followed by culture for 23 hours. Measurements were made from 4 biological replicates. Statistical significance was determined using one-way ANOVA, *-p<0.05. 


\section{Appendix 3 - Lactate dehydrogenase data}

Blank media controls were performed in triplicate while all other samples were performed in triplicate with technical duplicates. All technical duplicates are presented.

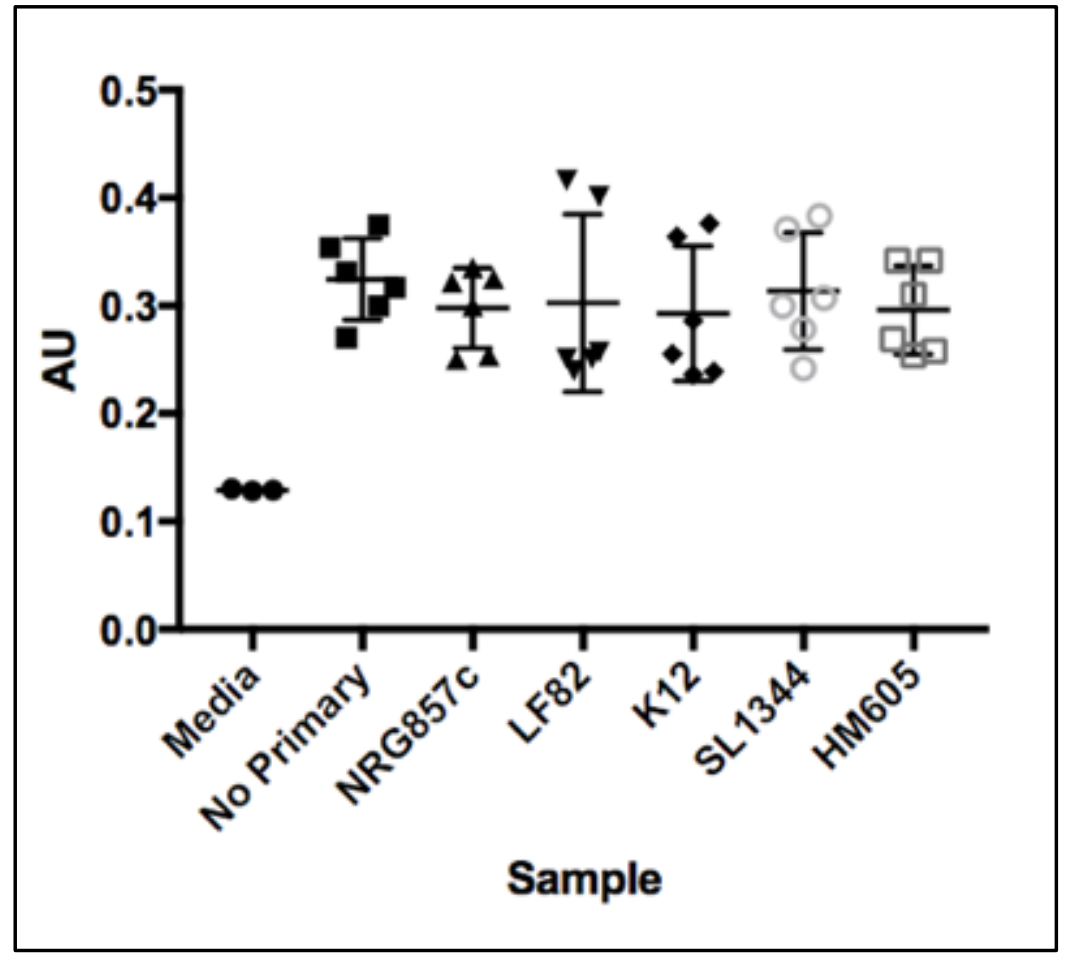

Figure 23: Absorbance units representing LDH levels in supernatant taken from RAW264.7 macrophages infected for 24 hours with bacterial strains. Biological $n$ of 3 with two technical replicates each. Error bars represent standard deviation. 


\section{REFERENCES}

1. Crohn's and Colitis Foundation of Canada. THE IMPACT OF INFLAMMATORY BOWEL DISEASE IN CANADA THE IMPACT OF INFLAMMATORY BOWEL DISEASE IN CANADA 2012 Final Report and Recommendations. 2012:96. http://www.isupportibd.ca/pdf/ccfc-ibdimpact-report-2012.pdf.

2. Crohn BB, Ginzburg L, Oppenheimer GD. Regional Ileitis: A Pathologic and Clinical Entity. J Am Med Assoc. 1932;99(16):1323-1329.

3. Bernstein CN. Treatment of IBD: where we are and where we are going. Am J Gastroenterol. 2015;110(1):114-126. doi:10.1038/ajg.2014.357.

4. Kaplan GG. The global burden of IBD: from 2015 to 2025. Nat Rev Gastroenterol Hepatol. 2015;12(12):720-727. doi:10.1038/nrgastro.2015.150.

5. Sartor RB. Mechanisms of Disease: pathogenesis of Crohn's disease and ulcerative colitis. NatClinPractGastroenterolHepatol. 2006;3(1743-4378; 7):390-407. doi:10.1038/ncpgasthep0528.

6. Jostins L, Ripke S, Weersma RK, et al. Host-microbe interactions have shaped the genetic architecture of inflammatory bowel disease. Nature. 2012;491(7422):119-124. doi:10.1038/nature11582.

7. Ellinghaus D, Jostins L, Spain SL, et al. Analysis of five chronic inflammatory diseases identifies 27 new associations and highlights disease-specific patterns at shared loci. Nat Genet. 2016;48(5):510-518. doi:10.1038/ng.3528.

8. Liu JZ, van Sommeren S, Huang H, et al. Association analyses identify 38 susceptibility loci for inflammatory bowel disease and highlight shared genetic risk across populations. Nat Genet. 2015;47(9):979-989. doi:10.1038/ng.3359.

9. Yang SK, Hong M, Zhao W, et al. Genome-wide association study of Crohn's disease in Koreans revealed three new susceptibility loci and common attributes of genetic susceptibility across ethnic populations. Gut. 2014;63(1):80-87. doi:10.1136/gutjnl-2013305193.

10. Sheng YH, Hasnain SZ, Florin THJ, McGuckin M a. Mucins in inflammatory bowel diseases and colorectal cancer. J Gastroenterol Hepatol. 2012;27(1):28-38. doi:10.1111/j.1440- 
1746.2011.06909.x.

11. Maaser C, Langholz E, Gordon H, et al. European Crohn's and Colitis Organisation Topical Review on environmental factors in IBD. J Crohn's Colitis. December 2016:1-43. doi:10.1093/ecco-jcc/jjw223.

12. Andoh A, Tsujikawa T, Sasaki M, et al. Faecal microbiota profile of Crohn's disease determined by terminal restriction fragment length polymorphism analysis. Aliment Pharmacol Ther. 2009;29(1):75-82. doi:10.1111/j.1365-2036.2008.03860.x.

13. Rausch P, Rehman A, Kunzel S, et al. Colonic mucosa-associated microbiota is influenced by an interaction of Crohn disease and FUT2 (Secretor) genotype. PNAS. 2011;108(47):19030-19035. doi:10.1073/pnas.1106408108.

14. Gevers D, Kugathasan S, Denson LA, et al. The treatment-naive microbiome in new-onset Crohn's disease. Cell Host Microbe. 2014;15(3):382-392. doi:10.1016/j.chom.2014.02.005.

15. Small CL, Xing L, McPhee JB, Law HT, Coombes BK. Acute Infectious Gastroenteritis Potentiates a Crohn's Disease Pathobiont to Fuel Ongoing Inflammation in the PostInfectious Period. Baumler AJ, ed. PLOS Pathog. 2016;12(10):e1005907. doi:10.1371/journal.ppat.1005907.

16. Gradel KO, Nielsen HL, Schønheyder HC, Ejlertsen T, Kristensen B, Nielsen H. Increased Short- and Long-Term Risk of Inflammatory Bowel Disease After Salmonella or Campylobacter Gastroenteritis. Gastroenterology. 2009;137(2):495-501. doi:10.1053/j.gastro.2009.04.001.

17. Jess T, Simonsen J, Nielsen NM, et al. Enteric Salmonella or Campylobacter infections and the risk of inflammatory bowel disease. Gut. 2011;60(3):318-324. doi:10.1136/gut.2010.223396.

18. Sepehri S, Khafipour E, Bernstein CN, et al. Characterization of Escherichia coli isolated from gut biopsies of newly diagnosed patients with inflammatory bowel disease. Inflamm Bowel Dis. 2011;17(7):1451-1463. doi:10.1002/ibd.21509.

19. Varol C, Vallon-Eberhard A, Elinav E, et al. Intestinal Lamina Propria Dendritic Cell Subsets Have Different Origin and Functions. Immunity. 2009;31(3):502-512. 
doi:10.1016/j.immuni.2009.06.025.

20. Uematsu S, Fujimoto $\mathrm{K}$, Jang $\mathrm{MH}$, et al. Regulation of humoral and cellular gut immunity by lamina propria dendritic cells expressing Toll-like receptor 5. Nat Immunol. 2008;9(7):769-776. doi:10.1038/ni.1622.

21. Goto Y, Panea C, Nakato G, et al. Segmented filamentous bacteria antigens presented by intestinal dendritic cells drive mucosal Th17 cell differentiation. Immunity. 2014;40(4):594-607. doi:10.1016/j.immuni.2014.03.005.

22. Wyllie DH, Kiss-Toth E, Visintin A, et al. Evidence for an Accessory Protein Function for Toll-Like Receptor 1 in Anti-Bacterial Responses. J Immunol. 2000;165(12):7125-7132. doi:10.4049/jimmunol.165.12.7125.

23. Underhill DM, Ozinsky A, Hajjar AM, et al. The Toll-like receptor 2 is recruited to macrophage phagosomes and discriminates between pathogens. Nature. 1999;401(6755):811-815. doi:10.1038/44605.

24. Fritz JH, Girardin SE, Fitting C, et al. Synergistic stimulation of human monocytes and dendritic cells by Toll-like receptor 4 and NOD1- and NOD2-activating agonists. Eur J Immunol. 2005;35(8):2459-2470. doi:10.1002/eji.200526286.

25. Liang J, Huang HI, Benzatti FP, et al. Inflammatory Th1 and Th17 in the Intestine Are Each Driven by Functionally Specialized Dendritic Cells with Distinct Requirements for MyD88. Cell Rep. 2016;17(5):1330-1343. doi:10.1016/j.celrep.2016.09.091.

26. Hue $S$, Ahern $\mathrm{P}$, Buonocore $\mathrm{S}$, et al. Interleukin-23 drives innate and T cell-mediated intestinal inflammation. J Exp Med. 2006;203(11):2473-2483. doi:10.1084/jem.20061099.

27. Shaw MH, Kamada N, Kim Y-G, Núñez G. Microbiota-induced IL-1 $\beta$, but not IL-6, is critical for the development of steady-state T H 17 cells in the intestine. J Exp Med. 2012;209(2):251-258. doi:10.1084/jem.20111703.

28. Abraham C, Medzhitov R. Interactions Between the Host Innate Immune System and Microbes in Inflammatory Bowel Disease. Gastroenterology. 2014;140(6):1729-1737. doi:10.1053/j.gastro.2011.02.012.Interactions.

29. Wehkamp J, Harder J, Weichenthal M, et al. NOD2 (CARD15) mutations in Crohn's 
disease are associated with diminished mucosal alpha-defensin expression. Gut. 2004;53(11):1658-1664. doi:10.1136/gut.2003.032805.

30. Ma TY, Iwamoto GK, Hoa NT, et al. TNF- $\alpha$-induced increase in intestinal epithelial tight junction permeability requires NF-kB activation. Am J Physiol - Gastrointest Liver Physiol. 2004;286(3):G367-G376. doi:10.1152/ajpgi.00173.2003.

31. Kalinski P. Regulation of Immune Responses by Prostaglandin E2. J Immunol. 2012;188(1):21-28. doi:10.4049/jimmunol.1101029.

32. Kühn R, Löhler J, Rennick D, Rajewsky K, Müller W. Interleukin-10-deficient mice develop chronic enterocolitis. Cell. 1993;75(2):263-274. doi:10.1016/0092-8674(93)80068-P.

33. Zigmond E, Bernshtein B, Friedlander G, et al. Macrophage-restricted interleukin-10 receptor deficiency, but not IL-10 deficiency, causes severe spontaneous colitis. Immunity. 2014;40(5):720-733. doi:10.1016/j.immuni.2014.03.012.

34. Castro-Santos P, Suarez A, López-Rivas L, Mozo L, Gutierrez C. TNF $\alpha$ and IL-10 gene polymorphisms in inflammatory bowel disease. Association of -1082 AA low producer IL10 genotype with steroid dependency. Am J Gastroenterol. 2006;101(5):1039-1047. doi:10.1111/j.1572-0241.2006.00501.x.

35. Hahm KB, Im YH, Parks TW, et al. Loss of transforming growth factor beta signalling in the intestine contributes to tissue injury in inflammatory bowel disease. Gut. 2001;49(2):190198. doi:10.1136/gut.49.2.190.

36. Kulkarni $A B$, Huh CG, Becker $D$, et al. Transforming growth factor beta 1 null mutation in mice causes excessive inflammatory response and early death. Proc Natl Acad Sci. 1993;90(2):770-774. doi:10.1073/pnas.90.2.770.

37. D'haens G, Van Deventer S, Van Hogezand R, et al. Endoscopic and histological healing with infliximab anti-tumor necrosis factor antibodies in Crohn's disease: A European multicenter trial. Gastroenterology. 1999;116(5):1029-1034. https://www.gastrojournal.org/article/S0016-5085(99)70005-3/pdf. Accessed May 16, 2018.

38. Hanauer SB, Sandborn WJ, Rutgeerts $P$, et al. Human anti-tumor necrosis factor monoclonal antibody (adalimumab) in Crohn's disease: The CLASSIC-I trial. 
Gastroenterology. 2006;130(2):323-332. doi:10.1053/j.gastro.2005.11.030.

39. Rutgeerts $P$, Van Assche G, Vermeire S. Optimizing Anti-TNF treatment in inflammatory bowel disease. Gastroenterology. 2004;126(6):1593-1610.

doi:10.1053/j.gastro.2004.02.070.

40. Rigottier-Gois L. Dysbiosis in inflammatory bowel diseases: The oxygen hypothesis. ISME J. 2013;7(7):1256-1261. doi:10.1038/ismej.2013.80.

41. Schlager TA, Hendley JO, Bell AL, Whittam TS. Clonal diversity of Escherichia coli colonizing stools and urinary tracts of young girls. Infect Immun. 2002;70(3):1225-1229. doi:10.1128/IAI.70.3.1225-1229.2002.

42. Conway T, Cohen PS. Commensal and Pathogenic Escherichia coli Metabolism in the Gut. Microbiol Spectr. 2015;3(3). doi:10.1128/microbiolspec.MBP-0006-2014.

43. Fabich AJ, Jones SA, Chowdhury FZ, et al. Comparison of carbon nutrition for pathogenic and commensal Escherichia coli strains in the mouse intestine. Infect Immun. 2008;76(3):1143-1152. doi:10.1128/IAI.01386-07.

44. Pacheco AR, Sperandio V. Enteric Pathogens Exploit the Microbiota-generated Nutritional Environment of the Gut. Microbiol Spectr. 2015;3(3):279-296. doi:10.1128/microbiolspec.MBP-0001-2014.

45. Theodoratou E, Campbell H, Ventham NT, et al. The role of glycosylation in IBD. Nat Rev Gastroenterol Hepatol. 2014;11(10):588-600. doi:10.1038/nrgastro.2014.78.

46. Darfeuille-michaud A, Neut C, Barnich N, et al. Presence of Adherent Escherichia coli Strains in Ileal Mucosa of Patients With Crohn's Disease. Gastroenterology. 1998;115(6):1405-1413. doi:10.1016/S0016-5085(98)70019-8.

47. Boudeau J, Glasser A, Masseret E, Joly B, Darfeuille-michaud A. Invasive Ability of an Escherichia coli Strain Isolated from the Ileal Mucosa of a Patient with Crohn's Disease Invasive Ability of an Escherichia coli Strain Isolated from the Ileal Mucosa of a Patient with Crohn 's Disease. 1999;67(9):4499-4509.

48. Bringer MA, Glasser AL, Tung CH, Méresse S, Darfeuille-Michaud A. The Crohn's diseaseassociated adherent-invasive Escherichia coli strain LF82 replicates in mature phagolysosomes within J774 macrophages. Cell Microbiol. 2006;8(3):471-484. 
doi:10.1111/j.1462-5822.2005.00639.x.

49. Barnich N, Carvalho FA, Glasser AL, et al. CEACAM6 acts as a receptor for adherentinvasive E. coli, supporting ileal mucosa colonization in Crohn disease. J Clin Invest. 2007;117(6):1566-1574. doi:10.1172/JCI30504.

50. Carvalho FA, Barnich N, Sivignon A, et al. Crohn's disease adherent-invasive Escherichia coli colonize and induce strong gut inflammation in transgenic mice expressing human CEACAM. J Exp Med. 2009;206(10):2179-2189. doi:10.1084/jem.20090741.

51. Small C-LN, Reid-Yu SA, McPhee JB, Coombes BK. Persistent infection with Crohn's disease-associated adherent-invasive Escherichia coli leads to chronic inflammation and intestinal fibrosis. Nat Commun. 2013;4:1957. doi:10.1038/ncomms2957.

52. Pullan RD, Thomas GA, Rhodes $M$, et al. Thickness of adherent mucus gel on colonic mucosa in humans and its relevance to colitis. Gut. 1994;35(3):353-359. doi:10.1136/gut.35.3.353.

53. An G, Wei B, Xia B, et al. Increased susceptibility to colitis and colorectal tumors in mice lacking core 3-derived O-glycans. J Exp Med. 2007;204(6):1417-1429. doi:10.1084/jem.20061929.

54. Bergstrom KSB, Kissoon-Singh V, Gibson DL, et al. Muc2 protects against lethal infectious colitis by disassociating pathogenic and commensal bacteria from the colonic mucosa. PLoS Pathog. 2010;6(5). doi:10.1371/journal.ppat.1000902.

55. Swidsinski A, Ung V, Sydora BC, et al. Bacterial overgrowth and inflammation of small intestine after carboxymethylcellulose ingestion in genetically susceptible mice. Inflamm Bowel Dis. 2009;15(3):359-364. doi:10.1002/ibd.20763.

56. Connell I, Agace W, Klemm P, Schembri M, Mărild S, Svanborg C. Type 1 fimbrial expression enhances Escherichia coli virulence for the urinary tract. Proc Natl Acad Sci U S A. 1996;93(18):9827-9832. doi:10.1073/pnas.93.18.9827.

57. Dreux N, Denizot J, Martinez-Medina M, et al. Point Mutations in FimH Adhesin of Crohn's Disease-Associated Adherent-Invasive Escherichia coli Enhance Intestinal Inflammatory Response. PLoS Pathog. 2013;9(1). doi:10.1371/journal.ppat.1003141.

58. Chassaing B, Rolhion N, Vallée A de, et al. Crohn disease-associated adherent-invasive E. 
coli bacteria target mouse and human Peyer's patches via long polar fimbriae. J Clin Invest. 2011;121(3):966-975. doi:10.1172/JCI44632.

59. Hancock RE, Scott MG. The role of antimicrobial peptides in animal defenses. Proc Natl Acad Sci U S A. 2000;97(16):8856-8861. doi:10.1073/pnas.97.16.8856.

60. Hancock REW, Haney EF, Gill EE. The immunology of host defence peptides: beyond antimicrobial activity. Nat Rev Immunol. 2016;16(5):321-334. doi:10.1038/nri.2016.29.

61. Vandamme D, Landuyt B, Luyten W, Schoofs L. A comprehensive summary of LL-37, the factoctum human cathelicidin peptide. Cell Immunol. 2012;280(1):22-35. doi:10.1016/j.cellimm.2012.11.009.

62. Henzler Wildman KA, Lee D-K, Ramamoorthy A. Mechanism of Lipid Bilayer Disruption by the Human Antimicrobial Peptide, LL-37. Biochemistry. 2003;42(21):6545-6558. doi:doi.org/10.1016/j.cellimm.2012.11.009.

63. Dhople V, Krukemeyer A, Ramamoorthy A. The human beta-defensin-3, an antibacterial peptide with multiple biological functions. Biochim Biophys Acta-Biomembr. 2006;1758(9):1499-1512. doi:10.1016/j.bbamem.2006.07.007.

64. Ganz T. Defensins: antimicrobial peptides of innate immunity. Nat Rev Immunol. 2003;3(9):710-720. doi:10.1038/nri1180.

65. Boniotto M, Antcheva N, Zelezetsky I, et al. A study of host defence peptide $\beta$-defensin 3 in primates. Biochem J. 2003;374:707-714.

https://www.ncbi.nlm.nih.gov/pmc/articles/PMC1223632/pdf/12795637.pdf. Accessed April 13, 2017.

66. Zilbauer M, Dorrell N, Boughan PK, et al. Intestinal innate immunity to Campylobacter jejuni results in induction of bactericidal human beta-defensins 2 and 3. Infect Immun. 2005;73(11):7281-7289. doi:10.1128/IAI.73.11.7281-7289.2005.

67. Swidsinski A, Ladhoff A, Pernthaler A, et al. Mucosal flora in inflammatory bowel disease. Gastroenterology. 2002;122:44-54. doi:10.1053/gast.2002.30294.

68. Johansson ME V, Phillipson M, Petersson J, Velcich A, Holm L, Hansson GC. The inner of the two Muc2 mucin-dependent mucus layers in colon is devoid of bacteria. Proc Natl Acad Sci U S A. 2008;105(39):15064-15069. doi:10.1073/pnas.0803124105. 
69. Barr JJ, Auro R, Furlan M, et al. Bacteriophage adhering to mucus provide a non-hostderived immunity. Proc Natl Acad Sci U S A. 2013;110(26):10771-10776. doi:10.1073/pnas.1305923110.

70. Png CW, Linden SK, Gilshenan KS, et al. Mucolytic bacteria with increased prevalence in IBD mucosa augment in vitro utilization of mucin by other bacteria. Am J Gastroenterol. 2010;105(11):2420-2428. doi:ajg2010281 [pii]\r10.1038/ajg.2010.281 [doi].

71. Grubman A, Kaparakis M, Viala J, et al. The innate immune molecule, NOD1, regulates direct killing of Helicobacter pylori by antimicrobial peptides. Cell Microbiol. 2010;12(5):626-639. doi:10.1111/j.1462-5822.2009.01421.x.

72. Meisch JP, Nishimura M, Vogel RM, et al. Human $\beta$-defensin 3 peptide is increased and redistributed in Crohn's ileitis. Inflamm Bowel Dis. 2013;19(5):942-953. doi:10.1097/MIB.0b013e318280b11a.

73. Schauber J, Rieger D, Weiler F, et al. Heterogeneous expression of human cathelicidin hCAP18/LL-37 in inflammatory bowel diseases. Eur J Gastroenterol Hepatol. 2006;18(6):615-621. http://www.ncbi.nlm.nih.gov/pubmed/16702850. Accessed April 13, 2017.

74. McPhee JB, Small CL, Reid-Yu SA, Brannon JR, Moual H Le, Coombes BK. Host defense peptide resistance contributes to colonization and maximal intestinal pathology by Crohn's disease-associated adherent-invasive Escherichia coli. Infect Immun. 2014;82(8):3383-3393. doi:10.1128/IAI.01888-14.

75. O'Brien CL, Bringer MA, Holt KE, et al. Comparative genomics of Crohn's diseaseAssociated adherent-invasive Escherichia coli. Gut. 2017;66(8):1382-1389. doi:10.1136/gutjnl-2015-311059.

76. Liss V, Hensel M. Take the tube: Remodelling of the endosomal system by intracellular Salmonella enterica. Cell Microbiol. 2015;17(5):639-647. doi:10.1111/cmi.12441.

77. Sorbara MT, Foerster EG, Tsalikis J, et al. Complement C3 Drives Autophagy-Dependent Restriction of Cyto-invasive Bacteria. Cell Host Microbe. 2018;23(5):644-652.e5. doi:10.1016/j.chom.2018.04.008.

78. Chauhan S, Mandell MA, Deretic V. IRGM Governs the Core Autophagy Machinery to 
Conduct Antimicrobial Defense. Mol Cell. 2015;58(3):507-521.

doi:10.1016/j.molcel.2015.03.020.

79. Travassos LH, Carneiro LAM, Ramjeet $M$, et al. Nod1 and Nod2 direct autophagy by recruiting ATG16L1 to the plasma membrane at the site of bacterial entry. Nat Immunol. 2010;11(1):55-62. doi:10.1038/ni.1823.

80. Inohara N, Ogura Y, Fontalba A, et al. Host recognition of bacterial muramyl dipeptide mediated through NOD2: Implications for Crohn's disease. J Biol Chem. 2003;278(8):5509-5512. doi:10.1074/jbc.C200673200.

81. Vazeille E, Buisson A, Bringer M-A, et al. Monocyte-derived Macrophages from Crohn's Disease Patients Are Impaired in the Ability to Control Intracellular Adherent-Invasive Escherichia coli and Exhibit Disordered Cytokine Secretion Profile. J Crohn's Colitis. 2015;9(5):410-420. doi:10.1093/ecco-jcc/jjv053.

82. Chu H, Khosravi A, Kusumawardhani IP, et al. Gene-microbiota interactions contribute to the pathogenesis of inflammatory bowel disease. Science. 2016;352(6289):1116-1120. doi:10.1126/science.aad9948.

83. Glasser A, Boudeau J, Barnich N, Perruchot M, Colombel J, Darfeuille-michaud A. Adherent Invasive Escherichia coli Strains from Patients with Crohn's Disease Survive and Replicate within Macrophages without Inducing Host Cell Death Adherent Invasive Escherichia coli Strains from Patients with Crohn's Disease Survive and Replicate. Infect Immun Immun. 2001;69(9):5529-5537. doi:10.1128/IAI.69.9.5529.

84. Subramanian S, Roberts CL, Hart CA, et al. Replication of colonic crohn's disease mucosal Escherichia coli isolates within macrophages and their susceptibility to antibiotics. Antimicrob Agents Chemother. 2008;52(2):427-434. doi:10.1128/AAC.00375-07.

85. Luzio JP, Pryor PR, Bright NA. Lysosomes: fusion and function. Nat Rev Mol Cell Biol. 2007;8(8):622-632. doi:10.1038/nrm2217.

86. Pauwels AM, Trost M, Beyaert R, Hoffmann E. Patterns, Receptors, and Signals: Regulation of Phagosome Maturation. Trends Immunol. 2017;38(6):407-422. doi:10.1016/j.it.2017.03.006.

87. Touret $\mathrm{N}$, Paroutis $\mathrm{P}$, Terebiznik $\mathrm{M}$, et al. Quantitative and dynamic assessment of the 
contribution of the ER to phagosome formation. Cell. 2005;123(1):157-170. doi:10.1016/j.cell.2005.08.018.

88. Gagnon E, Duclos S, Rondeau C, et al. Endoplasmic reticulum-mediated phagocytosis is a mechanism of entry into macrophages. Cell. 2002;110(1):119-131. doi:10.1016/S00928674(02)00797-3.

89. Hanadate Y, Saito-Nakano Y, Nakada-Tsukui K, Nozaki T. Endoplasmic reticulum-resident Rab8A GTPase is involved in phagocytosis in the protozoan parasite Entamoeba histolytica. Cell Microbiol. 2016;18(10):1358-1373. doi:10.1111/cmi.12570.

90. Smith AC, Won DH, Braun V, et al. A network of Rab GTPases controls phagosome maturation and is modulated by Salmonella enterica serovar Typhimurium. J Cell Biol. 2007;176(3):263-268. doi:10.1083/jcb.200611056.

91. Harrison RE, Bucci C, Vieira O V, Schroer TA, Grinstein S. Phagosomes Fuse with Late Endosomes and/or Lysosomes by Extension of Membrane Protrusions along Microtubules: Role of Rab7 and RILP. Mol Cell Biol. 2003;23(18):6494-6506. doi:10.1128/MCB.23.18.6494-6506.2003.

92. Stockinger $\mathrm{W}$, Zhang SC, Trivedi V, et al. Differential requirements for actin polymerization, calmodulin, and Ca2+ define distinct stages of lysosome/phagosome targeting. Mol Biol Cell. 2006;17(4):1697-1710. doi:10.1091/mbc.E05-12-1140.

93. Huynh KK, Eskelinen EL, Scott CC, Malevanets A, Saftig P, Grinstein S. LAMP proteins are required for fusion of lysosomes with phagosomes. EMBO J. 2007;26(2):313-324. doi:10.1038/sj.emboj.7601511.

94. Gonzalez-Polo R-A. The apoptosis/autophagy paradox: autophagic vacuolization before apoptotic death. J Cell Sci. 2005;118(14):3091-3102. doi:10.1242/jcs.02447.

95. Owen KA, Meyer CB, Bouton AH, Casanova JE. Activation of Focal Adhesion Kinase by Salmonella Suppresses Autophagy via an Akt/mTOR Signaling Pathway and Promotes Bacterial Survival in Macrophages. Deretic V, ed. PLoS Pathog. 2014;10(6):e1004159. doi:10.1371/journal.ppat.1004159.

96. Owen KA, Anderson CJ, Casanova JE. Salmonella suppresses the TRIF-dependent type I interferon response in macrophages. MBio. 2016;7(1):e02051-15. 
doi:10.1128/mBio.02051-15.

97. Figueira R, Holden DW. Functions of the Salmonella pathogenicity island 2 (SPI-2) type III secretion system effectors. Microbiology. 2012;158(5):1147-1161.

doi:10.1099/mic.0.058115-0.

98. Martinez-Medina M, Mora A, Blanco M, et al. Similarity and divergence among adherentinvasive Escherichia coli and extraintestinal pathogenic E. coli strains. J Clin Microbiol. 2009;47(12):3968-3979. doi:10.1128/JCM.01484-09.

99. Ellermann M, Huh EY, Liu B, Carroll IM, Tamayo R, Sartor RB. Adherent-invasive Escherichia coli production of cellulose influences iron-induced bacterial aggregation, phagocytosis, and induction of colitis. Infect Immun. 2015;83(10):4068-4080. doi:10.1128/IAI.00904-15.

100. Eto DS, Sundsbak JL, Mulvey MA. Actin-gated intracellular growth and resurgence of uropathogenic Escherichia coli. Cell Microbiol. 2006;8(4):704-717. doi:10.1111/j.14625822.2006.00691.x.

101. Berry RE, Klumpp DJ, Schaeffer AJ. Urothelial cultures support intracellular bacterial community formation by uropathogenic Escherichia coli. Infect Immun. 2009;77(7):27622772. doi:10.1128/IAI.00323-09.

102. Dikshit N, Bist P, Fenlon SN, et al. Intracellular Uropathogenic E. coli Exploits Host Rab35 for Iron Acquisition and Survival within Urinary Bladder Cells. PLoS Pathog. 2015;11(8). doi:10.1371/journal.ppat.1005083.

103. Eaves-Pyles T, Allen CA, Taormina J, et al. Escherichia coli isolated from a Crohn's disease patient adheres, invades, and induces inflammatory responses in polarized intestinal epithelial cells. Int J Med Microbiol. 2008;298(5-6):397-409.

doi:10.1016/j.ijmm.2007.05.011.

104. Hoiseth SK, Stocker BAD. Aromatic-dependent Salmonella typhimurium are non-virulent and effective as live vaccines. Nature. 1981;291(5812):238-239. doi:10.1038/291238a0.

105. Martin HM, Campbell BJ, Hart CA, et al. Enhanced Escherichia coli adherence and invasion in Crohn's disease and colon cancer. Gastroenterology. 2004;127(1):80-93. doi:10.1053/j.gastro.2004.03.054. 
106. Baba T, Ara T, Hasegawa M, et al. Construction of Escherichia coli K-12 in-frame, singlegene knockout mutants: The Keio collection. Mol Syst Biol. 2006;2. doi:10.1038/msb4100050.

107. Cieza RJ, Hu J, Ross BN, Sbrana E, Torres AG. The IbeA invasin of adherent-invasive Escherichia coli mediates nteraction with intestinal epithelia and macrophages. Infect Immun. 2015;83(5). doi:10.1128/IAI.03003-14.

108. Elliott TR, Hudspith BN, Rayment NB, et al. Defective macrophage handling of Escherichia coli in Crohn's disease. J Gastroenterol Hepatol. 2015;30(8):1265-1274. doi:10.1111/jgh.12955.

109. Elliott TR, Rayment NB, Hudspith BN, et al. Lamina propria macrophage phenotypes in relation to Escherichia coli in Crohn's disease. BMC Gastroenterol. 2015;15(1). doi:10.1186/s12876-015-0305-3.

110. Hampe J, Franke A, Rosenstiel P, et al. A genome-wide association scan of nonsynonymous SNPs identifies a susceptibility variant for Crohn disease in ATG16L1. Nat Genet. 2007;39(2):207-211. doi:10.1038/ng1954.

111. Jaslow SL, Gibbs KD, Fricke WF, et al. Salmonella Activation of STAT3 Signaling by SarA Effector Promotes Intracellular Replication and Production of IL-10. Cell Reports. https://journals-scholarsportalinfo.ezproxy.lib.ryerson.ca/pdf/22111247/v23i0012/3525_saossbirapoi.xml. Published 2018. Accessed July 5, 2018.

112. Hunter CA, Jones SA. IL-6 as a keystone cytokine in health and disease. Nat Immunol. 2015;16(5):448-457. doi:10.1038/ni.3153.

113. Chomarat P, Banchereau J, Davoust J, Palucka AK. IL-6 switches the differentiation of monocytes from dendritic cells to macrophages. Nat Immunol. 2000;1(6):510-514. doi:10.1038/82763.

114. Sommer J, Engelowski E, Baran P, Garbers C, Floss DM, Scheller J. Interleukin-6, but not the interleukin- 6 receptor plays a role in recovery from dextran sodium sulfate-induced colitis. Int J Mol Med. 2014;34(3):651-660. doi:10.3892/ijmm.2014.1825.

115. Shi Y, Liu CH, Roberts Al, et al. Granulocyte-macrophage colony-stimulating factor (GM- 
CSF) and T-cell responses: What we do and don't know. In: Cell Research. Vol 16. ; 2006:126-133. doi:10.1038/sj.cr.7310017.

116. Goldstein JI, Kominsky DJ, Jacobson N, et al. Defective leukocyte GM-CSF receptor (CD116) expression and function in inflammatory bowel disease. Gastroenterology. 2011;141(1):208-216. doi:10.1053/j.gastro.2011.03.060.

117. Sewell GW, Marks DJ, Segal AW. The immunopathogenesis of Crohn's disease: a threestage model. Curr Opin Immunol. 2009;21(5):506-513. doi:10.1016/j.coi.2009.06.003.

118. Tofaris GK, Patterson PH, Jessen KR, Mirsky R. Denervated Schwann cells attract macrophages by secretion of leukemia inhibitory factor (LIF) and monocyte chemoattractant protein-1 in a process regulated by interleukin-6 and LIF. J Neurosci. 2002;22(15):6696-6703. doi:20026699.

119. Jasper MJ, Care AS, Sullivan B, Ingman W V., Aplin JD, Robertson SA. MacrophageDerived LIF and IL1B Regulate Alpha(1,2)Fucosyltransferase 2 (Fut2) Expression in Mouse Uterine Epithelial Cells During Early Pregnancy. Biol Reprod. 2011;84(1):179-188. doi:10.1095/biolreprod.110.085399.

120. Maroni L, van de Graaf SFJ, Hohenester SD, Oude Elferink RPJ, Beuers U. Fucosyltransferase 2: A Genetic Risk Factor for Primary Sclerosing Cholangitis and Crohn's Disease - A Comprehensive Review. Clin Rev Allergy Immunol. 2015;48(2-3):182191. doi:10.1007/s12016-014-8423-1.

121. Gray MA, Choy CH, Dayam RM, et al. Phagocytosis Enhances Lysosomal and Bactericidal Properties by Activating the Transcription Factor TFEB. Curr Biol. 2016;26(15):1955-1964. doi:10.1016/j.cub.2016.05.070.

122. Etienne-Mesmin $L$, Chassaing $B$, Sauvanet $P$, et al. Interactions with $M$ cells and macrophages as key steps in the pathogenesis of enterohemorrhagic Escherichia coli infections. PLoS One. 2011;6(8):e23594. doi:10.1371/journal.pone.0023594.

123. Lapaquette $P$, Bringer MA, Darfeuille-Michaud A. Defects in autophagy favour adherentinvasive Escherichia coli persistence within macrophages leading to increased proinflammatory response. Cell Microbiol. 2012;14(6):791-807. doi:10.1111/j.14625822.2012.01768.x. 
124. Symington JW, Wang C, Twentyman J, et al. ATG16L1 deficiency in macrophages drives clearance of uropathogenic E. coli in an IL-1ß-dependent manner. Mucosal Immunol. 2015;8(6):1388-1399. doi:10.1038/mi.2015.7.

125. Nguyen HTT, Dalmasso G, Müller S, Carrière J, Seibold F, Darfeuille-Michaud A. Crohn's disease-associated adherent invasive escherichia coli modulate levels of microRNAs in intestinal epithelial cells to reduce autophagy. Gastroenterology. 2014;146(2):508-519. doi:10.1053/j.gastro.2013.10.021.

126. Clarke DJ, Chaudhuri RR, Martin HM, et al. Complete genome sequence of the crohn's disease-associated adherent-invasive Escherichia coli strain HM605. J Bacteriol. 2011;193(17):4540-4540. doi:10.1128/JB.05374-11.

127. Alcoforado Diniz J, Liu YC, Coulthurst SJ. Molecular weaponry: Diverse effectors delivered by the Type VI secretion system. Cell Microbiol. 2015;17(12):1742-1751. doi:10.1111/cmi.12532.

128. Suarez G, Sierra JC, Kirtley ML, Chopra AK. Role of Hcp, a type 6 secretion system effector, of Aeromonas hydrophila in modulating activation of host immune cells. Microbiology. 2010;156(12):3678-3688. doi:10.1099/mic.0.041277-0.

129. Zhou Y, Tao J, Yu H, et al. Hcp family proteins secreted via the type VI secretion system coordinately regulate Escherichia coli K1 interaction with human brain microvascular endothelial cells. Infect Immun. 2012;80(3):1243-1251. doi:10.1128/IAI.05994-11.

130. Nichols KB, Totsika M, Moriel DG, et al. Molecular characterization of the vacuolating autotransporter toxin in uropathogenic Escherichia coli. J Bacteriol. 2016;198(10):14871498. doi:10.1128/JB.00791-15.

131. Desvaux M, Parham NJ, Henderson IR. The autotransporter secretion system. Res Microbiol. 2004;155(2):53-60. doi:10.1016/j.resmic.2003.10.002.

132. Shen $\mathrm{HH}$, Leyton $\mathrm{DL}$, Shiota $\mathrm{T}$, et al. Reconstitution of a nanomachine driving the assembly of proteins into bacterial outer membranes. Nat Commun. 2014;5. doi:10.1038/ncomms6078.

133. Marani P. New Escherichia coli outer membrane proteins identified through prediction and experimental verification. Protein Sci. 2006;15(4):884-889. 
doi:10.1110/ps.051889506. 